COMPREHENSIVE SAFETY RECOMMENDATIONS FOR

LAND-BASED OIL AND GAS WELI DRILLING

U.S. DEPARTMENT OF HEALTH AND HUMAN SERVICES

Public Health Service

Centers for Disease Control

Nationa] Institute for Occupational Safety and Health

Division of Safety Research

Morgantown, West Virginia 26505

September 1983 


\section{DISCLAIMER}

Mention of company names or products does not constitute endorsement by the National Institute for Occupational Safety and Health.

DHHS (NIOSH) Publication No. 83-127

For sale by the Superintendent of Documents, U.S. Government

Printing Office, Washington, D,C. 20402 


\section{PREFACE}

The Occupational Safety and Health Act of 1970 (Public Law 91-596) states that the purpose of Congress expressed in the Act is "to assure so far as possible every working man and woman in the Nation safe and healthful working conditions and to preserve our human resources...by," among other things, "providing for research in the field of occupational safety and health... and by developing innovative methods, techniques, and approaches for dealing with occupational safety and health problems." Later in the Act, the National Institute for Occupational Safety and Health (NIOSH) is charged with carrying out this policy. One method by which NIOSH responds to this charge is to publish Technical Guidelines.

Technical Guidelines present the results of comprehensive systematic analyses of occupational hazards, and suggestions for preventing injury and disease among workers. They are intended to supplement existing Federal safety and health standards and may provide background useful in formulating new standards for development. In the interest of wide dissemination of this information, NIOSH distributes Technical Guidelines to other appropriate agencies, organized labor, industry, and public interest groups. We welcome suggestions concerning the content, style, and distribution of these documents.

This particular document addresses workers engaged in land-based oil and gas well drilling operations. It was prepared by the staff of the Division of Safety Research in conjunction with the Division of Standards Development and Technology Transfer, NIOSH. I am pleased to acknowledge the contributions made by consultants and reviewers, in particular the International Association of Drilling Contractors (IADC), the American Petroleum Institute (API), representatives of other Federal agencies, other reviewers, and the staff of the Institute. However, responsibility for the conclusions and recommendations belongs solely to the Institute. All comments by reviewers, whether or not incorporated into the final version, are being sent with this document to the Occupational Safety and Health Administration (OSHA) for consideration in standard sefting.

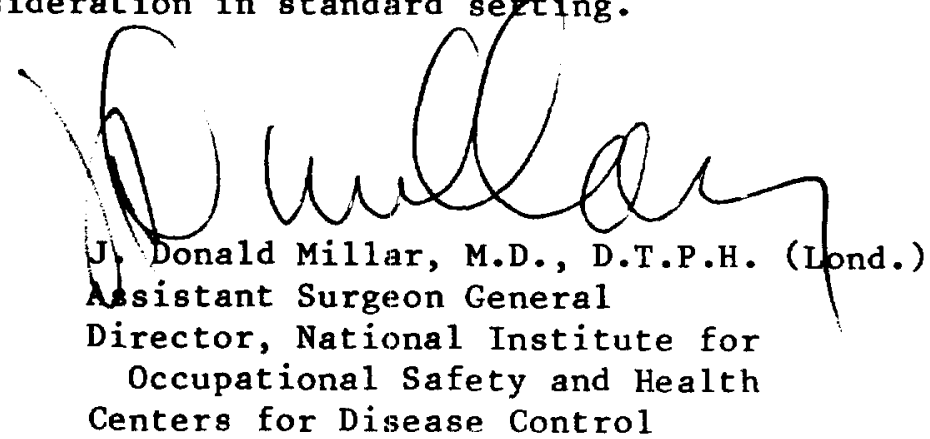




\section{ABSTRACT}

This report serves as an informative analysis of the safety hazards to which workers are exposed during the drilling of land-based oil and gas wells. Comprehensive safety recommendations are presented for the control of worker exposure to the hazards associated with the performance and/or use of the tasks, tools, equipment, and work practices in the drilling of land-based oil and gas wells.

The magnitude of the occupational safety problem in land-based oil and gas well drilling is defined through the development of data estimating the injury and illness incidence rates for the industry (SIC 1381). A detailed analysis of 738 accident case histories from Federal and state oSHA investigations, as well as workers' compensation injury reports, identifies which tasks, tools, and equipment are the most hazardous to the worker and how the worker is injured during well drilling operations. Recommendations are presented for engineering controls and/or operational safe work practices to reduce the occupational hazards of drilling operations. 


\title{
REVIEW CONSULTANTS
}

\author{
Ron Baker \\ Assistant Coordinator of Training \\ Petroleum Extension Service \\ University of Texas at Austin \\ c/o 4802 Eilers Avenue \\ Austin, Texas 78751 \\ Howard Cutter \\ Corporate Safety Director \\ Alyeska Pipeline Company \\ 1835 South Bragow Street \\ Anchorage, Alaska 99512 \\ Bill Person \\ Assistant Safety Director \\ Rowan Companies, Inc. \\ 1900 Post Oak Tower Building \\ 5051 Westheimer \\ Houston, Texas 77056
}


CONTENTS

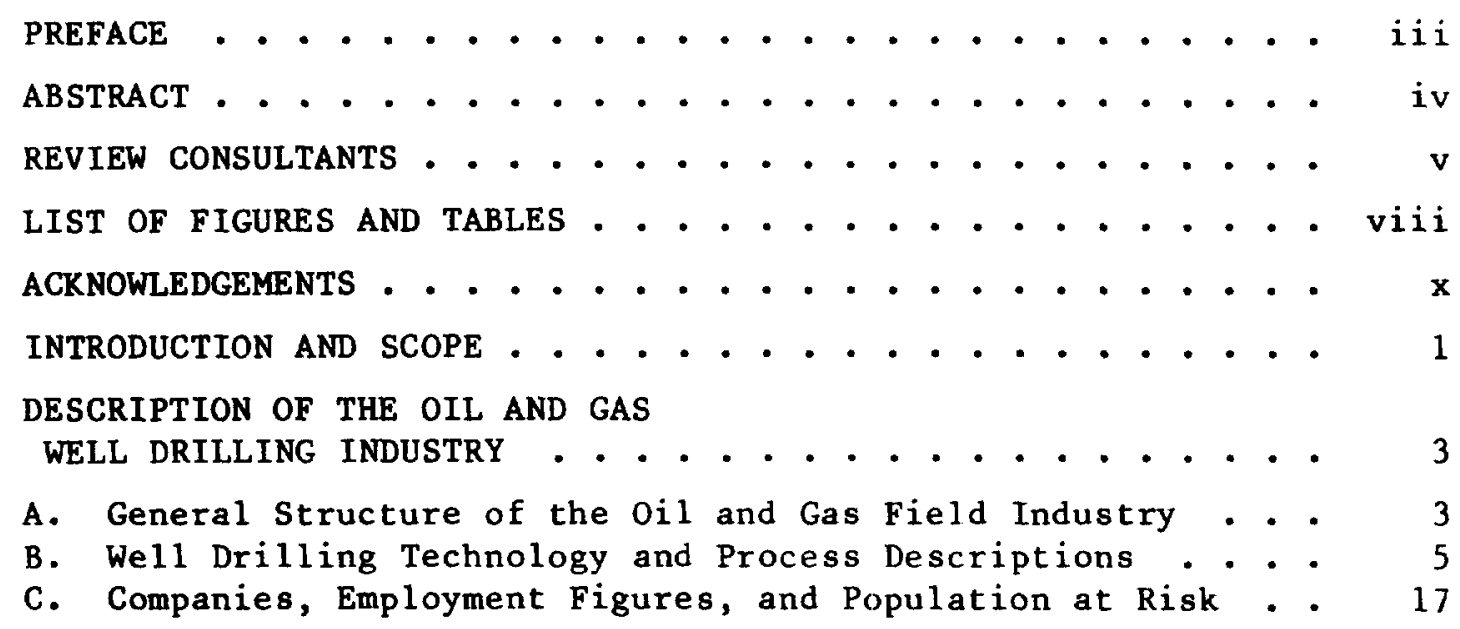

III. DEFINITION OF THE PROBLEM -

THE HAZARDS OF THE OIL AND GAS WELL DRILLING INDUSTRY . . . . 27

A. General Hazard Assessment of

the Oil and Gas Field Services Industry . . . . . . . . . 27

B. Hazard Assessment of the Drilling Industry . . . . . . . 27

C. Fatality Statistics . . . . . . . . . . . . . . 35

D. Hazardous Tasks Performed in Well Drilling Operations . $\quad 37$

E. How Injuries Occur in Drilling Operations . . . . . . . . 44

F. Costs of Injuries . . . . . . . . . . . . . . . . . 48

G. Training and the New Employee . . . . . . . . . . . . 48

H. Conclusion . . . . . . . . . . . . . . . . . . . 52

IV. COMPREHENSIVE SAFETY RECOMMENDATIONS

FOR OIL AND GAS WELL DRILLING . . . . . . . . . . . . . . 55

A. General Safety Recommendations . . . . . . . . . . . 55

B. Safety Guidelines for Well Drilling Machinery

and Equipment . . . . . . . . . . . . . . . . 73

C. Safe Work Practices . . . . . . . . . . . . . . 95

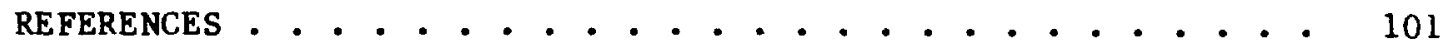

APPENDIX A. REVIEW OF ACCIDENT CASE HISTORIES • • • • • • • . . 109

APPENDIX B. REVIEW OF STATE, FEDERAL, INTERNATIONAL

AND CONSENSUS SAFETY STANDARDS . . . . . . . . 129

GLOSSARY OF TERMS USED IN THE OIL AND GAS

WELL DRILLING INDUSTRY . . . . . . . . . . . . . . . . . . 


\section{FIGURES}

II-1. Tasks Necessary to Drill and Maintain a Producing Oil or Gas Well .............. 4 4

II-2. Functional and Component Diagram of a Rotary Drilling Rig.................... 7

II-3. The Rotary Rig and Its Components . . . . . . . . 8

II-4. Rotary Drilling Rig Hoisting System . . . . . . . . . 10

II-5. Circulating Fluid System. . . . . . . ...... 12

II-6. Ten-Year Growth of the Average Number of Active U.S. Land Rigs $(1971-80)$. . . . . . . . . 24

II-7. Average Annual Employment For the Years 1972-80 (SIC 138) . 25

\section{TABLES}

II-1. Profile of 0 il and Gas Well Drilling Companies in 1980 (SIC 1381) . . . . . . 18

II-2. Number of Well Drilling Facilities and Employees (SIC 1381) ............. . . 18

II-3. Census of Active Drilling Rigs. . . . . . . . . . . 21

II-4. Population at Risk in Oil and Gas Well Drilling Operations (1971-80) (SIC 1381) .......... 23

II-5. Oil and Gas Well Drilling Activity (1974-80) . . . . 23

III-1. Average Occupational Injury and Illness Incidence Rates for Selected Industries, 1972 - 1980. . . . . . . .

III-2. Estimated Number of Employees Injured and Injury Incidence Rates for Oil and Gas Well Drilling Operations Based on Land-based Wells Drilled in Texas........

III-3. Estimated Number of Employees Injured and Injury Incidence Rates for $0 i 1$ and Gas Well Drilling Operations Based on Land-based Active Rigs in Texas. . . . . . .

III-4. Estimated Number of Employees Injured and Injury Incidence Rates for Oil and Gas Well Drilling Operations Based on Land-based Well Footage in Texas . . . . . .

III-5. Lost-Time Injury Incidence Rates for Oil and Gas Well Drilling Based on IADC Reports.....

III-6. Estimated Average Injury Incidence Rates for Oil and Gas Well Drilling (SIC 1381) in SDS Reporting States Based on SDS Injury Statistics for 1976-1980 ... 


\section{TABLES (CONTINUED)}

III-7. Fatalities That Occurred in Texas $0 i 1$ and Gas Well Drilling Operations Extrapolated to the Entire Oil and Gas Well Drilling Industry . . . . . . . . . 37

III-8. Drilling Operations and Injury Distribution . . . . . . . 38

III-9. Types and Causes of Accidents Sustained During Tasks Unique to Well Drilling Operations . . . . 39

III-10. Types and Causes of Accidents Sustained During

Tasks Not Unique to Well Drilling Operations. ... . . . 42

III-11. Injuries Associated with Rig Activity or Equipment, 1980. • 43

III-12. Type of Accident or Exposure for $0 i 1$ and Gas Well Drilling Activities (1977-79) . . . . . . . . . 44

III-13. Workers' Compensation Losses Incurred by

the 0il and Gas Well Drilling Industry, 1971-78 . . . . 49

III-14. Injury Breakdown by Length of Employment. . . . . . . . 52

III-15. Reported Accidents and Length of Employment . . . . . . 52

IV-1. Safe Bearing Capacity of Soils . . . . . . . . . . 76

IV-2. Number and Spacing of U-Bolt Wire Rope Clips. . . . . . 90

B-1. General Industry Standards which may be Applicable to the $0 i 1$ and Gas Well Drilling Industry . . . . . . 132 


\section{ACKNOWLEDGEMENTS}

This report was developed by the Division of Safety Research (DSR), National Institute for Occupational Safety and Health. Mr. Ted A. Pettit and Mr. Peter M. Bochnak, Standards and Consultation Branch, DSR, served as Project officer and Criteria Manager respectively. Technical editing for the report was provided by Herbert Linn, DSR. Support was provided under Contract No. 210-80-0040 by Enviro Control Division of Dynamac Corporation, Rockville, Mary land. 
CHAPTER I

INTRODUCTION AND SCOPE

Based on U.S. Department of Labor (DOL), Bureau of Labor Statistics (BLS) reports, it is estimated that employees in the oil and gas field service industries (Standard Industrial Classification (SIC) 138) were injured at about twice the rate of general industry employees from 1972 through 1980 . During this study, examination of three separate sources of injury data (Chapter III) indicated that in the oil and gas well drillingl industry (SIC 1381) workers (excluding clerical and administrative support personnel) may have been injured at an even higher rate. Calculations based on these sources of injury data have produced yearly injury incidence rates that range from 11.2 (lost-time injuries only, as computed by the International Association of Drilling Contractors) to 49.4 (compensable injuries recorded by the Texas Workers' Compensation State Board of Insurance) incidents per 100 person-years. The workers involved in drilling activities, the population at risk in this study, increased in number from approximately 25,000 in 1971 to nearly 80,000 in 1980 .

Employees who work on drilling rigs may be injured while performing tasks and using equipment unique to well drilling operations; furthermore, these tasks and operations are not specifically addressed by existing Federal occupational safety and health standards. The Occupational Safety and Health Administraticn (OSHA) General Industry Standards (29 CFR 1910) are applicable to many of the general tasks, equipment, and conditions that are present at well drilling operations; e.g., welding and cutting, scaffolding, handtools, ladders, hydrogen sulfide exposure levels and electrical equipment. However, many of the tasks, equipment, and conditions present at well drilling sites are not specifically regulated by existing Federal safety standards. Some of these include:

\begin{tabular}{|c|c|}
\hline o & Tongs \\
\hline 0 & Rotary tables and bushings \\
\hline & Catheads and catlines \\
\hline & Elevators and slips \\
\hline & Drill pipe and casing \\
\hline & Derrick operations \\
\hline & Making and breaking drill pipe connection \\
\hline & Well blowout \\
\hline & Hydrogen sulfide monitoring. \\
\hline
\end{tabular}

The scope of this report is to identify the hazards resulting in accidents and injuries during the performance of oil and gas well drilling operations

1 The term "oil and gas well drilling" as used in this report refers to "land-based oil and gas well drilling." 
(SIC 1381), and to recommend safe work practices and technologic improvements that will reduce worker exposure to the identified hazards.

The multiplicity of well servicing and completion operations, as performed by SIC 1389 companies, has not been included in the statistical development of this document; however, this is not intended to exclude servicing and completion contractors from utilizing all applicable safety recommendations presented in Chapter IV.

Chapter II discusses the processes and technologies used to drill oil and gas wells and defines the population at risk in the industry. Chapter III defines the problems: injury incidence rates for the population at risk are presented, and hazardous tasks are identified. Chapter IV presents comprehensive safety recommendations for the oil and gas well drilling industry. Appendix A presents representative case histories of oil and gas well drilling accidents that further demonstrate the uniqueness of drilling operations. An evaluation of the applicability of existing standards (State, Federal, international, and consensus) to oil and gas well drilling operations, and specifically to situations involving unique drilling equipment and tasks, is presented in Appendix B. A glossary of general industry terms is also included at the end of this report. 


\section{CHAPTER II \\ DESCRIPTION OF THE OIL AND GAS WELL DRILLING INDUSTRY}

The first section of this chapter briefly describes the oil and gas field industries that interact in developing an oil or gas well; the next section describes the technology and processes used by oil and gas well drilling companies; and the final section assesses the population at risk in the oil and gas well drilling industry.

This document is specifically directed toward tasks associated with oil and gas well drilling and, concomitantly, those industries performing the drilling (SIC 1381). To facilitate an understanding of the development of an oil well, an overview of all tasks necessary to complete a well is presented in the following section.

\section{A. General Structure of the 0 il and Gas Field Industry}

Oil and gas field companies (SIC 138) perform tasks associated with the construction of oil or gas wells and the subsequent maintenance of a producing field. The industry is composed of companies that erect the rig and drill the hole (SIC 1381); companies that provide ancillary services such as well completion, casing, and perforating (SIC 1389); and companies that offer exploratory services (SIC 1382).

The size of the drilling rig, the number of employees, and the duration of the drilling operation depends on the depth of the well to be drilled, which may range from a few hundred feet to over 30,000 feet. Drilling times tend to increase exponentially with well depth and may vary from a week to more than 2 years.

As many as 20 different companies may perform their specialized operations at each well site. The scope of this document is limited to the tasks and operations performed in drilling a well. Figure II-l is a flow chart showing the individual operations (underscored in the section below) required in the construction and maintenance of a producing well, starting from the geological survey.

Once a well site has been selected by a geological survey team, the site preparation will usually be subcontracted to a company specializing in earthmoving operations. This contractor will level the site, dig and dike any required reservoirs, and excavate the cellar. The "spudding-in" of the starter hole and running of conductor casing may be subcontracted to a service company, or the drilling contractor may choose to perform this task itself after it has erected the derrick. The surface casing will then be cemented in place to ensure well integrity and blowout prevention. Meanwhile, a trucking company will be transporting the drilling rig and 


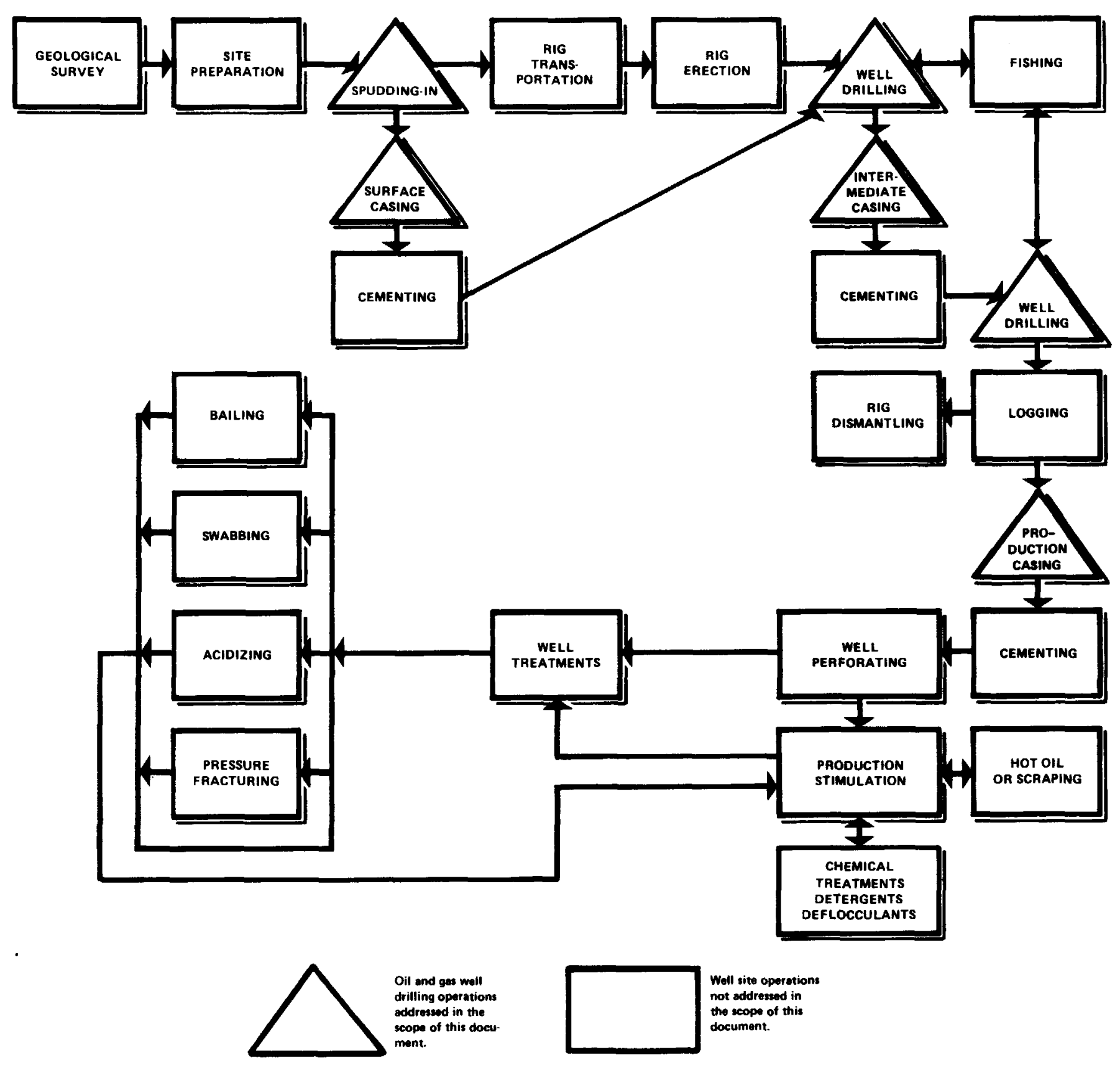

FIGURE II-1. TASKS NECESSARY TO DRILL AND MAINTAIN A PRODUCING OIL OR GAS WELL 
accessories to the well site for assembly and erection by the drilling contractor. As the well drilling proceeds, it is probable that intermediate protective casings will have to be run and cemented in place. If the drill string breaks and a section is lost in the well bore, then a fishing company may be contracted to remove the portion of broken drill string remaining in the we11 bore.

When the well depth has reached the hydrocarbon-bearing formation, a logging company may be hired to test the formation for oil and gas production potential. If the well is to be completed--that is, if the well bore has penetrated a formation that contains commercial quantities of oil and/or gas--then production casing will be run, sometimes by a contractor who specializes in this service. Usually the drilling contractor's rig remains onsite during the running and cementing of production casing. Once the casing has been cemented, frequently a company specializing in well perforating is engaged.

Many hydrocarbon-bearing formations can be stimulated to produce at faster rates than initially evidenced. Pressure fracturing or acidizing companies may be used to improve formation channelization. Bailing may be necessary to remove sand from the perforated area, or the well may have to be swabbed. Finally, once well production has been maximized, a "Christmas tree" may be added if the well is a flowing gas well, or a pump may be installed if it is an oil producer. Most new oil wells, like gas wells, will flow on their own.

Additional stimulation and well service may be required throughout the producing life of a well. Hot oil or scraping may be used to remove paraffin buildup in the casing.

The addition of detergents, deflocculants, or other chemicals may be required to maintain the flow rate. Acidizing or pressure fracturing may again be necessary.

\section{B. Well Drilling Technology and Process Descriptions}

The following process descriptions concentrate on the activities associated with oil and gas well drilling (SIC 1381). Hazardous exposures associated with these tasks are mentioned (briefly) and detailed in Chapter III.

\section{Rigging-Up}

Before describing the functional components of a drilling operation and their attendant hazards, it is necessary to mention rigging-up; i.e., assembling and erecting the derrick and associated gear. This phase, however, is similar to many other rigging operations with common procedures and hazards and does not require special treatment in this study. Equipment is designed for rapid assembly and economy of labor. In most cases, it is offloaded from trucks by winch and skid techniques. The substructure supporting the drill deck and derrick is either placed intact or assembled over a previously completed cellar. 
In many instances, the spudding-in, or augering of the large-diameter starter hole, will have been completed earlier by a contractor using a workover rig. In this case the spud hole will be 1 ined with conductor casing, which is likely to be cemented in place. Then the drilling rig will be assembled (rigged-up) and used to drill the hole below the conductor casing. Surface casing is then run and cemented.

Technically, the derricks in use today are, for the most part, masts in that they are not erected piece by piece. Instead, they are raised either by jackknifing or by hydraulic telescoping. On truck-mounted rigs and small workover rigs, guy lines are strung from the mast to the ground. On large jackknife masts, guy lines are not used as they are self-supporting. An emergency derrick line with escape trolley is strung from the derrick board, also called a "monkey board." The hazards of these operations are those commonly associated with construction sites and are not addressed in this document.

\section{Rotary Drilling}

The functional components of a rotary drilling rig have been grouped under these activities/systems:
- Power generation and transmission
o Hoisting the drill string
- Rotating the drill string
- Circulating fluid systems
- Materials handling during drilling operations.

These components, described in more detail below, are shown in a functional diagram (Figure II-2) and are depicted in Figure II-3.

\section{a. Power Generation and Transmission}

The primary power source is normally one or more internal combustion engines. On larger, modern rigs, the engines are frequently located at ground level, 100 or more feet from the derrick. This is to minimize the potential of fires caused by engines igniting gases that could escape from the well bore. On smaller rigs, the engines frequently are mounted immediately next to the derrick. The most common fuel used is diesel; but gasoline, natural gas, liquefied petroleum gas, and purchased electricity are also used. Typically, several hundred horsepower (HP) will be generated and used on a drilling rig, although a larger rig may produce more than $3,000 \mathrm{HP}$.

The transmission is mechanical or electric. A mechanical transmission, which is more common in older rigs, utilizes a "compound" of clutches, chains and sprockets, belts and pulleys, 


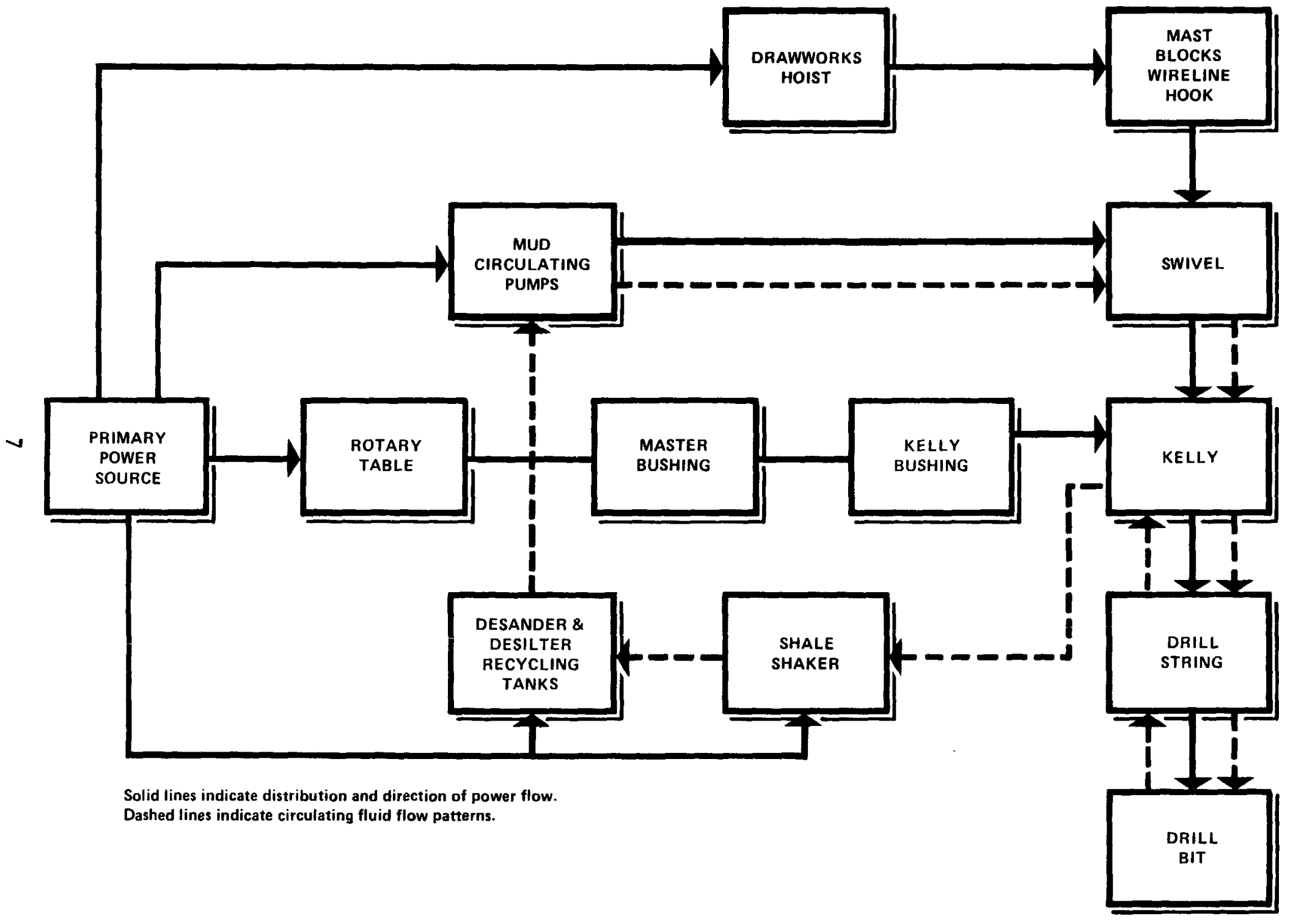

FIGURE II-2, FUNCTIONAL AND COMPONENT DIAGRAM OF A ROTARY DRILLING RIG 
Reprinted with special permission by Department of Health and Human Services 1983 . Further reproduction prohibited without permission of copyright holder.

\section{The Rotary Rig and Its Components}

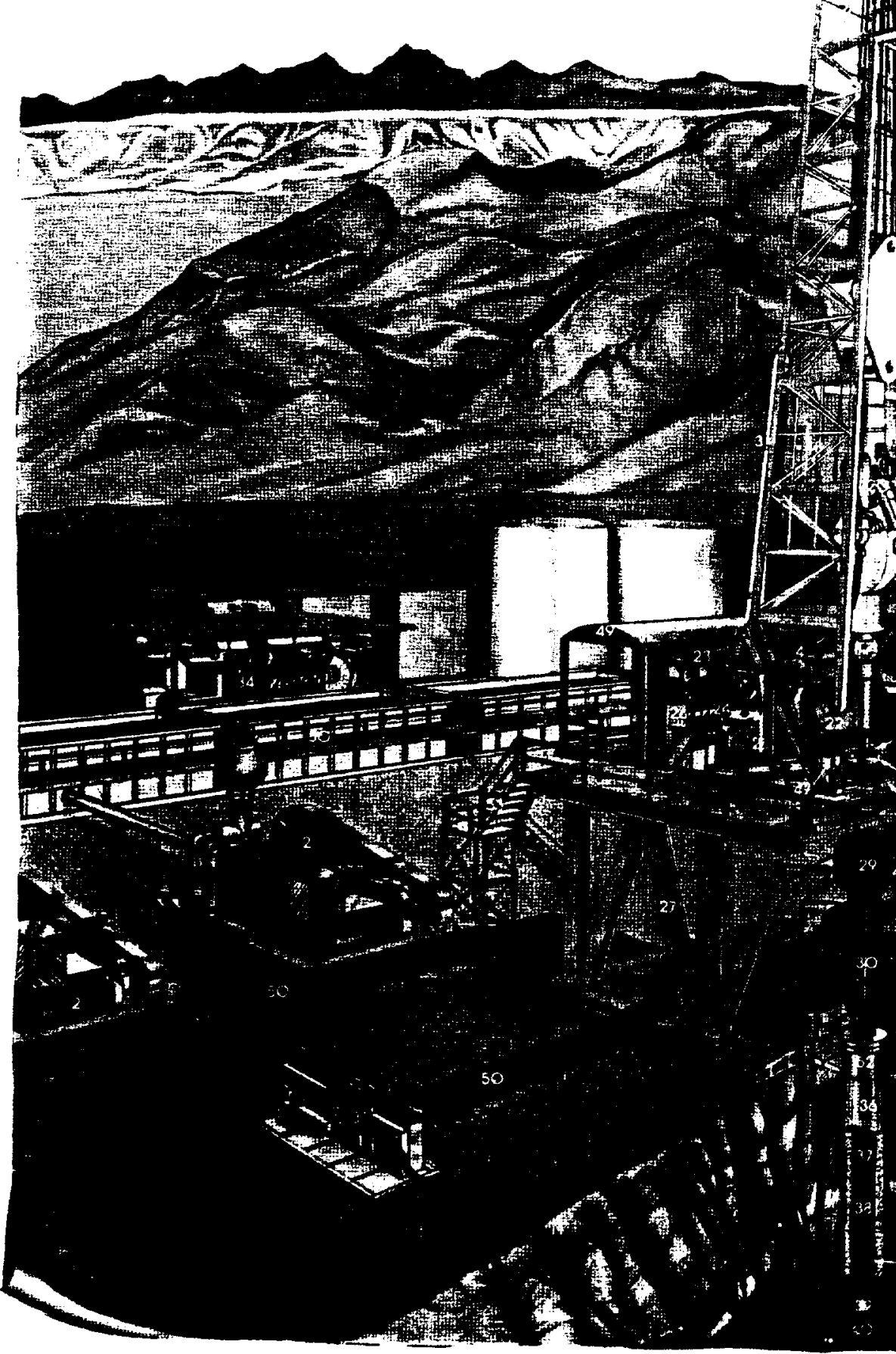

CAnculating STSTEM

1. Mud plts

2. Mud pumpe

4. Aotary hos

5. Bulk mud

nte slorage

B. Degitier

9. Dewander

10. Degaserer

11. Recerve pits
nOTATING EOUIPMENT

12. Swivel

15. Kotry bushing table

MOLNNE EYSTEM

16. Crown block and

17. Monkeyboard

18. Mant

19. Treveling
21. Elewators

23. Catheed

25. Werant indicato

28. Drillere conecor
27. Subatructure

WELL-CONTRO

EOUPACNT

29. Annular blowoul prewenter

\section{Accumuletor untt}

32. Chollo manitold

POWEA SYSTEM

34. Power-ponerating plent

MPE AND PAPE-handuno

POPE AND PIPE

36. Conductor pipe

37. Surface casing

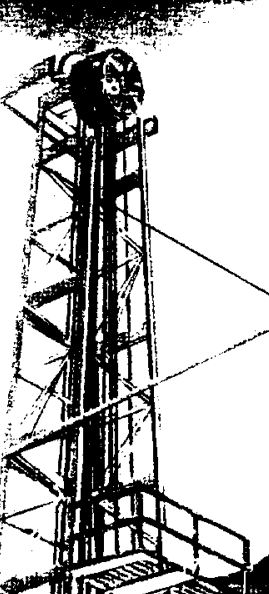


and a number of driving and driven shafts. An electric transmission is more common in newer equipment.

Most exposures to hazards associated with the power generation and transmission system occur during maintenance, fueling, and lubrication. Inadequate or nonexistent equipment guards and ineffectual (or the lack of) lockout procedures for maintenance operations during continuous drilling increase the risk of physical injury. Other hazards include high voltages, chemical injury to the eyes during fueling, fire, and explosion. The noise levels in power generation areas may be high, with the risk of hearing loss.

b. Hoisting the Drill String

The primary functions of the hoisting apparatus are to raise and lower the drill string components during tripping and drill stem lengthening operations and to support the drill string at the desired bit weight during drilling. The drawworks is essentially a rotating spool, usually located on the drill deck, controlled by a clutch and brake system operated by the driller. The wire rope drill line runs from the drawworks to the crown block at the top of the derrick, and then to the traveling block and hook, which is attached to the drill string during drilling operations. The drilling line diameter and reeving sequence of the blocks are determined by maximum drill string weight. The deadline anchor, usually located on the derrick substructure, serves as an adjustable terminal anchor point for the wire rope (Figure II-4). Typically, the dead line anchor will be adjustable to allow for the continual addition of new wire rope to the hoisting system.

Employee exposure to hazards associated with hoisting should be slight unless structural defects exist or system overloading occurs. Routine inspection of elevated hoist mechanisms involves the risk of falls. Pinched fingers and injuries from wire rope splinters are other hazards.

\section{c. Rotating the Drill String}

In addition to rotating the drill string and bit, the rotary table provides for free vertical motion of the drill as the bit penetrates into the earth. Torque is transmitted from the rotary table to the drill by the kelly, which also conveys the drilling mud that is pumped into it through a swivel connector.

The kelly is a three-, four-, six-, or eight-sided 40-foot-long conduit (i.e., longer than the 30-foot drill pipe sections) that threads into the drill pipe and is connected to the hoist traveling block by the swivel. The swivel supports the buoyed weight of the drill string while allowing the kelly to rotate and the pressurized drilling fluid to enter the drill stem. The kelly is rotated by a suitably structured kelly bushing that transfers rotational force 


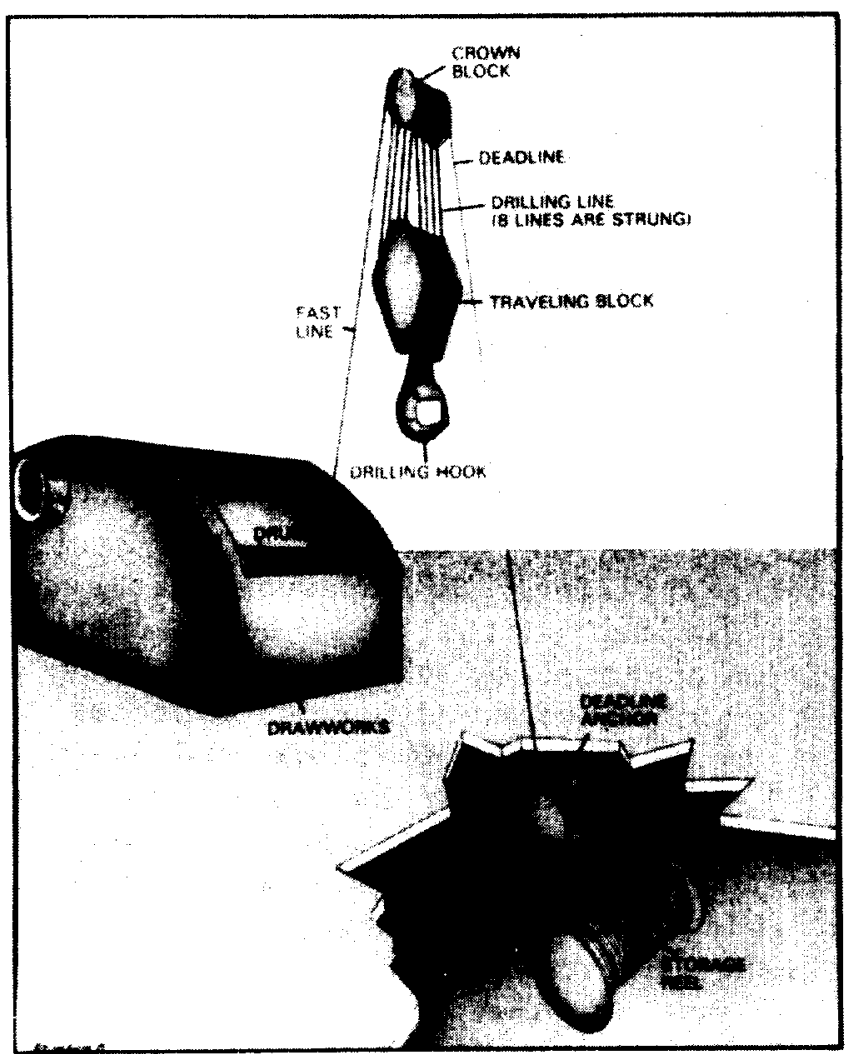

FIGURE II-4. ROTARY DRILLING RIG HOISTING SYSTEM [1] Copyright by the University of Texas at Austin (PETEX). Reprinted by the Department of Health and Human Services with permission. Further reproduction without permission of copyright holder prohibited.

without impeding the continuous downward movement of the kelly. During operations such as tripping, the kelly bushing must be easily removable to permit the drill pipe to be withdrawn from the well. When the kelly is hoisted and stored in the rathole during a trip, the kelly bushing is removed as an integral part of the kelly assembly. To facilitate this maneuver, the kelly bushing sits inside a three-, four-, six-, or eight-sided master bushing that is a fixed portion of the rotary table. The rotary table (and other rotating parts) may turn at rates of up to $400 \mathrm{rpm}$; however, much slower speeds are usual, perhaps in the range of 25-100 rpm. The driller operates the rotary table clutch controls and hoist controls from the same station. The power source is either an electric motor or mechanical power that is connected to the rotary table by a compounded chain drive. 
A typical drill string consists of 30-foot sections of drill pipe, male and female threaded, that weigh between 14 and 18 pounds/foot (500 pounds/joint). Several heavy, thick-walled joints of pipe, called drill collars, are made up in the drill stem, just above the bit, so the bit will penetrate into the formation being drilled. A single drill collar can weigh between 2,500 and 4,000 pounds (or more) depending on its diameter.

The hazards associated with this equipment are discussed in section e., Materials Handling During Drilling Operations. However, it should be noted that employee exposure to rotating parts during drilling makes this operation one with a high potential for severe injuries, although the frequency of occurrence is low. The rotary table and kelly bushing are in nearly continuous motion and are not usually provided with any guarding mechanism. Contact with either is likely to cause slips, falls, and bruising accidents; also, there is a risk of being caught between stationary and rotating parts.

\section{d. Circulating Fluid Systems}

Drilling fluid, or "mud," is typically a mixture of water and bentonite (an absorbent, gel-forming clay) and sometimes oil or other components. It has four primary functions: cooling, lubricating, and cleaning the bit; removing the cuttings; providing hydrostatic pressure to prevent entry of formation fluids into the well bore; and reducing the risk of hazardous blowouts.

Mud pumps force the mud up a standpipe and through the flexible kelly hose to the swivel, where it enters the drill string via the kelly and eventually emerges at the bit in the well bore. Continuous pressure (up to $3,000 \mathrm{psi}$ ) forces the mud up the well annulus and out the mud return pipe, where it is first screened of larger cuttings at a shale shaker and then processed through a series of desanders and desilters prior to recycling (Figure II-5). Cuttings carried by the drilling fluid are taken for analysis to determine the composition of the stratum being drilled.

Hazards associated with working on or around components of circulating fluid systems are various. Mixing of the mud exposes workers to airborne respirable dust and chemical splashes. Tanks in which mud is mechanically stirred are hazardous when unguarded, or when effective lockout procedures are not followed during maintenance operations. Walking surfaces nearby may be slippery, especially in wet or icy weather. Pressure surges causing line rupture are an occasional hazard.

e. Materials Handling During Drilling Operations

On a drill rig, most of the materials handling equipment is unique to the oil field. This equipment is used in the working routines 


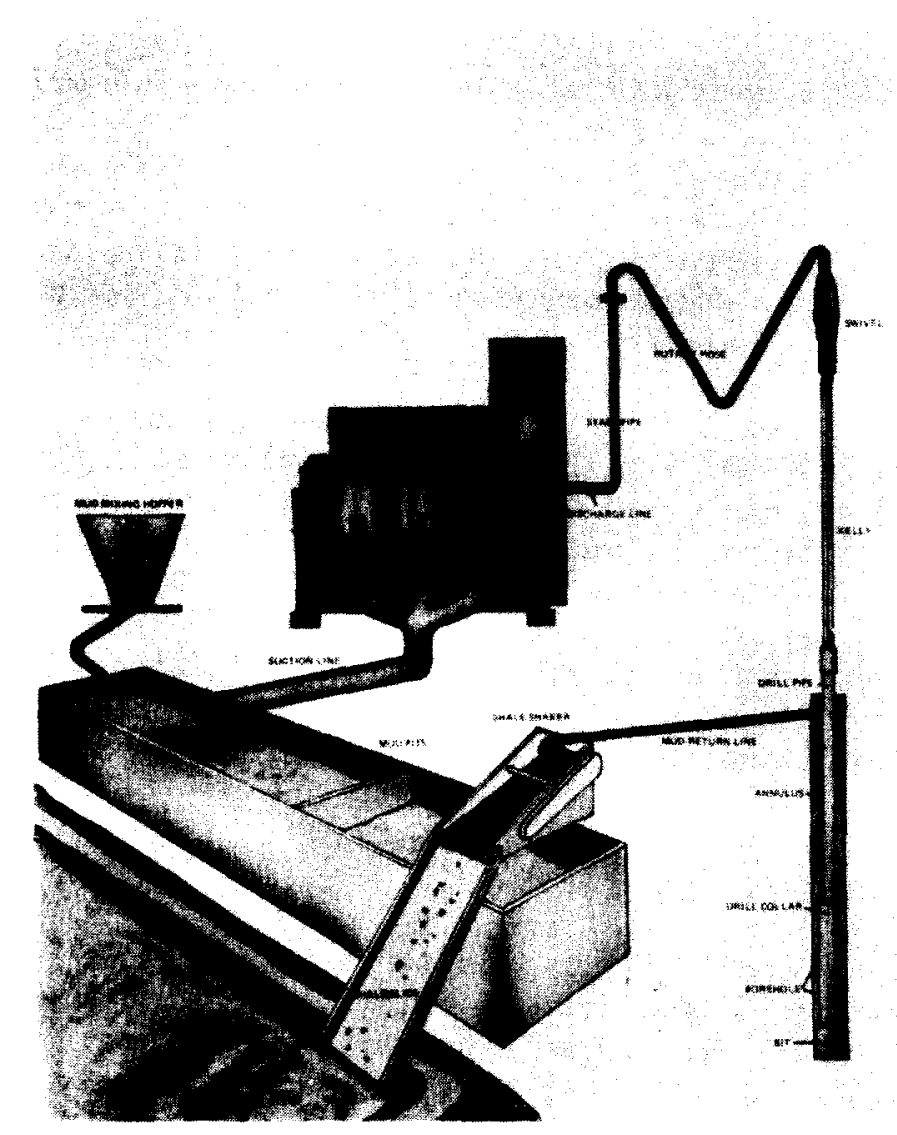

FIGURE II-5. CIRCULATING FLUID SYSTEM [1]

Copyright by the University of Texas at Austin (PETEX). Reprinted by the Department of Health and Human Services with permission. Further reproduction without permission of copyright holder prohibited.

of raising and lowering the drill string, adding new sections of drill pipe, and tripping. This equipment and its operation are described in operational sequence in this section.

To extend the length of the drill string, a joint (30-foot section) is hoisted from horizontal pipe storage racks (located at ground level) to the drill deck. The joint is lowered into a hole in the drill deck (known as a mousehole), where it is stored until it is added to the string. This hoisting operation can be performed with a fiber rope, hands-on friction pulley (known as a cathead) that protrudes from each side of the drawworks. Most modern drilling rigs have steel cable air hoists to perform the hoisting of the drill pipe. When the kelly is at the level of the kelly bushing, the rotary table and mud circulating pumps are stopped. The driller raises the drill stem until the bottom of the kelly pipe joint connection is about 2 feet above the level of the rotary table. A set of "slips" is wedged into the space between the 
master bushing and the drill stem to maintain the drill pipe's position. A large pair of counterweight-suspended wrenches, called tongs, are used to "break out" the torqued kelly pipe joint connection. Once the tongs are clamped above and below the connection, mechanical force is applied to the handle of the breakout tong by a tong pull line originating from a mechanical cathead located on the drawworks. When the connection has been loosened, the joints are "spun out." Some rigs use an air-operated kelly spinner to spin out the kelly from the drill pipe, whereas others spin out the drill pipe with the rotary table after the tool joint has been "broken" with the pipe tongs. When making up a connection, some rigs use a pipe spinner to spin the joint up; then it is tightened with the pipe tongs. Many rigs use the traditional spinning chain to make up a joint of pipe; then it is tightened with the pipe tongs.

Once disengaged, the lower end of the kelly, suspended by the hoist, is pushed/pulled by the floorhands until it is centered over the pipe joint that was temporarily stored in the mousehole. The kelly is "stabbed" into the pipe joint, spun up, and tong tightened. The driller next engages the drawworks and raises the kelly and pipe joint assembly, which in turn is stabbed into the drill stem that is held by the slips. This connection is then spun up and tong tightened. The slips are removed, the mud pumps and rotary table are reactivated, and the drilling operation proceeds.

Tripping is a procedure used when well bore inspections and bit changes are necessary. The entire drill string must be removed from the hole and later returned if the drilling is to proceed. During a "round trip" (cycle of removal and replacement), the kelly is disconnected and stored in the rathole, a hole in the rig floor into which the kelly and swivel are placed during hoisting operations. Elevators, a set of clamps affixed to the bails on the swivel below the traveling block, are attached to the bell portion (tool joint) of the drill pipe and used to raise the drill string from the hole. Pipe tongs and frequently the rotary table are used to disconnect the stands (usually 90 feet of drill pipe) as one unit. The initial breaking of the pipe joint is properly performed by the automatic cathead tensioning the breakout tong. To ensure well control, drilling mud is usually added to the well bore to replace the fluid volume displaced by the drill stem and to maintain hydrostatic pressure when the drill stem is removed. The derrickman, usually using a fall-arresting derrick climber, climbs the derrick and works from the monkey board, which is usually located 90 feet above the rig floor. His task is to coordinate the placement of the triple joints between the fingers of the "finger board" for temporary storage during the trip and to disconnect the drill pipe from the elevators.

Once the bit has been removed from the hole, it is inspected for wear and replaced as necessary. "Logging" devices may be lowered 
into the hole on a stranded wire electric cable by a cathead power takeoff system or an independent electric winch. If the well drilling operation is to continue, the above sequence is reversed, completing the round trip.

Workers directly involved in these operations are close to moving equipment components, while performing tasks that require substantial exertion and good coordination between individuals. Transferring drill pipe from the rack to the drilling platform may result in the stockpile rolling or in the mishandling of suspended loads, with the risk of crushing injury. Handling of the tongs requires well-coordinated efforts and proper body limb placement. Mistakes in the hands-on spinning chain operations can lead to entanglement that may result in crushing, amputation, and death. Machinery is activated by an operator who depends on visual and/or audible cues; a mistake can lead to premature activation while workers are still in contact with moving parts. Mechanical failure from overloading systems can occur. Lifting and moving heavy items on wet surfaces may lead to slips, falls, and overexertion. Eyes are at risk from material falling off the drill pipe. Potential hazards in these operations can be increased if the drilling crew has not worked together very long; teamwork is necessary to carry out the operations quickly and safely.

3. Other Drilling Techniques

\section{a. Compressed Air}

Compressed air may be used instead of drilling mud when there is no risk of encountering high-pressure, permeable formations or formations containing water. It has the advantages of faster drilling and of not having to recondition the circulating mud. The drilling dust is discharged from the "blooey line" and may be blown across the working area to cause a respiratory hazard; dust particles may cause eye injuries.

\section{b. Directional Drilling}

Directional drilling occurs when a contractor intentionally drills a well that is out of plumb. Surface conditions may dictate that a drilling rig cannot be erected over the formation to be explored or, as in offshore operations, the rig may be costly enough that multiple formations should be explored from a central drilling position. Directional drilling is achieved by a number of different methods. Directional tools include downhole hydraulic turbine motors, jet deflector bits, bent subs, flexible joints, or, most common in past years, whipstocks.

c. Redrilling

The redrilling of a well takes place when well depth must be 
extended. (The existing formation may not be productive and the well may be extended to tap a lower formation.) In some instances the prior drilling operation may have stopped for reasons associated with annulus collapse, damaged casing, lost drilling string, or blowout.

Operationally, the drilling procedure and hazard exposure are the same as described earlier; however, techniques may have to be altered to overcome any formation or well bore irregularities.

\section{Casing Operations}

Lining or casing a well is a task performed to ensure the integrity of the well bore throughout the drilling and production phases. Large-diameter surface casing characteristically is used in the uppermost portion to ensure well wall integrity and for well control. The use of intermediate casings is determined by the depth that the surface casing is set and the relative pressures. of shallow formations as compared to deeper formations. Production casing, which may be set by the drilling contractor, is normally required if the well is to be brought to production.

In most instances, a subcontractor is hired to install the casing. The casing contractor supplies the larger elevators and pipe tongs necessary to handle the larger-diameter casing materials. Most frequently, the manpower comprises a few direct employees of the casing contractor and the employees of the drilling contractor supervised by the subcontractor. However, there is no standard procedure governing manpower supply during casing operations. The casing operation proceeds in a manner fundamentally the same as multiple repetitions of adding new sections of pipe to the drill string. Surface and intermediate casing is larger in diameter, and is likely to result in a greater severity of materials handing or rolling stock incidents. Production casing is normally run by a casing contractor using the same rig used to drill the hole, although in some cases it may be run by a completion contractor using his own mobile rig.

Casing operations are conducted by companies that are classified by the SIC system into the oil and gas field services (1389) category. The operational procedures and equipment used are sufficiently similar to those in the actual drilling operations to yield similar accident/injury potentials. However, data on injury incidence rates for this specific portion of SIC 1389 are not available.

\section{Special Hazards}

In certain areas and depths, if proper precautions and control methods are not employed, two conditions may be encountered that have the potential to cause major disasters: blowouts and the escape of hydrogen sulfide. 


\section{a. Blowouts}

A blowout is an uncontrolled escape of gas, oil, or formation fluids that may lead to fire, explosion, drilling rig destruction, injury, or death.

Blowouts may occur when the formation fluid pressure exceeds the hydrostatic pressure of the circulating fluid in the well annulus such as the totally unexpected encountering of unpredictable pressures and/or when mechanical controlling methods; e.g., blowout preventers (BOP's) or other pressure-control techniques, fail through misuse, misapplication, or malfunction. During a drilling operation, the mud serves as the first control method. If there is a pit level increase (or any of several other indications), then the formation pressure exceeds the hydrostatic pressure of the mud. This is called a kick. If a kick occurs, the driller should take steps to close in the well with the BOP's. After the BOP's are closed, the mud weight is increased so that it can exert a pressure equal to, or slightly higher than, the pressure of the formation.

Most wells are drilled in oil fields with predictable formation pressures. BOP's selected to be compatible with these pressures are installed as soon as the surface casing is in place. BOP's function by sealing off the well bore. A series of hydraulic (and some manual) rams activated from ground level (not on the derrick) seal and contain the formation pressures.

If the kick is not noticed in time or the techniques used to control the formation pressures are not adequate, then a blowout occurs. Since blowouts and subsequent fires involve the loss of equipment and time (as well as employee exposure to extremely hazardous conditions), the industry usually takes great care to prevent their occurrences.

\section{b. Hydrogen Sulfide}

Hydrogen sulfide is a highly toxic, colorless gas. It is a very insidious industrial hazard for two reasons: unreliability of odor as a warning, and sudden onset of incapacitation. Hydrogen sulfide has been identified by NIOSH as a leading cause of sudden workplace death [2]. At concentrations up to 30 parts per million (ppm), it has an odor of rotten eggs [2]. However, at more deadly concentrations ( $100 \mathrm{ppm}$ ), hydrogen sulfide rapidly fatigues the olfactory nerves [3-5?. A person may momentarily smell the gas but think little of it when the odor is no longer detectable. If exposure is sufficiently intense, unconsciousness and respiratory failure may occur without warning symptoms. The gas is 1.2 times denser than air, and at high concentrations will tend to accumulate in low spots. Mixed with air in concentrations of $4.3-45.5 \%$, 
hydrogen sulfide is explosive [2]. It may also burn with the production of toxic sulfur dioxide.

During oil and gas well drilling operations, $\mathrm{H}_{2} \mathrm{~S}$ is first released to the atmosphere at the shale shaker area and later at the circulation fluid treatment areas. It may also be released during tripping procedures in the immediate area around the drilling operation. Typically, however, only nominal amounts of $\mathrm{H}_{2} \mathrm{~S}$ are released during normal drilling operations.

The effect of hydrogen sulfide on metals, known variously as metal fatigue, hydrogen embrittlement, and sulfide stress cracking, can cause failure of the drill string during a well control situation $[3,6,7]$. Such failure can result in the release of hazardous concentrations of $\mathrm{H}_{2} \mathrm{~S}$ in the drilling area. Careful selection of resistant metals and chemical treatment of drilling fluids can effectively guard against such failure.

With the exception of exploratory or "wildcat" wells, drilling operations take place in oil fields where the hydrogen sulfide locations and formation pressures likely to be encountered are known. With the demand for hydrocarbons increasing, formations historically deemed too dangerous to produce are now being developed. In some instances, there is frequent to nearly continuous employee exposure to hydrogen sulfide at concentrations from $10 \mathrm{ppm}$ (OSHA 8-hour permissible exposure limit (PEL)) to life-threatening levels requiring the wearing of self-contained breathing apparatus. Innovative technologies, alarm systems, and respiratory protective equipment and programs are being employed without uniform Federal regulation.

\section{Companies, Employment Figures, and Population at Risk}

The companies that perform the tasks necessary to construct and maintain oil wells are grouped by the SIC system into the oil and gas field service companies (SIC 138). They are composed of companies that offer exploratory services (SIC 1382); companies that perform drilling operations (SIC 1381) such as spudding-in, air drilling, redrilling, offshore drilling, and directional drilling; and companies that perform tasks associated with well completion and stimulation (SIC 1389).

As shown in Table II-1, 764 companies were engaged in oil and gas drilling operations in 1980 [8]. The sizes of the companies, as defined by the number of drilling rigs owned, ranged from one-rig operations to companies that owned more than 20 drilling rigs. The Dun and Bradstreet Industrial Profile Data for 1980 indicates that the number of employees at each facility ranged from 1 to 7 to more than 500 employees (Table II-2). The number of workers estimated by NIOSH to be employed by drilling contractors during 1980 was 88,116 [9]. However, included in the NIOSH estimate were employees of companies engaged in water well drilling, offshore drilling, 
and exploratory drilling; as such, they were not part of the employee population at risk in the land-based oil and gas well drilling industry.

TABLE II-1

PROFILE OF OIL AND GAS WELL DRILLING

COMPANIES IN 1980 (SIC 1381)

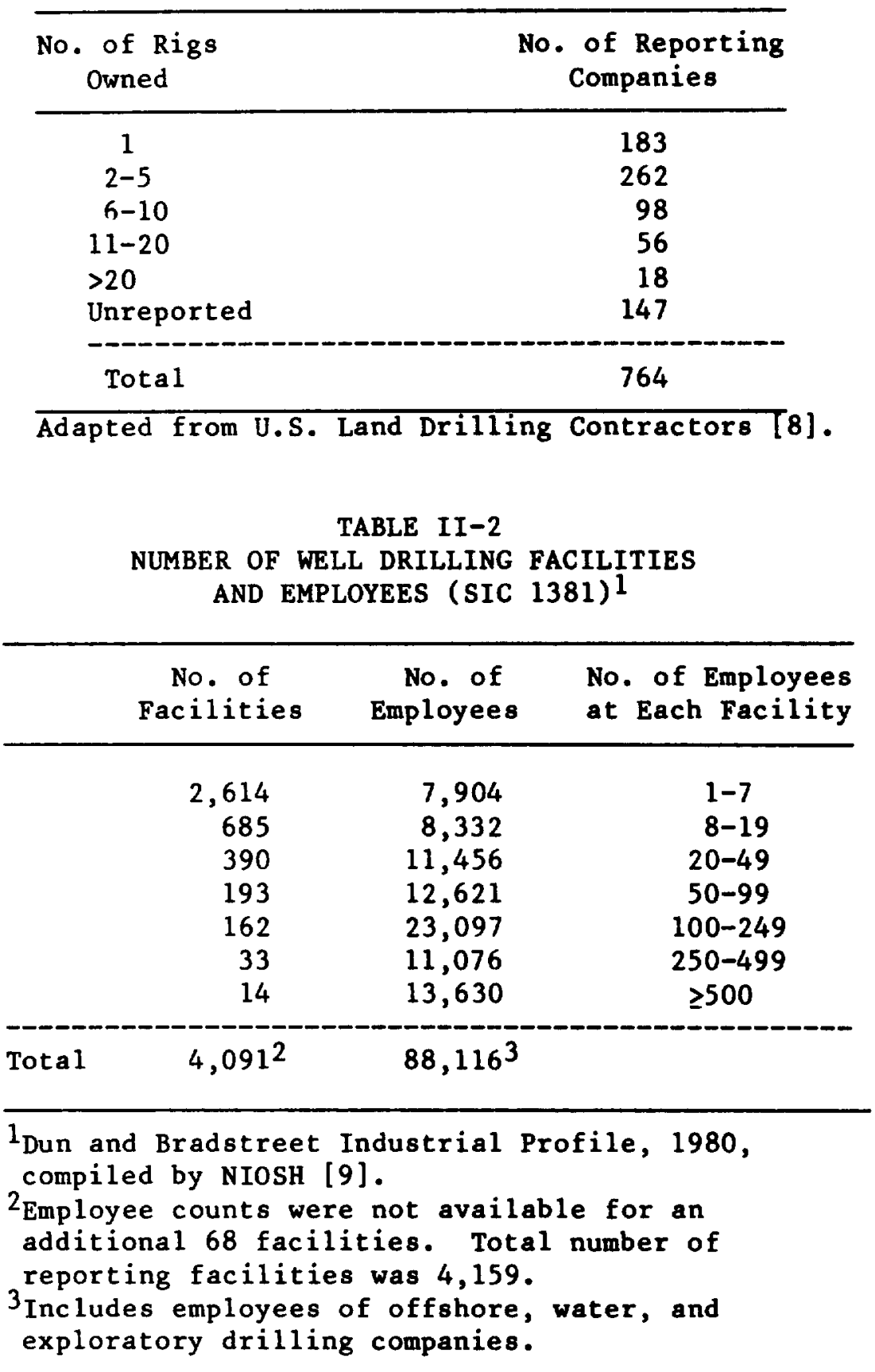




\section{Drilling Activities and Population at Risk}

Regardless of company size, the task force employed at a well site is fairly small. A typical drilling rig employs a tool pusher to supervise the drilling operation. Depending on well site location, he may be in charge of more than one rig. The driller (shift foreman) is responsible for the immediate direction of work on the drilling rig. He operates the rig controls, supervises the changing of drill pipe and tripping operations, and directs any maintenance or repair work. His crew usually consists of one derrickman performing tasks from the upper portion of the derrick during tripping operations (the derrickman is normally the second man in charge of drilling operations; i.e., the relief driller), three rotary helpers (floormen) performing those tasks associated with the addition of pipe joints during drilling and tripping.

For large operations; e.g., deeper wells, the crew usually includes a motorman (usually most experienced rotary helper) who is in charge of the mechanics of the equipment and also acts as a floorhand during tripping procedures, and an additional rotary helper.

An electrician normally is employed on electrically powered drilling rigs. Smaller drilling rigs normally require an average of five persons per shift (not including the pusher), whereas seven or eight persons per shift are needed on a larger rotary rig.

Drilling operations are continuous ( 24 hours/day, 7 days/week) until the well has been completed. When a well is being drilled, the rig usually is staffed for three 8-hour shifts, although in some remote areas the operation uses two 12-hour shifts. Approximately seven employees per shift is a reasonable estimate of the number of persons at risk on a typical drilling operation. The estimate of seven employees per rig also corresponds with field observations made during site visits and data presented in the NIOSH "Safety Information Profile oil and Gas Field Operations" [10].

The 0il and Gas Journal's "Rotary-rig Activity by States" [11] provides weekly counts, by State, of all active drilling operations. Drilling rigs are considered by the census takers to be active whenever they are drilling, tripping, or performing any task associated with making an oil or gas well. In fact, a rig is considered to be active unless it is down for repair or in storage [12]. Table II-3 contains the yearly average of active drilling rigs, by State, for the past 10 years.

The average number of active rigs and the number of workers on a shift can be used to estimate the number of workers at risk in oil and gas well drilling operations. The reason for determining the population at risk for the drilling industry is to establish an injury incidence rate for those workers exposed to the hazards attendant to drilling operations. For the purpose of comparison between industries, a "person," as defined by the BLS, works 2,000 hours during a year. In other words, for statistical comparisons, an individual who has worked 
3,000 hours in a year would be counted as 1.5 person-years. A reasonable estimate of the population at risk in the land-based drilling industry can be arrived at by multiplying the number of employees per rig (7) by the number of shifts per day (3) by the number of hours per shift (8) by the number of days per year (365) by the average number of rigs active during a year (rounded to the nearest whole number) and dividing by 2,000 (the number of hours worked by an individual in a year). The estimated population at risk in the oil and gas well drilling industry $(1971-80)$ is shown in Table II-4. For example, during 1980, the Oil and Gas Journal reported an average of 2,605 land-based active rigs [11]. The population at risk would then be estimated as 79,869 person-years during 1980. It should be noted that this estimate of population at risk is less than that reported in the Dun and Bradstreet Industrial Profile, which includes all employees in the industry as well as those involved in offshore and exploratory drilling.

\section{Trends and Projections}

Economic pressures and government actions have resulted in a steady and substantial increase in oil field activity over the past decade. The average number of active drilling rigs nearly tripled between 1972 and 1980 (Figure II-6 and Table II-4), as did the number of oil field employees in SIC 138 (Figure II-7). There was an increase of approximately 692 drilling rigs during 1980--setting what was an al1-time drilling record for the industry $[11,13]$. The average active rig count in July 1981 set a new record of 3,681--an increase of more than 1,000 active rigs over the previous July [14]. The population at risk in drilling activities would also be expected to have increased by an estimated additional 32,990 in July 1981 resulting in a predicted population at risk of approximately 112,859 person-years. Land-based drilling operations completed 63,337 wells during 1980 , an average of 24 wells drilled per rig (number of wells divided by the average number of active rigs), and almost 14,599 more than during the previous year (Table II-5).

\section{Trade Associations and Unions}

The International Association of Drilling Contractors (IADC) had about 1,000 member companies in 1981 and represented approximately $95 \%$ of all drilling companies. The current boom in drilling is rapidly increasing the number of IADC member companies but has not appreciably affected the percentage of representation of the trade association. The land-based drilling companies and member companies are urged by IADC to participate in intercompany, IADC-sponsored safety award programs and to avail themselves of IADC publications on safe working practices in drilling operations. A safety committee attends to accident prevention concepts and compiles a yearly analysis of drilling accidents for member companies. IADC also cosponsors a number of entry-level rotary helper schools that teach safe working practices, as well as advanced schools for derrickmen, drillers, and tool pushers. 
TABLE II-3

CENSUS OF ACTIVE DRILLING RIGS

\begin{tabular}{|c|c|c|c|c|c|c|c|c|c|c|}
\hline \multirow[b]{2}{*}{ State } & \multicolumn{10}{|c|}{ Average Rig Activity } \\
\hline & 1980 & 1979 & 1978 & 1977 & 1976 & 1975 & 1974 & 1973 & 1972 & 1971 \\
\hline Alabama & 10.8 & 12.6 & 12.5 & 13 & 17 & 14 & 12 & 13 & 15 & 8 \\
\hline Alaska & 13.8 & 13.5 & 15.5 & 15 & 14 & 14 & 9 & 5 & 5 & 5 \\
\hline Arkansas & 26.8 & 10.4 & 13.9 & 15 & 15 & 14 & 18 & 15 & 15 & 15 \\
\hline Arizona & 1.0 & 0.0 & 0.4 & 1 & 1 & 0 & 1 & 2 & 1 & 1 \\
\hline California & 120.2 & 95.6 & 94.1 & 89 & 89 & 80 & 72 & 51 & 46 & 46 \\
\hline In 1 and & 104.7 & 85.7 & 86.3 & 81 & 85 & 77 & 70 & 49 & 45 & 40 \\
\hline offshore & 15.5 & 9.9 & 7.8 & 8 & 4 & 3 & 2 & 2 & 1 & 6 \\
\hline Colorado & 61.1 & 40.2 & 41.1 & 45 & 38 & 42 & 45 & 42 & 35 & 30 \\
\hline Florida & 4.1 & 5.3 & 6.3 & 6 & 5 & 9 & 7 & 9 & 19 & 11 \\
\hline Id aho & 2.6 & 1.8 & 3.2 & 1 & 1 & 0 & 0 & 0 & 0 & 0 \\
\hline Illinois & 25.4 & 13.1 & 28.4 & 16 & 22 & 19 & 7 & 6 & 14 & 13 \\
\hline Indiana & 0.1 & 0.3 & 4.4 & 3 & 2 & 2 & 1 & 0 & 1 & 1 \\
\hline Kansas & 120.2 & 66.0 & 75.5 & 67 & 51 & 57 & 44 & 28 & 24 & 29 \\
\hline Kentucky & 1.7 & 0.4 & 3.3 & 2 & 1 & 1 & 2 & 1 & 2 & 2 \\
\hline Louisiana & 427.4 & 347.0 & 338.3 & 292 & 231 & 227 & 203 & 205 & 214 & 194 \\
\hline North & 54.9 & 34.5 & 39.8 & 45 & 34 & 31 & 29 & 23 & 19 & 16 \\
\hline Inland Waters & 76.6 & 62.1 & 62.5 & 57 & 49 & 55 & 58 & 55 & 54 & 50 \\
\hline South & 156.4 & 112.3 & 113.9 & 81 & 65 & 64 & 49 & 56 & 59 & 54 \\
\hline of fshore & 139.4 & 138.1 & 122.1 & 109 & 83 & 77 & 67 & 71 & 82 & 74 \\
\hline Maryland & 0.2 & 0.5 & 0.7 & 0 & 1 & 0 & 0 & 0 & 0 & 1 \\
\hline Michigan & 30.7 & 25.1 & 24.0 & 24 & 24 & 28 & 24 & 20 & 17 & 12 \\
\hline Mississippi & 57.6 & 40.2 & 44.5 & 42 & 32 & 25 & 29 & 29 & 37 & 39 \\
\hline Montana & 49.2 & 32.9 & 30.1 & 27 & 28 & 27 & 24 & 19 & 20 & 17 \\
\hline Nebraska & 14.3 & 9.2 & 9.6 & 9 & 8 & 9 & 7 & 5 & 6 & 5 \\
\hline Nevada & 4.6 & 4.1 & 2.9 & 3 & 2 & 0 & 1 & 0 & 0 & 1 \\
\hline New Mexico & 117.6 & 87.5 & 75.5 & 70 & 54 & 71 & 79 & 62 & 55 & 47 \\
\hline New York & 7.0 & 8.7 & 7.0 & 6 & 9 & 8 & 7 & 1 & 0 & 1 \\
\hline North Dakota & 83.4 & 56.5 & 39.1 & 24 & 19 & 17 & 12 & 10 & 7 & 9 \\
\hline Ohio & 73.7 & 46.3 & 45.6 & 33 & 26 & 21 & 30 & 36 & 22 & 17 \\
\hline
\end{tabular}


TABLE II-3

CENSUS OF ACTIVE DRILLING RIGS (Concluded)

\begin{tabular}{|c|c|c|c|c|c|c|c|c|c|c|}
\hline \multirow[b]{2}{*}{ State } & \multicolumn{10}{|c|}{ Average Rig Activity } \\
\hline & 1980 & 1979 & 1978 & 1977 & 1976 & 1975 & 1974 & 1973 & 1972 & 1971 \\
\hline Ok1ahoma & 397.3 & 246.7 & 258.2 & 233 & 186 & 177 & 146 & 115 & 90 & 90 \\
\hline $\begin{array}{l}\text { Pennsy Ivania } \\
\text { Rhode Is land }\end{array}$ & 29.0 & 28.9 & 25.2 & 15 & 10 & 10 & 14 & 11 & 8 & 9 \\
\hline offshore & 2.1 & 4.0 & 4.3 & 1 & 0 & 0 & 0 & 0 & 0 & 0 \\
\hline South Dakota & 1.9 & 1.4 & 2.3 & 3 & 2 & 1 & 1 & 1 & 1 & 1 \\
\hline Texas & 987.7 & 770.2 & 855.0 & 779 & 653 & 637 & 508 & 376 & 338 & 291 \\
\hline Gulf Coast & 210.5 & 141.3 & 197.0 & 175 & 160 & 142 & 128 & 109 & 95 & 79 \\
\hline offshore & 72.1 & 50.3 & 46.9 & 42 & 36 & 21 & 21 & 9 & 6 & 5 \\
\hline North & 147.2 & 122.4 & 153.2 & 142 & 111 & 107 & 67 & 22 & 16 & 15 \\
\hline Panhandle & 50.8 & 48.1 & 60.4 & 42 & 37 & 41 & 35 & 23 & 22 & 16 \\
\hline East & 119.8 & 107.0 & 116.6 & 73 & 54 & 47 & 45 & 30 & 26 & 23 \\
\hline West Central & 140.4 & 109.4 & 117.2 & 136 & 101 & 100 & 62 & 82 & 78 & 76 \\
\hline West & 247.1 & 191.7 & 163.7 & 169 & 154 & 179 & 150 & 101 & 95 & 77 \\
\hline Utah & 1.2 .4 & 28.9 & 32.1 & 30 & 19 & 26 & 42 & 38 & 34 & 17 \\
\hline West Virginia & 37.8 & 29.8 & 27.1 & 17 & 12 & 10 & 16 & 20 & 16 & 17 \\
\hline Wyoming & 155.5 & 147.2 & 136.4 & 118 & 86 & 107 & 107 & 70 & 60 & 45 \\
\hline Others & 3.3 & 2.9 & 2.0 & 2 & 0 & 7 & 3 & 3 & 4 & 2 \\
\hline $\begin{array}{l}\text { Total } 1 \\
\text { Total Land-ba }\end{array}$ & $\begin{array}{l}2,910.3 \\
\text { sed }\end{array}$ & $2,177.2$ & $2,258.8$ & 2,001 & 1,658 & 1,660 & 1,471 & 1,194 & 1,107 & 976 \\
\hline Rigs $^{2}$ & $2,604.6$ & $1,912.8$ & $2,015.2$ & 1,784 & 1,486 & 1,504 & 1,323 & 1,057 & 964 & 841 \\
\hline
\end{tabular}

${ }^{1}$ Total rig census figures are shown as reported in the $0 i 1$ and Gas Journal [11].

2Total land-based rigs have been calculated by summing the offshore and inland water rig counts and subtracting this figure from the total rig count.

Adapted from the 0il and Gas Journal's "Rotary-rig Activity by States" [11]. 
The International Union of Operating Engineers (IUOE) has a small membership of drilling contractor employees that encompasses about 100 land-based rigs in California. The dearth of labor organization in the oil fields probably is due in part to the small employment size of many facilities and may be influenced by the frequent inaccessibility of well sites, which are not uncommonly more than 2 hours from the closest accommodations.

TABLE II-4

POPULATION AT RISK IN OIL AND GAS WELL DRILLING OPERATIONS (1971-80) (SIC 1381)

$\begin{array}{llllllllll}1971 & 1972 & 1973 & 1974 & 1975 & 1976 & 1977 & 1978 & 1979 & 1980\end{array}$

\begin{tabular}{|c|c|c|c|c|c|c|c|c|c|c|}
\hline $\begin{array}{l}\text { Total } \\
\text { Rigs } 1\end{array}$ & 841 & 964 & 1,057 & 1,323 & 1,504 & 1,486 & 1,784 & 2,015 & 1,913 & 2,605 \\
\hline \multicolumn{11}{|c|}{$\begin{array}{l}\text { Estimated } \\
\text { Pop. }{ }^{2} \text { at }\end{array}$} \\
\hline Risk & 25,785 & 29,556 & 32,408 & 40,563 & 46,113 & 45,561 & 54,697 & 61,780 & 58,653 & 79,869 \\
\hline
\end{tabular}

TABLE II-5

OIL AND GAS WELL DRILLING ACTIVITY (1974-80)

\begin{tabular}{|c|c|c|c|c|c|c|c|}
\hline & \multicolumn{7}{|c|}{ Activity by Year } \\
\hline & 1974 & 1975 & 1976 & 1977 & 1978 & 1979 & 1980 \\
\hline $\begin{array}{l}\text { Total No. } \\
\text { of Wells } \\
\text { Completed }\end{array}$ & 32,450 & 37,614 & 37,648 & 44,870 & 46,974 & 48,738 & 63,337 \\
\hline $\begin{array}{l}\text { Total } \\
\text { Footage } \\
(1,000 \mathrm{ft})\end{array}$ & 150,310 & 170,722 & 170,406 & 199,951 & 218,454 & 231,818 & 282,488 \\
\hline $\begin{array}{l}\text { Average } \\
\text { Wel1 } \\
\text { Depth ( } f t)\end{array}$ & 4,632 & 4,539 & 4,526 & 4,456 & 4,651 & 4,756 & 4,460 \\
\hline $\begin{array}{l}\text { Average No. } \\
\text { of Active L } \\
\text { Rotary Rigs }\end{array}$ & nd 1,323 & 1,504 & 1,486 & 1,784 & 2,015 & 1,913 & 2,605 \\
\hline
\end{tabular}




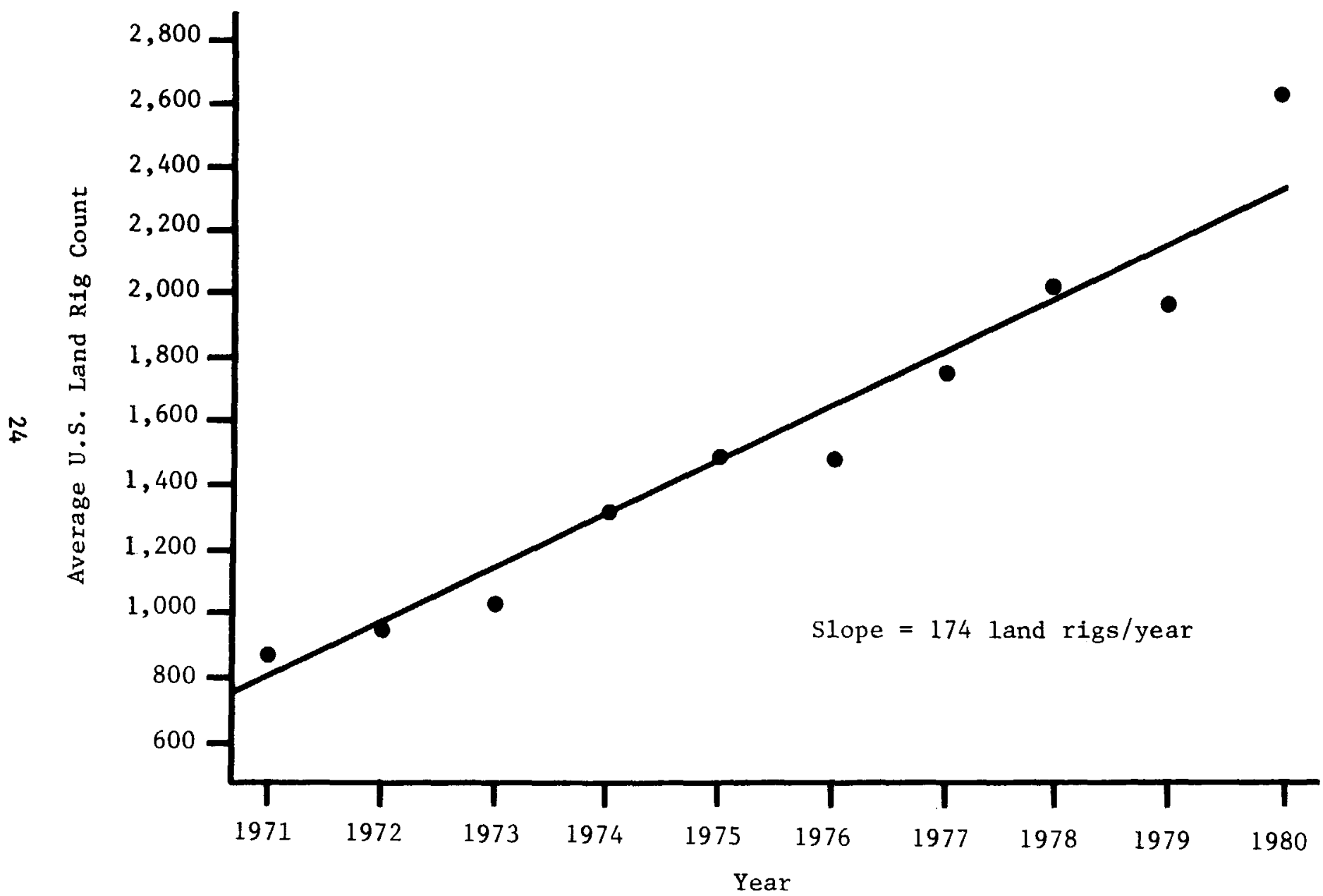

FIGURE II-6. TEN-YEAR GROWTH OF THE AVERAGE NUMBER OF ACTIVE U.S. LAND RIGS (1971-80) Compiled from the $0 i 1$ and Gas Journal's "Rotary-rig Activity by States" [11] (See Table II-3). 


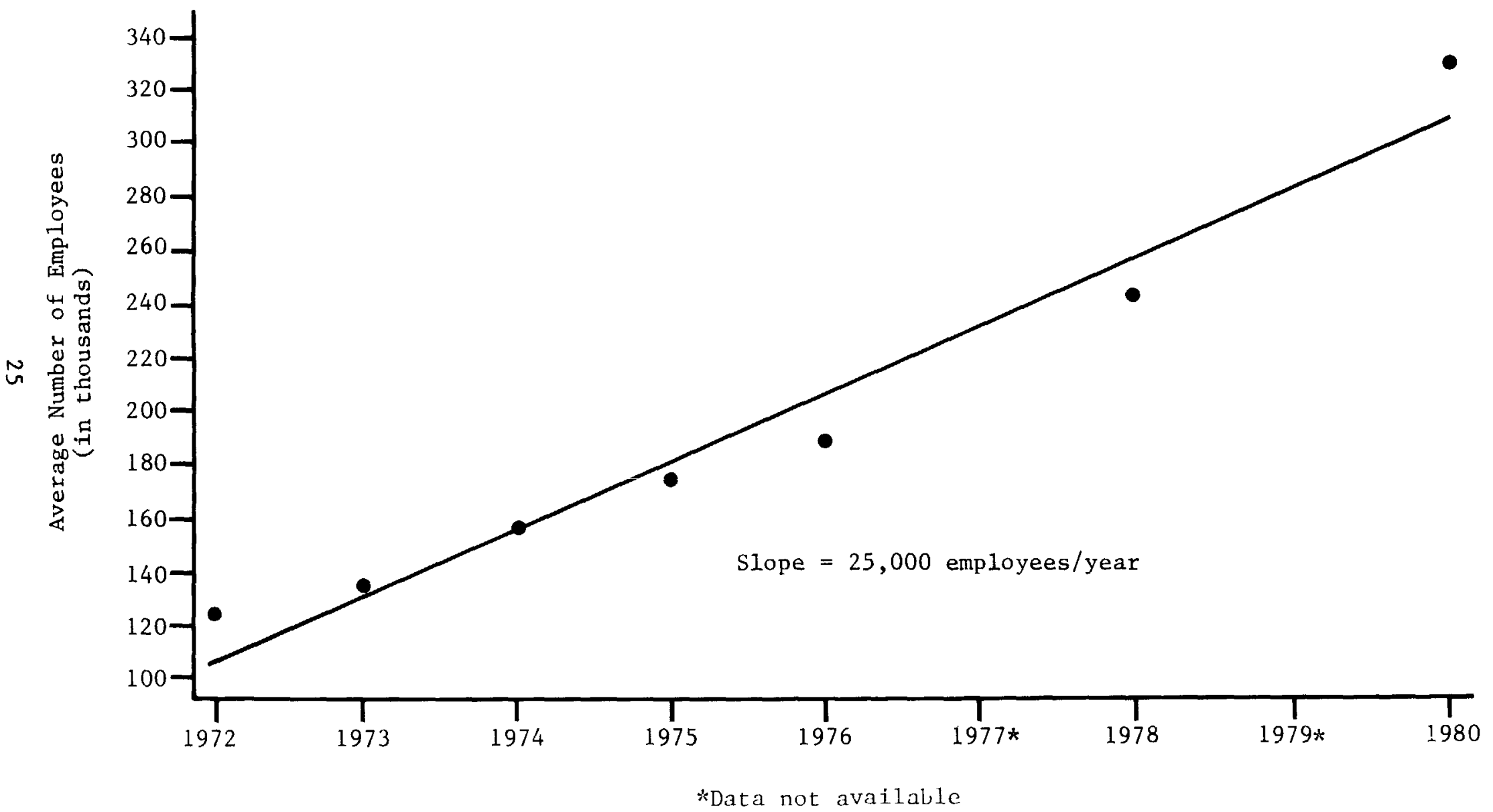

FIGURE II-7. AVERAGE ANNUAL EMPLOYMENT FOR THE YEARS 1972-80 (SIC 138) Compiled from Bureau of Labor Statistics [20-28]. 


\section{CHAPTER III \\ DEFINITION OF THE PROBLEM--THE HAZARDS OF THE OIL AND GAS WELL DRILLING INDUSTRY}

This chapter is divided into two major areas of emphasis: the development of data pertaining to the injury incidence rates of the oil and gas well drilling industry, and an identification of the tasks performed in well drilling operations that are most hazardous to the population at risk. Also included is a discussion of training and the new employee, as well as a discussion of the costs of injuries to the industry.

\section{A. General Hazard Assessment of the Oil and Gas Field Services Industry}

For the oil and gas field services industry (SIC 138), the BLS reported that between 1972 and 1980 the average yearly injury and illness incidence rate was about 19.5 cases per 100 full-time workers (Table III-1). For these same years, the average injury incidence rata for heavy construction, not including highway, was 18.3; for bituminous coal mining, about 12.1 ; and for the private sector manufacturers of durable goods, about 14.9 (Table III-1). Although the tasks performed by the oil and gas well field services industry are not entirely equatable to coal mining or heavy construction, they are all high-hazard industries (as evidenced by their injury statistics) and can be used for comparative purposes. The severity rate for the oil and gas field services industry (SIC 138) averaged 211.8; i.e., for every 100 employees there were 211.8 lost workdays (Table III-1). The average severity rates for heavy construction, bituminous coal mining, and the durable goods industries for the same years were $116.5,158.4$, and 82.5 , respectively (Table III-1).

\section{B. Hazard Assessment of the Drilling Industry}

National injury statistics compiled by the BLS are not available for the specific four-digit classifications of the industries that comprise SIC 138; i.e., drilling, 1381; exploration, 1382; and oil field services, 1389 . Consequently, three techniques using different data bases were used to estimate injury incidence rates for the drilling industry: injury statistics tabulated by the Texas Workers' Compensation State Board of Insurance (TWC), injury data developed by the International Association of Drilling Contractors (IADC), and state injury statistics compiled by the Department of Labor's Supplementary Data System (SDS). The injury incidence rates calculated in this section are not directly comparable to BLS rates since the population at risk is limited to the workers at risk at the drilling operations and does not include the entire worker population for drilling companies (i.e., support staff, clerical, and sales personnel in addition to those workers at risk in drilling operations). 
TABLE III-1

AVERAGE OCCUPATIONAL INJURY AND ILLNESS INCIDENCE RATES FOR SELECTED INDUSTRIES, 1972-1980

\begin{tabular}{|c|c|c|c|c|c|}
\hline Industry & $\begin{array}{l}\text { Avg. Annual } \\
\text { Employment } \\
\text { (Thousands) }\end{array}$ & $\begin{array}{c}\text { Total } \\
\text { Cases } 1 \\
\text { (Thousands) }\end{array}$ & $\begin{array}{c}\text { Incidence } \\
\text { Rate }^{2}\end{array}$ & $\begin{array}{l}\text { Severity } \\
\text { Rate }^{3}\end{array}$ & $\begin{array}{c}\text { Lost } \\
\text { Workdays } \\
\text { (Thousands) }\end{array}$ \\
\hline $\begin{array}{l}\text { All } \\
\text { Heavy Construction } \\
\text { (Exc. Highway) }\end{array}$ & $67,245.4$ & $5,641.0$ & 9.7 & 58.9 & $34,481.4$ \\
\hline $\begin{array}{l}\text { (SIC 162) } \\
\text { Bituminous Coal }\end{array}$ & 511.9 & 92.3 & 18.3 & 116.5 & 597.5 \\
\hline $\begin{array}{l}\text { (SIC 12) } \\
\text { Manufacturing: }\end{array}$ & 210.1 & 24.8 & 12.1 & 158.4 & 344.2 \\
\hline $\begin{array}{l}\text { Durable Goods } \\
\text { Oil and Gas }\end{array}$ & $11,673.2$ & $1,735.8$ & 14.9 & 82.5 & $9,666.2$ \\
\hline (SIC 138) & 192.4 & 37.7 & 19.5 & 211.8 & 414.0 \\
\hline
\end{tabular}

1 Estimated by multiplying the number of employees by the reported incident rate and dividing by 100.

2 Number of total recordable injuries and illnesses/100 full-time workers.

3 Number of lost workdays/100 full-time workers.

Reported by the Bureau of Labor Statistics [20-28].

Note: Data for 1972 were not reported for SIC 12, and data for 1977 were not reported for SIC 138. Only data for the years reported were used to calculate averages. 
1. Estimates of Injury Incidence Rates Based on Texas Workers' Compensation State Board of Insurance Data

The first method used to estimate injury incidence rates for the oil and gas well drilling industry entails the extrapolation of injury data reported by the TWC to the entire drilling industry. The types of injuries reported are injuries requiring medical treatment and/or indemnity payments.

Drilling activities in Texas are assumed to be typical and representative of all drilling activities. Texas represents a cross section of major drilling contractors and small, one-rig companies; deep and shallow wells; and large and small rigs. Drilling contractors basically operate in areas that are expected to produce hydrocarbons. The same equipment (tongs, spinning chains, kelly bushings, drill pipes, etc.) is utilized in a similar manner regardless of the well site location. There is little indication that the oil field operations or the accident statistics of Texas differ from national figures.

The injury incidence rate was estimated by extrapolating the actual number of compensable (medical/indemnity) injuries for employees of drilling companies reported in Texas to all drilling. The assumption was that if the rate of injuries in Texas for a given amount of drilling activity was representative of national drilling injury rates, and there was a reported number of drilling injuries in Texas, then a reasonable number for compensable injuries nationwide could be estimated as in Tables III-2, III-3, and III-4.

The proportion of total drilling activity attributable to Texas, as a percentage of national figures, was developed using three independent comparison factors: number of wells drilled (Table III-2), number of active rigs (Table III-3), and well footage (Table III-4). For example, Texas was determined to account for approximately $39.6 \%$ (a range of $34.7 \%$ to $41.5 \%$ ) of the Nation's drilling activity based on the number of active rigs from 1973 to 1978 (Table III-3). Estimates were then made of the number of drilling employees injured nationwide based on the number of compensable claims by employees of Texas drilling contractors.

The average injury incidence rate, based on the actual number of paid medical and/or indemnity claims to employees of drilling companies in Texas, was 38.1 between 1973 and 1978 (a range of 26.5 to 49.4). Tables III-2, III-3, and III-4 present the estimated compensable injury incidence rates for the drilling industry for 1973 to 1978.

2. Estimates of Injury Incidence Rates Based on IADC Data

A second data source to be considered when evaluating injury incidence rates for the drilling industry are those developed by the IADC. Table III-5 presents the lost-time injury incidence rates developed by the IADC for oil and gas well drilling for 1975-80. 
TABLE III-2

ESTIMATED NUMBER OF EMPLOYEES INJURED AND INJURY INCIDENCE RATES FOR OIL AND GAS WELL DRILLING OPERATIONS BASED ON LAND-BASED WELLS DRILLED IN TEXAS

\begin{tabular}{|c|c|c|c|c|c|c|c|}
\hline Year & $\begin{array}{c}\text { Wells Drilled } \\
\text { in Texas }{ }^{1}\end{array}$ & $\begin{array}{c}\text { Wells Drilled } \\
\text { Nationwide }\end{array}$ & $\begin{array}{c}\text { Texas as a } \% \\
\text { of Nationwide } 2\end{array}$ & $\begin{array}{l}\text { Injuries } \\
\text { in Texas }\end{array}$ & $\begin{array}{r}\text { Est. Injuries } \\
\text { Nationwide } 4\end{array}$ & $\begin{array}{c}\text { Est. Population } \\
\text { at Risk }\end{array}$ & $\begin{array}{c}\text { Incidence } \\
\text { Rate }^{6}\end{array}$ \\
\hline $\begin{array}{l}1973 \\
1974 \\
1975 \\
1976 \\
1977 \\
1978 \\
\text { Tot./ }\end{array}$ & $\begin{array}{r}8,422 \\
9,645 \\
12,309 \\
12,514 \\
14,421 \\
14,747\end{array}$ & $\begin{array}{l}26,543 \\
31,954 \\
38,151 \\
40,471 \\
45,238 \\
47,413\end{array}$ & $\begin{array}{l}31.7 \\
30.2 \\
32.3 \\
30.9 \\
31.9 \\
31.1\end{array}$ & $\begin{array}{l}4,499 \\
5,533 \\
6,360 \\
6,340 \\
8,625 \\
6,820\end{array}$ & $\begin{array}{l}14,192 \\
18,321 \\
19,690 \\
20,518 \\
27,038 \\
21,929\end{array}$ & $\begin{array}{l}32,408 \\
40,563 \\
46,113 \\
45,561 \\
54,697 \\
61,780\end{array}$ & $\begin{array}{l}43.8 \\
45.2 \\
42.7 \\
45.0 \\
49.4 \\
35.5\end{array}$ \\
\hline Avg. & 72,058 & 229,770 & 31.4 & 38,177 & 121,688 & 281,122 & $43.3^{7}$ \\
\hline
\end{tabular}

1 From the American Petroleum Institute Quarterly Review of Drilling Statistics [29-34].

2 Calculated by dividing the number of wells drilled in Texas by the number of wells drilled nationwide and multiplying by 100 .

3 Reported by the Texas Workers' Compensation State Board of Insurance [35] (Adjusted to reflect land-based injuries).

4 Extrapolated from the percentage of drilling activity and the number of injuries in Texas.

5 Person-years (from Table II-4.)

6 Injuries per 100 person-years. Calculated by dividing the estimated number of injuries nationwide by the estimated population at risk and multiplying by 100 .

7 Calculated by dividing the total estimated number of injuries nationwide by the total estimated population at risk and multiplying by 100 . 
TABLE III-3

ESTIMATED NUMBER OF EMPLOYEES INJURED AND INJURY INCIDENCE RATES FOR OIL AND GAS WELL DRILLING OPERATIONS BASED ON LAND-BASED ACTIVE RIGS IN TEXAS

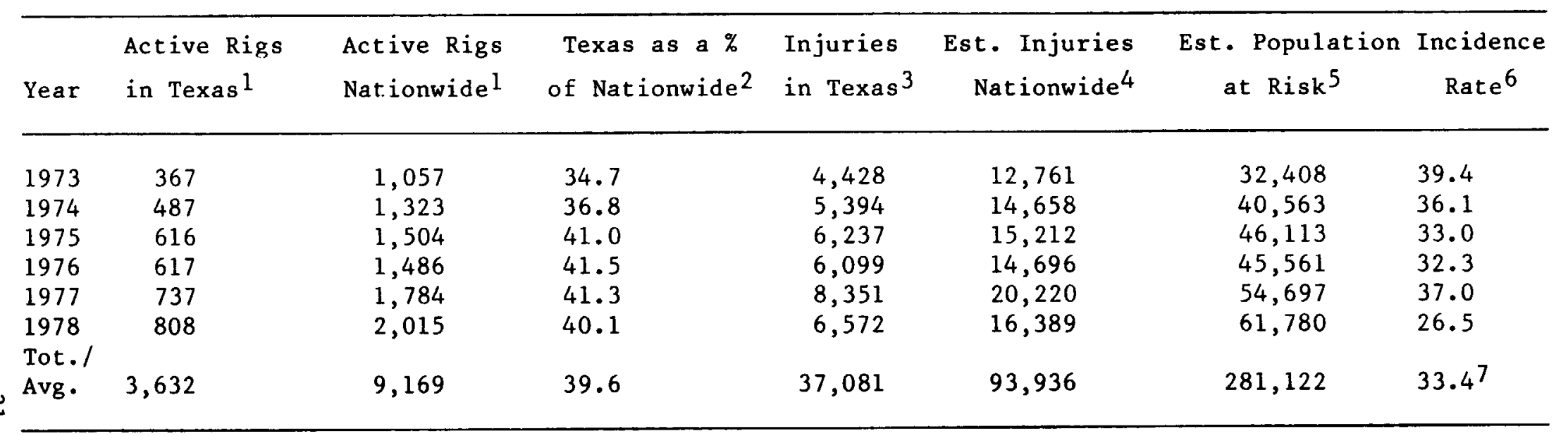

1 From the 0 il and Gas Journal (see Table II-3)[11].

2 Calculated by dividing the number of active rigs in Texas by the number of active rigs nationwide and multiplying by 100 .

3 Reported by the Texas Workers' Compensation State Board of Insurance [35] (Adjusted to reflect land-based injuries).

4 Extrapolated from the percentage of drilling activity and the number of injuries in Texas.

5 Person-years (from Table II-4.)

6 Injuries per 100 person-years. Calculated by dividing the estimated number of injuries nationwide by the estimated population at risk and multiplying by 100 .

7 Calculated by dividing the total estimated number of injuries nationwide by the total estimated population at risk and multiplying by 100 .

NOTE: The injury incidence rate calculated in this table would be identical to the injury incidence rate calculated for Texas since rig count is not only used to develop the population at risk (Tables II-3, II-4) but is also the basis for the extrapolation of the estimated injuries nationwide. 
TABLE III-4

ESTIMATED NUMBER OF EMPLOYEES INJURED AND INJURY INCIDENCE RATES FOR OIL AND GAS WELL DRILLING OPERATIONS BASED ON LAND-BASED WELL FOOTAGE IN TEXAS

\begin{tabular}{|c|c|c|c|c|c|c|c|}
\hline Year & $\begin{array}{l}\text { Weil Footage } \\
\text { in Texas } 1 \\
\text { (Thousands) }\end{array}$ & $\begin{array}{l}\text { Well Footage } \\
\text { Nationwide } \\
\text { (Thousands) }\end{array}$ & $\begin{array}{c}\text { Texas as a } \% \\
\text { of Nationwide } 2\end{array}$ & $\begin{array}{l}\text { Injuries } \\
\text { in Texas }\end{array}$ & $\begin{array}{r}\text { Est. Injuries } \\
\text { Nationwide } 4\end{array}$ & $\begin{array}{c}\text { Est. Population } \\
\text { at Risk }\end{array}$ & $\begin{array}{c}\text { Incidence } \\
\text { Rate }^{6}\end{array}$ \\
\hline $\begin{array}{l}1973 \\
1974 \\
1975 \\
1976 \\
1977 \\
1978\end{array}$ & $\begin{array}{l}44,654 \\
49,677 \\
61,484 \\
63,743 \\
75,346 \\
78,516\end{array}$ & $\begin{array}{l}129,175 \\
144,990 \\
170,041 \\
176,871 \\
204,040 \\
221,401\end{array}$ & $\begin{array}{l}34.6 \\
34.3 \\
36.2 \\
36.0 \\
36.9 \\
35.5\end{array}$ & $\begin{array}{l}4,473 \\
5,480 \\
6,293 \\
6,263 \\
8,483 \\
6,743\end{array}$ & $\begin{array}{l}12,928 \\
15,977 \\
17,384 \\
17,397 \\
22,989 \\
18,994\end{array}$ & $\begin{array}{l}32,408 \\
40,563 \\
46,113 \\
45,561 \\
54,697 \\
61,780\end{array}$ & $\begin{array}{l}39.9 \\
39.4 \\
37.7 \\
38.2 \\
42.0 \\
30.7\end{array}$ \\
\hline Avg. & 373,420 & $1,046,518$ & 35.7 & 37,735 & 105,669 & 281,122 & $37.6^{7}$ \\
\hline
\end{tabular}

1 From the American Petroleum Institute Quarterly Review of Drilling Statistics [29-34].

2 Calculated by dividing the number of well footage in Texas by the number of well footage nationwide and multiplying by 100 .

3 Reported by the Texas Workers' Compensation State Board of Insurance [35] (adjusted to reflect land-based injuries).

4 Extrapolated from the percentage of drilling activity and the number of injuries in Texas.

5 Person-years (from Table II-4)

6 Injuries per 100 person-years. Calculated by dividing the estimated number of injuries nationwide by the estimated population at risk and multiplying by 100 .

7 Calculated by dividing the total estimated number of injuries nationwide by the total estimated population at risk and multiplying by 100 . 
Accident/injury information is collected from IADC member companies participating in a yearly safety awards program [36]. The reporting format adheres to the American National Standards Institute (ANSI) Z16.1 guidelines [37]. The injuries tabulated under the ANSI guidelines by the IADC are lost-time injuries--those injuries resulting in a time loss beyond the day of the accident. The reported employee person-hour figures include those hours worked by all company employees--support staff, secretarial help, sales personnel, as well as those persons at risk in drilling operations.

Examination of Table III-5 shows that the lost-time injury incidence rate for reporting drilling contractors in 1980 was 11.6. National BLS incidence rates for oil field workers show that lost-time injuries consistently account for about $50 \%$ of the total recordable injuries in the oil field [20-28]. This means that the recordable injury incidence rate for the IADC reporting companies for 1980 should be approximately 23 (about two times the reported lost-time injury incidence rate of 11.6).

TABLE III-5

LOST-TIME INJURY INCIDENCE RATES FOR OIL AND GAS WELL DRILLING BASED ON IADC REPORTS

\begin{tabular}{|c|c|c|c|c|c|c|}
\hline Year & $\begin{array}{l}\text { No. of } \\
\text { Reporting } \\
\text { Companies }\end{array}$ & $\begin{array}{l}\text { Injury } \\
\text { Frequency } 1 \\
\text { (per million } \\
\text { person-hours) }\end{array}$ & $\begin{array}{l}\text { Total } \\
\text { Person- } \\
\text { hours } 1 \\
\text { (Thousands) }\end{array}$ & $\begin{array}{l}\text { Lost-time } \\
\text { Injuries } 1\end{array}$ & $\begin{array}{l}\text { Est. } \\
\text { Person- } \\
\text { years }{ }^{2}\end{array}$ & $\begin{array}{c}\text { Lost-time Injury } \\
\text { Incidence Rate } 3 \\
\text { (per } 100 \text { person- } \\
\text { years) }\end{array}$ \\
\hline 1975 & 57 & 59.1 & 24,337 & 1,439 & 12,169 & 11.8 \\
\hline 1976 & 92 & 56.2 & 35,961 & 2,020 & 17,981 & 11.2 \\
\hline 1977 & 92 & 59.8 & 41,466 & 2,480 & 20,733 & 12.0 \\
\hline 1978 & 116 & 63.7 & 54,646 & 3,478 & 27,323 & 12.7 \\
\hline 1979 & 113 & 58.1 & 54,181 & 3,147 & 27,091 & 11.6 \\
\hline 1980 & 131 & 57.8 & 74,972 & 4,330 & 37,486 & 11.6 \\
\hline \multicolumn{7}{|c|}{ Tot. 1} \\
\hline Avg. & 601 & 59.1 & 285,563 & 16,894 & 142,783 & $11.8^{4}$ \\
\hline \multicolumn{7}{|c|}{$\begin{array}{l}1 \text { Compiled from IADC reports [38-43]. } \\
2 \text { Calculated by dividing total person-hours by } 2,000 \text { person-hours per } \\
\text { person-year. } \\
3 \text { Calculated by dividing the lost-time injuries by the estimated } \\
\text { person-years and multiplying by } 100 \text {. } \\
4 \text { Calculated by dividing the total lost-time injuries by the total } \\
\text { estimated person-years and multiplying by } 100 \text {. }\end{array}$} \\
\hline
\end{tabular}


Recognizing that a portion of the IADC employment figure is not at risk in drilling operations, the injury incidence rate for those employees at risk should be higher. The reporting base for the IADC "Injury Statistics Reports" is heavily weighted toward the larger contractor (companies more likely to have active safety and employee training programs). Only five companies, $4 \%$ of the 131 contractors participating in 1980 were estimated to be small, one-rig companies. 1 The median number of rigs owned by the companies not participating in the safety awards program was reported by the IADC to be one. Approximately $83 \%$ (629 companies) of the IADC membership (approximately 760 total companies in 1980 [8]) did not contribute to the injury data base. These nonparticipating, smaller companies account for approximately $53 \%^{2}$ of the worker population and are less likely to have an active safety and/or employee training program.

\section{Estimates of Injury Incidence Rates Based on SDS Statistics}

The third method utilizes the SDS injury data base. This data base differs from that used by the BLS to develop the incidence rates presented earlier in Table III-1. The SDS tabulates those injuries that are reported to workers' compensation carriers and subsequently to state compensation insurance boards. BLS incidence rates are based on a sample of OSHA 200 forms [44]. These forms, completed by the employer, report all work-related injuries including those that involve such circumstances as medical treatment beyond "first aid," transfer to another work assignment, and loss of time from work. It would be expected that SDS injury figures would be lower than BLS figures because injuries not resulting in medical treatment or time loss are not included in the SDS reports but are frequently recordable under the BLS criteria [44]. Of the states which report SIC 1381 injury data to SDS, a total of 17 states also reported average rig activity for the years 1976-1980. The proportion of total drilling activity based on average rig count (1976-1980) for these states, as a percentage of national figures, was $18.4 \%$ compared to $38.7 \%$ for Texas (Table II-3).

1 Calculated by dividing reported annual person-hours [43] by the estimated number of person-hours necessary to run a 21-person rig 365 days; i.e., 21 workers for 8 hours/day for 365 days/year $=61,320$ person-hours per rig per year.

2 The IADC reports that 74,971,823.01 person-hours [43] are included in its 1980 report. If a "person", as defined by the BLS, works 2,000 hours per year, then $37,486(74,971,823.01$ divided by 2,000$)$ person-years are included in the 1980 report. These figures include all person-years and are not limited to the population at risk. The actual population at risk in drilling operations has been estimated to be 79,869 person-years in 1980 (Table II-4). The IADC report represents, at most, $47 \%$ of the industry population. 
The SDS data were analyzed to determine the injury incidence rate for the states reporting to SDS. Table III-6 summarizes the analysis and shows the average injury incidence rate in these states to be 21.8 .

\section{Summary of Injury Incidence Rates for $0 i 1$ and Gas Well Drilling}

Because national injury incidence figures have not been compiled and reported, three data sources and three techniques have been used to estimate the injury incidence rates for oil and gas well drilling injuries. Two estimating techniques used the actual numbers of paid injury claims (medical and/or indemnity) reported to the TWC and the SDS.

The first estimating technique used actual workers' compensation injury claims for employees of oil and gas well drilling contractors that were paid in the state of Texas. The percentage of nationwide drilling activity which Texas represented was determined utilizing three technology variables. Extrapolating injury figures to all drilling activities shows that the average incidence rate of compensable injuries requiring medical treatment was 38.1 (Tables III-2, $-3,-4$ ).

The second estimating method is based on the annual safety awards competition hela by the IADC. Participating companies, representing about $47 \%$ of the employment figures and $17 \%$ of the member companies in 1980 , report only disabling" "lost-time) injuries and compute the incidence rates based on total employment figures (population at risk plus support staff). The IADC disabling (lost-time) injury incidence rate for oil and gas well drilling averaged about 11.8 between 1975 and 1980 (Table III-5).

The third method is based on the 1976-1980 SDS injury data base which includes accident information from a 17-state sample representing only $18.4 \%$ of the drilling nationwide (Table II-3). It was estimated that the injury incidence rate in these states was 21.8 (Table III-6).

It is the conclusion of this study that regardless of which data source and estimating method are used, workers in the oil and gas well drilling industry are injured at an unacceptably high rate.

\section{Fatality Statistics}

The number of active oil and gas well drilling rigs in the state of Texas between 1973 and 1978 accounted for approximately $39.6 \%$ of the drilling in the United States (Table III-3). Table III-7 presents data for these years on the number of worker fatalities, reported by the TWC, in the oil and gas well drilling industry [35]. There were 148 deaths in the Texas drilling industry during these 6 years--an average of approximately 25 deaths per year. Since Texas represents approximately $39.6 \%$ of the national drilling activity, based on active rigs, an average of 63 fatalities per year of workers in the oil and gas well drilling industry may be estimated by extrapolating the average number of deachs per year in Texas to the entire industry. 
TABLE III-6

ESTIMATED AVERAGE INJURY INCIDENCE RATES FOR OIL AND GAS WELL DRILLING (SIC 1381) IN SDS REPORTING STATES BASED ON SDS INJURY STATISTICS FOR 1976-1980

\begin{tabular}{|c|c|c|c|c|c|c|}
\hline $\begin{array}{l}\text { No. } \\
\text { In } j \\
\text { Rep }\end{array}$ & $\begin{array}{l}\text { ears } \\
\text { ries } \\
\text { rted }\end{array}$ & $\begin{array}{l}\text { No. Reported } \\
\text { Injuries } \\
1976-1980^{1}\end{array}$ & $\begin{array}{l}\text { Ad justed No. } \\
\text { Injuries } \\
1976-1980^{2}\end{array}$ & $\begin{array}{l}\text { Reported No. } \\
\text { Active Rigs } \\
1976-1980^{3}\end{array}$ & $\begin{array}{c}\text { Est. Pop. } \\
\text { at Risk } \\
\text { (Person-years) }\end{array}$ & $\begin{array}{l}\text { Incidence } \\
\text { Rate }^{5}\end{array}$ \\
\hline ALASKA & 5 & 1236 & 1236 & 71.8 & 2201.4 & 56.1 \\
\hline ARIZONA & 1 & 2 & 10 & 3.4 & 104.2 & 9.6 \\
\hline ARKANSAS & 4 & 89 & 111 & 81.1 & 2486.5 & 4.5 \\
\hline COLORADO & 5 & 1236 & 1236 & 225.4 & 6910.8 & 17.9 \\
\hline IDAHO & 5 & 106 & 106 & 9.6 & 294.3 & 36.0 \\
\hline INDIANA & 4 & 22 & 28 & 9.8 & 300.5 & 9.3 \\
\hline KENTUCKY & 5 & 434 & 434 & 8.4 & 257.5 & 168.5 \\
\hline MARYLAND & 5 & 8 & 8 & 2.4 & 73.6 & 10.9 \\
\hline MICHIGAN & 5 & 836 & 836 & 127.8 & 3918.3 & 21.3 \\
\hline MISSISSIPPI & 1 & 258 & 1290 & 216.3 & 6631.8 & 19.5 \\
\hline MONTANA & 5 & 2280 & 2280 & 167.2 & 5126.4 & 44.5 \\
\hline NEBRASKA & 5 & 359 & 359 & 50.1 & 1536.1 & 23.4 \\
\hline N.MEXICO & 3 & 698 & 1163 & 404.6 & 12405.0 & 9.4 \\
\hline NEW YORK & 3 & 106 & 177 & 37.7 & 1155.9 & 15.3 \\
\hline OHIO & 2 & 806 & 2015 & 224.6 & 6886.2 & 29.3 \\
\hline S.DAKOTA & 4 & 34 & 43 & 10.6 & 325.0 & 13.2 \\
\hline UTAH & 5 & 743 & 743 & 152.4 & 4672.6 & 15.9 \\
\hline \multicolumn{2}{|l|}{ TOT./AVG. } & 9253 & 12075 & 1803.2 & 55286.1 & $21.8^{6}$ \\
\hline
\end{tabular}

1 Reported by the Bureau of Labor Statistics, Supplementary Data System [45].

2 Adjusted to reflect total injuries for states reporting for less than five years.

3 Total rig activity for SDS reporting states [11] (Table II-3).

4 Calculated by multiplying the number of employees per rig (7) by the number of shifts per day (3) by the number of hours per shift (8) by the number of days per year (365) by the average number of rigs and dividing the result by 2,000 (the number of hours worked by an individual in a year).

5 Injuries per 100 person-years. Calculated by dividing adjusted injuries for SIC 1381 by the estimated population at risk, multiplied by 100 .

6 Calculated by dividing total adjusted injuries for SIC 1381 by the total estimated population at risk, multiplied by 100 . 
Thirty-seven fatalities were reported by the oil and gas well drilling companies participating in the IADC safety awards program for 1980 [43]. If the participating companies in the 1980 IADC report represent about $47 \%$ of the employment figures for drilling activities and 37 deaths were reported, then 79 deaths can be estimated for the entire drilling industry.

TABLE III-7

FATALITIES THAT OCCURRED IN TEXAS OIL AND GAS WELL DRILLING OPERATIONS EXTRAPOLATED TO THE ENTIRE OIL AND GAS WELL DRILLING INDUSTRY

\begin{tabular}{llcccc}
\hline Year & $\begin{array}{c}\text { Active Rigs } \\
\text { in Texas }\end{array}$ & $\begin{array}{c}\text { Active Rigs } \\
\text { Nationwide }\end{array}$ & $\begin{array}{c}\text { Texas as a \% } \\
\text { of Nationwide }\end{array}$ & $\begin{array}{r}\text { Fatalities } \\
\text { in Texas }{ }^{3}\end{array}$ & $\begin{array}{c}\text { Est. Fatalities } \\
\text { Nationwide }\end{array}$ \\
\hline 1973 & 367 & 1,057 & 34.7 & 27 & 78 \\
1974 & 487 & 1,323 & 36.8 & 26 & 71 \\
1975 & 616 & 1,504 & 41.0 & 17 & 41 \\
1976 & 617 & 1,486 & 41.5 & 20 & 48 \\
1977 & 737 & 1,784 & 41.3 & 32 & 77 \\
1978 & 808 & 2,015 & 40.1 & 26 & 65 \\
& & 1,528 & 39.6 & 25 & 63 \\
\hline
\end{tabular}

1 From the Oil and Gas Journal [11].

2 Calculated by dividing the active rigs in Texas by the active rigs nationwide and multiplying by 100 .

3 Reported by the Texas Workers' Compensation State Board of Insurance [35] (Adjusted to reflect only land-based fatalities).

4 Estimated by extrapolating the percentage of total active rigs in Texas and the reported fatalities [35] to the entire industry.

\section{Hazardous Tasks Performed in Well Drilling Operations}

An analysis of detailed accident and injury reports was performed to determine causative factors in drilling accidents. The accidents included in the analysis tended to be representative of the more serious events--detailed sumaries of minor injuries/accidents are not commonly available. However, the comparison of accident causative factors with accident analysis developed by IADC in its reports, as well as the SDS analysis of accident types, led to the conclusion that the analysis is representative of accidents that occur during drilling operations.

The analysis of 738 accident and injury reports indicated that approximately $82 \%$ of the reported injuries and fatalities were directly attributable to drilling activities such as tripping, adding drill pipe, and torquing the drill string (Table III-8). The remaining injuries (18\%) were associated with tasks performed in many industries such as using handtools, 4.3\%; performing pump inspection and maintenance, $1.9 \%$; and other, $8.5 \%$. 
TABLE III-8

DRILLING OPERATIONS AND INJURY DISTRIBUTION

\begin{tabular}{|c|c|c|c|c|c|c|}
\hline $\begin{array}{l}\text { Drilling } \\
\text { Activities }\end{array}$ & $\begin{array}{l}\text { Hand- } \\
\text { tools }\end{array}$ & $\begin{array}{c}\text { Falls } \\
\text { from } \\
\text { Ladders }\end{array}$ & $\begin{array}{c}\text { Falls } \\
\text { on } \\
\text { Stairway }\end{array}$ & $\begin{array}{l}\text { Mud } \\
\text { Tank } \\
\text { Tasks }\end{array}$ & $\begin{array}{l}\text { Pump } \\
\text { Inspection and } \\
\text { Maintenance }\end{array}$ & Burns Other \\
\hline
\end{tabular}

No. of

Reported

Injuries

603

$32 \quad 2$

12

5

14

7

63

Percentage

of Total

81.7

$\begin{array}{lll}4.3 & 0.3 \quad 1.6\end{array}$

0.7

1.9

$1.0 \quad 8.5$

Compiled from 738 accident reports of OSHA investigations, company accident reports, workers' compensation reports, and published case histories (Tables III-9 and III-10) [10, 46-49].

After further refinement of the 603 fatality and injury reports (Table III-9) attributable specifically to well drilling activities, the major activities (tasks, tools, and equipment) contributing to oil and gas well drilling accidents were found to be as follows:

- Handling of drill pipes, collars, and casings resulted in $22.2 \%$ of the accidents and $16 \%$ of the reported fatalities.

- Tong operations resulted in $15.3 \%$ of the accidents and $10 \%$ of the reported fatalities.

o Derrick operations resulted in $8.3 \%$ of the accidents and $31 \%$ of the reported fatalities.

o Cables and chains were involved in $8.0 \%$ of the accidents and $6 \%$ of the reported fatalities.

- Elevator operations resulted in $6.3 \%$ of the accidents and $4 \%$ of the reported fatalities.

Table III-9 presents a detailed analysis of accident reports specific to drilling activities, and Table III-10 presents an analysis of accidents that occurred while tasks typical of other industries were being performed. Case histories representative of these accidents are presented in Appendix $A$.

The IADC, in its "Charlie Report for 1980", classifies total injuries associated with rig activity or equipment (Table III-11) [43]. In 1977 through 1979 the IADC also reported major categories (Table III-12) [40-42], which are similar to those used by the SDS for reporting state injury data; e.g., caught in or between, struck by or against, falls of personnel, overexertion, falling objects, flying objects, and temperature extremes. Further examination of Table III-11 shows that approximately $48 \%$ of the 
TABLE III-9

TYPES AND CAUSES OF ACCIDENTS SUSTAINED DURING TASKS UNIQUE TO WELL DRILLING OPERATIONS ${ }^{1}$

\begin{tabular}{|c|c|c|c|c|c|c|c|c|c|}
\hline \multirow[b]{2}{*}{$\begin{array}{l}\text { Too1/equipment } \\
\text { Associated with } \\
\text { Accident } \\
\end{array}$} & \multicolumn{6}{|c|}{ Type of Accident } & \multirow[b]{2}{*}{$\begin{array}{l}\text { Nonclas- } \\
\text { sifiable }\end{array}$} & \multirow[b]{2}{*}{ TOTAL $(\%)$} & \multirow[b]{2}{*}{ Fatal } \\
\hline & $\begin{array}{c}\text { Struck by/ } \\
\text { against } \\
\end{array}$ & $\begin{array}{l}\text { Caught in/ } \\
\text { between }\end{array}$ & $\begin{array}{l}\text { Overexer- } \\
\text { tion(lift) }\end{array}$ & $\begin{array}{l}\text { Foreign } \\
\text { Substance } \\
\text { in Eye } \\
\end{array}$ & $\begin{array}{l}\text { Fal1 to } \\
\text { Working } \\
\text { Surface } \\
\end{array}$ & $\begin{array}{l}\text { Fall to } \\
\text { Below }\end{array}$ & & & \\
\hline Tongs & 53 & 35 & 3 & & & & 1 & $92(15.3)$ & 10 \\
\hline $\begin{array}{l}\text { Drill pipes, } \\
\text { collars, casing }\end{array}$ & 51 & 62 & 13 & 2 & 3 & & 3 & $134(22.2)$ & 17 \\
\hline Elevators & 12 & 21 & 1 & & & 4 & & $38(6.3)$ & 4 \\
\hline s1ips & 3 & 9 & 11 & & & & & $23(3.8)$ & \\
\hline Catheads, catlines & 4 & 5 & 1 & & & & & $10(1.6)$ & \\
\hline Ke1ly & 4 & 3 & 3 & & & & & $10(1.6)$ & \\
\hline Spinning chains & & 5 & 1 & & & & 1 & $7(1.2)$ & 2 \\
\hline $\begin{array}{l}\text { Cables, Chains, } \\
\text { Ropes, Lines }\end{array}$ & 23 & 8 & 5 & 1 & 3 & 3 & 5 & $48(8.0)$ & 6 \\
\hline Traveling blocks & 14 & 2 & & & & & & $16(2.7)$ & 4 \\
\hline Rotary table & 4 & 4 & & & 2 & & & $10(1.6)$ & 2 \\
\hline $\begin{array}{l}\text { Hose, Pipe, } \\
\text { Flow line }\end{array}$ & 16 & 5 & 2 & 1 & 1 & & 2 & $27(4.5)$ & 6 \\
\hline $\begin{array}{l}1 \text { Seven hundred th } \\
\text { accident reports } \\
\text { accident reports } \\
\text { table. An analy }\end{array}$ & $\begin{array}{l}\text { irty-eight } \\
\text {, workers' } \\
\text { relate dir }\end{array}$ & $\begin{array}{l}\text { accident re } \\
\text { compensatio } \\
\text { ectly to we }\end{array}$ & $\begin{array}{l}\text { ports have } \\
\text { n reports, } \\
11 \text { drilling }\end{array}$ & $\begin{array}{l}\text { been compi } \\
\text { and publisl } \\
\text { activitie }\end{array}$ & $\begin{array}{l}\text { iled from } \\
\text { shed case } \\
\text { es (Table }\end{array}$ & $\begin{array}{l}\text { OSHA inv } \\
\text { historie } \\
\text { III-8) a }\end{array}$ & $\begin{array}{l}\text { estigatio } \\
\text { s [10, } 46 \\
\text { nd are an }\end{array}$ & $\begin{array}{l}\text { company } \\
+9] ; 603 \text { of } \\
\text { lyzed in th }\end{array}$ & the \\
\hline
\end{tabular}


TABLE III-9

TYPES AND CAUSES OF ACCIDENTS SUSTAINED DURING TASKS

UNIQUE TO WELL DRILLING OPERATIONS (Continued)

\begin{tabular}{|c|c|c|c|c|c|c|c|c|c|}
\hline \multirow[b]{2}{*}{$\begin{array}{l}\text { Tool/equipment } \\
\text { Associated with } \\
\text { Accident } \\
\end{array}$} & \multicolumn{6}{|c|}{ Type of Accident } & \multirow[b]{2}{*}{$\begin{array}{l}\text { Nonclas- } \\
\text { sifiable }\end{array}$} & \multirow[b]{2}{*}{ TOTAL $(\%)$} & \multirow[b]{2}{*}{ Fatal } \\
\hline & $\begin{array}{l}\text { Struck by/ } \\
\text { against }\end{array}$ & $\begin{array}{l}\text { Caught in/ } \\
\text { between }\end{array}$ & $\begin{array}{l}\text { Overexer- } \\
\text { tion ( } 1 \text { ift })\end{array}$ & $\begin{array}{l}\text { Foreign } \\
\text { Substance } \\
\text { in Eye } \\
\end{array}$ & $\begin{array}{l}\text { Fall to } \\
\text { Working } \\
\text { Surface }\end{array}$ & $\begin{array}{c}\text { Fall to } \\
\text { Below }\end{array}$ & & & \\
\hline Pipe rack & & & & & 4 & & & $4(0.7)$ & \\
\hline Swivel & 3 & 1 & & & & & & $4(0.7)$ & 1 \\
\hline Snubs & 3 & 2 & 3 & & 1 & & & $9(1.5)$ & \\
\hline Jets & 2 & & & & & & & $2(0.3)$ & \\
\hline Boards & 3 & & & & & & & $3(0.5)$ & \\
\hline Drill bits & 2 & & & & & & & $2(0.3)$ & \\
\hline Brakes & 4 & & & & & & & $4(0.7)$ & 1 \\
\hline BOP & 9 & 5 & 2 & 1 & 1 & 3 & 1 & $22(3.6)$ & 6 \\
\hline Derrick & & 1 & & & 7 & 41 & 1 & $50(8.3)$ & 33 \\
\hline Rig floor & & & & & & 5 & & $5(0.8)$ & 1 \\
\hline Substructure & & & & & & 3 & & $3(0.5)$ & 1 \\
\hline $\begin{array}{l}\text { Mousehole, } \\
\text { Rathole }\end{array}$ & 2 & & & & 2 & & 3 & $7(1.2)$ & \\
\hline
\end{tabular}


TABLE III-9

TYPES AND CAUSES OF ACCIDENTS SUSTAINED DURING TASKS

UNIQUE TO WELL DRILLING OPERATIONS (Concluded)

\begin{tabular}{|c|c|c|c|c|c|c|c|c|c|}
\hline \multirow[b]{2}{*}{$\begin{array}{l}\text { Tool/equipment } \\
\text { Associated with } \\
\text { Accident }\end{array}$} & \multicolumn{6}{|c|}{ Type of Accident } & \multirow[b]{2}{*}{$\begin{array}{l}\text { Nonclas- } \\
\text { sifiable }\end{array}$} & \multirow[b]{2}{*}{ TOTAL $(\%)$} & \multirow[b]{2}{*}{ Fata1 } \\
\hline & $\begin{array}{c}\text { Struck by/ } \\
\text { against }\end{array}$ & $\begin{array}{c}\text { Caught in/ } \\
\text { between }\end{array}$ & $\begin{array}{l}\text { Overexer- } \\
\text { tion }(1 \mathrm{ift})\end{array}$ & $\begin{array}{l}\text { Foreign } \\
\text { Substance } \\
\text { in Eye } \\
\end{array}$ & $\begin{array}{l}\text { Fall to } \\
\text { Working } \\
\text { Surface }\end{array}$ & $\begin{array}{l}\text { Fall to } \\
\text { Below }\end{array}$ & & & \\
\hline Vee-door & & & & & & 2 & & $2(0.3)$ & \\
\hline Cellar & & & & & & 4 & & $4(0.7)$ & 1 \\
\hline Ladder into $\mathrm{Cell}$ & & & & & & 2 & & $2(0.3)$ & \\
\hline $\begin{array}{l}\text { Valve cap on } \\
\text { mud tank }\end{array}$ & 3 & & & & & & & $3(0.5)$ & 2 \\
\hline Drawworks & 1 & 1 & & & & & & $2(0.3)$ & 2 \\
\hline Rigging & 4 & & & & & & & $4(0.7)$ & \\
\hline Welding, Cutting & & & & 1 & & & 1 & $2(0.3)$ & \\
\hline Reserve pit & & & & & & 1 & & $1(0.2)$ & 1 \\
\hline Motor vehicle & & & & & & & 3 & $3(0.5)$ & 3 \\
\hline Other & & 7 & 10 & 7 & 7 & & 19 & $50(8.3)$ & 2 \\
\hline $\begin{array}{c}\text { TOTAL } \\
(\%)\end{array}$ & $\begin{array}{l}220 \\
(36.5)\end{array}$ & $\begin{array}{l}176 \\
(29.2)\end{array}$ & $\begin{array}{l}55 \\
(9.1)\end{array}$ & $\begin{array}{l}13 \\
(2.2)\end{array}$ & $\begin{array}{l}31 \\
(5.1)\end{array}$ & $\begin{array}{c}68 \\
(11.3)\end{array}$ & $\begin{array}{l}40 \\
(6.6)\end{array}$ & $\begin{array}{c}603 \\
(100.0)\end{array}$ & $\begin{array}{l}105 \\
(17.4)\end{array}$ \\
\hline
\end{tabular}


TABLE III-10

TYPES AND CAUSES OF ACCIDENTS SUSTAINED DURING TASKS NOT UNIQUE TO WELL DRILLING OPERATIONS ${ }^{1}$

\begin{tabular}{|c|c|c|c|c|c|c|c|c|c|}
\hline Accident Types & Handtools & Ladders & Stairways & Mud Tank & Pump & Burns & Other & Total (\%) & Fatal \\
\hline $\begin{array}{l}\text { Foreign substances } \\
\text { in the Eye }\end{array}$ & 3 & & & & & & 10 & $13(9.6)$ & \\
\hline $\begin{array}{l}\text { Fall to working } \\
\text { surface }\end{array}$ & 2 & & 8 & 3 & 2 & & 6 & $21(15.6)$ & \\
\hline Fall to below & & 1 & 4 & & 7 & & 3 & $15(11.1)$ & 1 \\
\hline Struck by/against & 25 & & & & & & 14 & $39(28.9)$ & \\
\hline Caught in/between & 2 & & & & 4 & & 8 & $14(10.4)$ & \\
\hline $\begin{array}{l}\text { Contact with } \\
\text { temperature extreme }\end{array}$ & & & & & & 5 & & $5(3.7)$ & \\
\hline Overexertion & & & & 1 & & & 4 & $5(3.7)$ & \\
\hline Puncture & & & & & & & 3 & $3(2.2)$ & \\
\hline Heat exposure & & & & & & 1 & 2 & $3(2.2)$ & \\
\hline Electrocution & & & & 1 & & 1 & 3 & $5(3.7)$ & 4 \\
\hline Motor vehicle & & & & & & & 3 & $3(2.2)$ & \\
\hline Nonclassifiable & & 1 & & & 1 & & 7 & $9(6.7)$ & 1 \\
\hline $\begin{array}{l}\text { TOTALS } \\
(\%)\end{array}$ & $\begin{array}{c}32 \\
(23.7)\end{array}$ & $\begin{array}{r}2 \\
1.5)\end{array}$ & $\begin{array}{c}12 \\
(8.9)\end{array}$ & $\begin{array}{c}5 \\
(3.7)\end{array}$ & $\begin{array}{c}14 \\
(10.4)\end{array}$ & $\begin{array}{c}7 \\
(5.2)\end{array}$ & $\begin{array}{c}63 \\
(46.6)\end{array}$ & $\begin{array}{l}135 \\
100.0)\end{array}$ & $\begin{array}{c}6 \\
(4.4)\end{array}$ \\
\hline
\end{tabular}

1 Seven hundred thirty-eight accident reports have been compiled from OSHA investigations, company accident reports, workers' compensation reports, and published case histories [10, 46-49]; 135 of the accident reports concerned activities not unique to well drilling activities (Table III-8) and are analyzed in this table. An analysis of the remaining 603 accident reports is presented in Table III-9. 
reported accidents involved equipment and/or machinery that is directly associated with tripping and drill string lengthening procedures; e.g., tongs, $13.0 \%$; cables, chains, and ropes, $8.4 \%$; slips, $3.2 \%$; pipe, $16.8 \%$; elevators, $4.5 \%$; and rotary tables, $1.8 \%$. Similar results reported by the Union of Soviet Socialist Republics (USSR) researchers show that more than $50 \%$ of the accidents involved adding drill pipe to the string $[50,51]$.

This study suggests that the specific handing of drill pipes, collars, and casings was responsible for more injuries than any other task (22\% of the accidents), and that tongs were involved in more accidents (15\%) than any other type of equipment or tool (Table III-9). Two studies of offshore drilling accidents also reported that tongs were the most hazardous piece of equipment [52, 53]. Falls of personnel accounted for almost $15 \%$ of the injuries, and overexertion caused an additional $6 \%$ of the injuries reported during 1980 by the IADC (Table III-11) [43]. Falls were determined by this study to be responsible for $16 \%$ of the injuries (Table III-9).

TABLE III-11

INJURIES ASSOCIATED WITH RIG ACTIVITY OR EQUIPMENT, 1980

Rig Activity or Equipment

Reported

Disabling Injuries

$(\%)$

\begin{tabular}{lrr}
\hline Tongs & 427 & 13.03 \\
Pipe & 552 & 16.84 \\
Cables, Chains, Ropes & 276 & 8.42 \\
Hose & 48 & 1.46 \\
Cathead & 19 & .58 \\
Elevator & 148 & 4.52 \\
Hand Tools & 155 & 4.73 \\
Air Tugger & 13 & .40 \\
Vehicles & 30 & .92 \\
Motors or Generators & 41 & 1.25 \\
Fans & 2 & .06 \\
Clutches or Brakes & 19 & .58 \\
Slips & 106 & 3.23 \\
Falling Objects & 147 & 4.48 \\
Cranes & 16 & .49 \\
Belts or Pulleys & 42 & 1.28 \\
Personnel Falls & 490 & 14.95 \\
Overexertion & 182 & 5.55 \\
Rotary Tables & 60 & 1.83 \\
Temperature Extremes & 25 & .76 \\
Harmful Substances & 74 & 2.26 \\
Other & 406 & 12.38 \\
Total & & 100.00
\end{tabular}

Adapted from the International Association of Drilling Contractors'

"Charlie Report for 1980" [43]. 
The percentage distribution of accident types, as reported by both the IADC and SDS for the 3-year period, 1977-1979, is highly correlated (Table III-12).

TABLE III-12

TYPE OF ACCIDENT OR EXPOSURE FOR OIL AND GAS WELL DRILLING ACTIVITIES (1977-79)

\begin{tabular}{|c|c|c|c|c|c|c|}
\hline \multirow{2}{*}{$\begin{array}{l}\text { Type of Accident } \\
\text { or Exposure }\end{array}$} & \multicolumn{2}{|c|}{ IADC $^{1}$} & \multicolumn{2}{|c|}{$\begin{array}{c}\text { SDS }^{2} \\
\text { SIC } 138\end{array}$} & \multicolumn{2}{|c|}{$\begin{array}{c}\text { SDS }^{2} \\
\text { SIC } 1381\end{array}$} \\
\hline & Number & Percent & Number & Percent & Number & Percent \\
\hline Struck by or against & 1,913 & 22.4 & 5,118 & 20.7 & 1,078 & 19.7 \\
\hline Falls of personnel & 1,725 & 20.2 & 3,592 & 14.6 & 829 & 15.2 \\
\hline Caught in or Between & 1,694 & 19.9 & 4,162 & 16.9 & 975 & 17.9 \\
\hline Overexertion & 920 & 10.8 & 2,841 & 11.5 & 602 & 11.0 \\
\hline Falling objects & 602 & 7.1 & 2,925 & 11.9 & 660 & 12.1 \\
\hline Flying objects & 273 & 3.2 & 645 & 2.6 & 221 & 4.1 \\
\hline Temperature extremes & 265 & 3.1 & 748 & 3.0 & 169 & 3.1 \\
\hline All others & 1,130 & 13.3 & 4,648 & 18.8 & 927 & 16.9 \\
\hline TOTAL & 8,552 & 100.0 & 24,679 & 100.0 & 5,461 & 100.0 \\
\hline
\end{tabular}

1 Compiled from reports of the International Association of Drilling Contractors (IADC) [40-42].

2 Reported by the Bureau of Labor Statistics, Supplementary Data System (SDS) [45].

\section{E. How Injuries Occur in Drilling Operations}

Inherent in all tasks is the potential that an accident will occur, although the accident potential may be greater for some tasks than for others. Accidents, in turn, may result in injuries, some more severe than others. Injury severity is reflected by the nature of the injury (amputation, fracture, laceration) and by the amount of time the injured employee is unable to work.

A hazard has been defined as "a thing or condition that might operate against success or safety: a possible source of peril, danger, duress, or difficulty" [54]. In this report, which takes an operational approach to the concept of hazard, those tasks which are more likely to result in severe injuries to workers are considered the more hazardous tasks. 
Injuries that result from hazards unique to oil and gas well drilling operations can be broadly classified into two major categories: those injuries incurred from task-specific accidents and those injuries incurred during more catastrophic events such as blowouts, derrick collapse, and hydrogen sulfide exposures.

1. Task-Specific Accidents

The first major category of accidents is representative of incidents that occur during task-specific operations. Accident case histories, typical to these operations, are presented in Appendix A. This major category has been further subdivided into accidents that occur during drilling operations, derrick tasks, and materials handling activities.

a. Drilling operations have been further categorized by the tools or equipment used in performing the task, such as:

\section{(1) S1ips}

Slips are the toothed wedges that are positioned between the drill pipe and the master bushing/rotary table to suspend the drill string in the well bore when it is not supported by the hoist. Most of the accidents attributable to slip operations occur in relationship to materials handling; strained backs and shoulders are common. Furthermore, the working surface may be wet and slippery, contributing to muscle strains, as well as to accidents such as falls and dropping the slips onto the feet. Lack of communication between the driller and the employees engaged in the slip operations and lack of coordination between employees engaged in the task contribute to accident potentials in slip handing.

\section{(2) Tongs}

Tongs are the large, counterweight-suspended wrenches used to "break out" the torqued couplings on the drill pipe. Both sets of tongs have safety 1 ines; when breakout force is put on the tongs, employees should step back from the outside radius of the tongs in the event a tong slips or a safety line slips or breaks. In these instances, employees positioned in the path of travel can suffer serious injury.

Another likely accident can occur when the driller actuates the wrong tong lever and an unsecured tong swings across the rig floor at an uncontrolled velocity. Sometimes the wrong lever is pulled because the levers are not placed in such a manner as to make them readily distinguishable, and sometimes because the driller is distracted or fatigued. 
A common accident attributable to tongs can occur when an employee has his hand or finger in the wrong place as he attempts to swing and latch the tong onto the drill pipe resulting in crushing injuries and amputations of the fingers.

\section{(3) Elevators}

Elevators are a set of clamps affixed to the bails on the swivel below the traveling block. They are used to clamp each side of a drill pipe (the pipe is belled in this area) and hold the pipe as it is pulled from the well bore.

A number of accidents and associated injuries can occur during the latching and unlatching tasks--fingers and hands can get caught and crushed in the elevator latch mechanisms. The more severe injuries involve improper attachment of the pipe to the elevator. If the pipe is overhead when the latching mechanism fails, then the pipe may fall on employees working on the drill floor.

\section{(4) Catlines}

Catlines are used on drilling rigs to hoist material. The revolving cathead on the drawworks powers the friction pulley system. An employee wraps a rope, usually 1-1/4 inches in diameter, around the cathead and tensions the line. The tighter the rope and the more wraps around the cathead, the faster the material is hoisted.

Accidents that occur during catline operations may injure the employee doing the rigging as well as injure the operator. Minimal hoisting control causes sudden and erratic load movements, which may result in hand and foot injuries.

\section{(5) Working surfaces}

The rig floor is the working surface for most tasks performed in well drilling operations. This surface is frequently wet from circulating fluid and/or water used to wash it down. Prevailing weather may further increase the slipperiness of the surface.

Employees must lift, push, and pull heavy items as a routine part of their assignments. Slippery working surfaces can increase the likelihood of back injuries and other overexertion injuries. Slips and falls may result in sprains, strains, contusions, and lacerations. Exposed moving parts (rotary table and kelly bushing) may compound the injury potential and severity. 
Additionally, the rathole (although usually an elevated tube) and mousehole, used to temporarily store the kelly bar and drill pipe, may be uncovered when not in use. Stepping into a floor hole can result in fractures and sprains.

The cellar is a pit in the ground below the derrick structure. Hydrogen sulfide, if released, and water may accumulate in this low area. Ladder access into the cellar is a potential accident source, as is lack of proper guarding.

b. Derrick Operations

The derrickman on a well drilling operation performs his tasks from various elevated work platforms in the mast. He is exposed to falls when not utilizing fall protection equipment while climbing the derrick ladder, while working with the pipe stands, and while moving from the ladder to his platform station. The derrickman is also exposed to crushing injuries from shifting stands of pipe and elevator latching tasks.

Adequate and continuous fall protection is a prerequisite for the safety of employees working on a derrick. Conditions beyond the control of the derrickman (wind, vibration, pipe movement) make even momentary unprotected exposures hazardous.

c. Materials Hand 1 ing

The most common type of accident that occurs in materials handing operations is the "caught between" situation; e.g., when a load is being handled and a finger or toe gets caught between two objects. Rolling stock (drill pipe and collars) can shift and/or fall from a pipe rack or truckbed. Employees must be alert to the hazards attendant to pipe handling and racking.

Vertical and near-vertical storage of drill pipe on the inclined ramp requires adequate slippage protection and employee procedural training for safe handling.

Improper rigging of loads can result in load shifts and objects falling on those below. Materials handling is a support activity, so safe materials handling procedures frequently are not given the necessary emphasis.

\section{Catastrophic Events}

Catastrophic accidents involve the destruction of the drilling rig and/or injuries to multiple employees. Blowouts, derrick collapse, and hydrogen sulfide accidents are included in this category. Even though these accidents frequently may involve loss of 1 ife as well as the major destruction of equipment, the actual number of casualties 
represent only a small percentage of the total well drilling occupational injury incidence and severity rates [3, 55].

Although not a common occurrence, derrick or mast collapse most frequently happens during rigging-up and rigging-down procedures. The greatest strains are exerted on the mast components during these operations. Derrick frames subjected to abuse during movement may be damaged and wrecked. Inspection of the derrick structure is important for the detection of weld weakness, oxidation, and bent members [6, 7]. Weight indicators and recorders allow the driller to stay within mast load tolerances; consequently, they must be maintained and inspected. Manufacturers' rig capacities and guying requirements should always be followed.

\section{F. Costs of Injuries}

Workers' compensation insurance carriers, representing oil and gas well drilling companies in 15 states and accounting for approximately $81 \% 1$ of the total number of active rigs, made actual compensation payments (medical and indemnity) averaging $\$ 28,840,230$ per year between 1971 and 1978 (Table III-13). Since data were not available from every state for the entire time span, a very conservative estimate of the medical/indemnity expenditure per employee at risk in the drilling industry between 1971 and 1978 is approximately $\$ 686$ per employee (average number of employees between 1971 and 1978 was 42,058 (Table II-4); this figure divided into the total reported dollars per year spent on medical and indemnity for empioyees of drilling companies-- \$28,840,230 (Table III-13)--is \$685.73) [35, 56]. Compensation payments for injured employees accounted for $8.6 \%$ of the corporate payroll in these states--a range of $26.2 \%$ of the total payroll in Louisiana to $3.8 \%$ in Indiana (Table III-13). Additional indirect costs of employee injuries (e.g., new employee training, administration, and overhead) are estimated by the National Safety Council to be more than four times the actual medical/ indemnity payments, or approximately $\$ 115,000,000$ per year for the oil and gas well drilling industry during the 8-year period (1971-78) (Table III-13) [57].

For the states indicated in Table III-13 (representing approximately $80 \%$ of the total footage drilled) (Tables III-4 and III-13), the average incurred workers' compensation loss per foot of well drilled was $\$ 0.21$.

\section{G. Training and the New Employee}

Traditionally, training of oil field employees has been by on-the-job exposure under the guidance of an experienced hand and the supervision of a fully qualified driller; years were required for advancement from floorhand to driller. In the past it was unusual for a young person to be a driller,

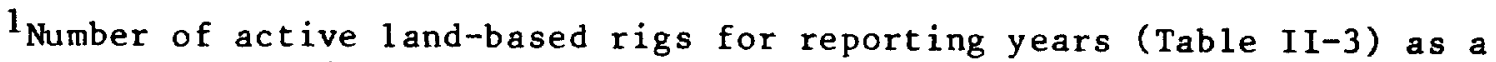
percentage of total land based active rigs.
} 
TABLE III-13

WORKERS' COMPENSATION LOSSES INCURRED BY THE

OIL AND GAS WELL DRILLING INDUSTRY, 1971-78

\begin{tabular}{|c|c|c|c|c|c|c|}
\hline State & $\begin{array}{l}\text { Years } \\
\text { Reported }\end{array}$ & $\begin{array}{l}\quad \text { Average } \\
\text { Compensation } \\
\text { Losses } 1 \text { ( } \$ \text { /year) }\end{array}$ & $\begin{array}{l}\text { Average } \\
\text { Payro } 111 \\
\text { ( } \$ \text { /year) }\end{array}$ & $\begin{array}{l}\text { Payroll Paid } \\
\text { in Compensa- } \\
\text { tion Losses }(\%)\end{array}$ & $\begin{array}{l}\text { Average Wel1 } \\
\text { Footage Drilled } 2 \\
\quad \text { (ft./year) }\end{array}$ & $\begin{array}{l}\text { Compensa- } \\
\text { tion Losses } \\
\text { per Foot }{ }^{3}(\$)\end{array}$ \\
\hline Al abama & $1973-77$ & 329,985 & $5,004,462$ & 6.6 & $1,123,655$ & 0.29 \\
\hline Alaska & $1972-77$ & $1,203,597$ & $18,152,949$ & 6.6 & 446,814 & 2.69 \\
\hline Arkansas & $1973-77$ & 416,865 & $5,692,735$ & 7.3 & $1,963,036$ & 0.21 \\
\hline Colorado & $1973-76$ & $1,083,862$ & $13,718,224$ & 7.9 & $5,823,623$ & 0.19 \\
\hline Illinois & $1972-77$ & 608,125 & $7,019,205$ & 8.7 & $2,564,963$ & 0.24 \\
\hline Indiana & $1973-77$ & 46,891 & $1,240,933$ & 3.8 & 856,158 & 0.05 \\
\hline Kansas & $1972-77$ & $1,544,177$ & $22,037,448$ & 7.0 & $10,743,261$ & 0.14 \\
\hline Louisiana & $1973-77$ & $3,139,169$ & $11,997,301$ & 26.2 & $16,477,052$ & 0.19 \\
\hline Michigan & 1972-77 & $1,203,170$ & $8,762,933$ & 13.7 & $2,241,429$ & 0.54 \\
\hline Mississippi & $1972-76$ & 755,648 & $14,131,438$ & 5.3 & $3,905,173$ & 0.19 \\
\hline Montana & 1971-77 & 536,564 & $7,176,740$ & 7.5 & $2,383,769$ & 0.23 \\
\hline New Mexico & $1973-77$ & $1,755,866$ & $20,647,992$ & 8.5 & $6,709,484$ & 0.26 \\
\hline Oklahoma & $1973-77$ & $6,698,880$ & $70,225,608$ & 9.5 & $20,826,149$ & 0.32 \\
\hline Texas & $1971-78$ & $9,105,563$ & $140,258,688$ & 6.5 & $62,236,657$ & 0.15 \\
\hline Utah & $1973-76$ & 411,868 & $9,674,385$ & 4.3 & $1,533,450$ & 0.27 \\
\hline Tota 1 & & $28,840,230$ & $355,741,041$ & & $139,834,673$ & \\
\hline Average & & $1,922,682$ & $23,716,069$ & 8.6 & $9,322,312$ & $0.21^{4}$ \\
\hline
\end{tabular}

1 Compiled from reports by the National Council of Compensation Insurance [56] and the Texas Workers' Compensation State Board of Insurance [35] (Adjusted to reflect land-based compensation losses and payroll).

2 Compiled from the American Petroleum Institute Quarterly Review of Drilling Statistics [29-34] (for years 1973-78).

3 Calculated by dividing average incurred compensation loss by average well footage drilled for reporting states.

4 This statistical analysis incorporates a weighting factor that attributes greater representation to $1,000,000$ feet drilled than to 100,000 feet drilled. 
but with the present level of drilling activity it has become a necessity [58]. Skilled hands are now at a premium and technical development may lag behind job advancement. Insufficient crew training and lack of experienced hands have been targeted by industry experts as the "greatest problem facing the industry today" $[59,60]$.

A 1979 study of Canadian oil field accidents, conducted for the Alberta Division of Occupational Safety and Health, concludes:

The data suggests that accidents will be reduced when people who work on well sites are selected properly, oriented well, trained completely, retrained constantly, motivated always, and retained to become career oil field staff.

Selecting properly from a more qualified pool of applicants will begin to occur when escalation of activity in the industry decreases, or levels out, or when better retention of workers reduces the need for constant replacements. At the present time manpower needs are so urgent that normal selection procedures are often by-passed.

Orientation would be improved by industry cooperating with educational institutions in providing information and courses to prospective employees about opportunities in the oil fields. Recruitment should include exposure to packaged audio visual orientation material that would take the surprise out of first days on the job.

Training must compensate for lack of experience when new men, because of necessity, are promoted rapidly. The industry will be challenged to research best methods and to implement excellent programs.

Remaining aware of danger, as familiarity kills caution, requires constant retraining in a variety of ways in order to retain interest. This constitutes another developmental thrust for training institutions and personnel.

Motivation to work safely and to stay with the industry must come from the companies. The opportunity to be employed year around, developing pride in working for a good company, experiencing satisfaction with job conditions, knowing that the work is meaningful and in being rewarded generously should lessen the movement of workers through the industry. It will assist in raising public opinions about oil field work to the status of a respected career. This should reduce the number of workers who say they are in it for the money only.

Government cooperation with company management in addressing the high priority strategic failure paths identified in this 
study should help to reduce the number of severity and accidents in the Alberta oil fields [61].

A disproportionately high percentage of injuries are sustained by new employees. The IADC determined that $61 \%$ of the reported drilling injuries for 1979 happened to persons employed for 6 months or less (Table III-14). An analysis of more than 738 accident reports compiled from OSHA investigations, company accident reports, workers' compensation reports, and published case histories [10, 46-49] of injuries sustained by employees during well drilling operations showed that about $72 \%$ of the injured workers had been employed for less than 6 months (Table III-15). Furthermore, 45\% of the injured employees actually had been employed for 1 month or less. Other researchers have noted similar relationships between length of employment and injury incidence rates. For example, a Canadian study of well drilling accidents showed that 58\% of those injured in 1977 had been employed for less than 6 months [62]. Recent studies of accidents that occurred during offshore drilling operations have reported that $76.5 \%$ of those injured were employed for less than 1 year, and $54.8 \%$ of the injuries occurred to employees with less than 6 months' experience $[52,53]$. A study reporting on worker turnover and safety found that the new workers were the most vulnerable to accidents [63]. These studies did not determine what proportion of the work force was made up of new employees or whether the tasks assigned to new employees posed a greater exposure to hazards. It should be noted that in the drilling industry the new employee traditionally advances from the position of a rotary helper to a derrickman and eventually to the position of driller. The tasks performed by a rotary helper (e.g., handling and torquing drill pipe during drilling and tripping, tongs, catlines, and slips) have been demonstrated by this study to be precisely those most frequently associated with worker injuries; therefore, employees new to these drilling tasks should be trained in proper operational procedures. Similar task/injury relationships were reported in studies of offshore drilling operations $[52,53,64]$, as well as in a Canadian study of drilling accidents [62].

Some drilling contractors have implemented extensive training programs by using courses developed by the American Petroleum Institute (API), the Petroleum Extension Service of the University of Texas (over 200 audio-visual programs), and the IADC, as well as their own multimedia introductions to drilling and its hazards. A month-long school for drilling rig rotary helpers in South Texas reports that for approximately 500 persons who graduated after 1975, only three serious disabling accidents have been recorded and two of these were snakebite incidents [65]. Louisiana initiated a similar 8-week training course in 1980 [66]. This trend is unlikely to immediately affect the many small firms in the industry, since new employees may be hired at the well sites without the benefit of preliminary training and orientation.

However, one major drilling contractor recently implemented a mobile training unit to teach safety to crews drilling in remote locations. Although these crews still exhibit the highest turnover rate, they have gone 
TABLE III-14

INJURY BREAKDOWN BY LENGTH OF EMPLOYMENT

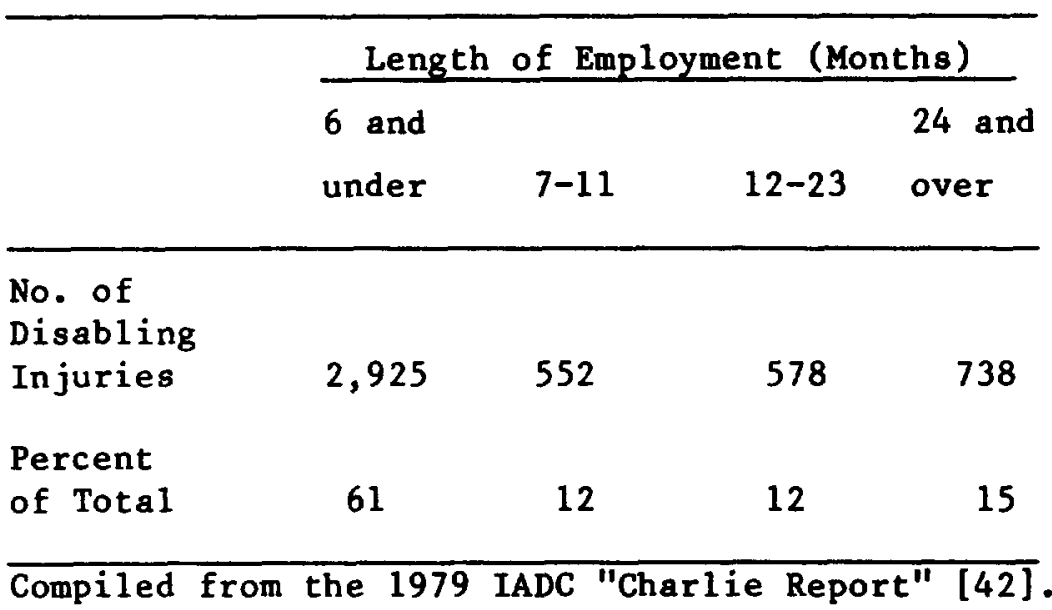

TABLE III-15

REPORTED ACCIDENTS AND LENGTH OF EMPLOYMENT ${ }^{1}$

Length of Employment (Months)

\begin{tabular}{|c|c|c|c|c|c|}
\hline & 1 & $2-3$ & $3-6$ & $6-12$ & $\begin{array}{l}12 \text { and } \\
\text { over }\end{array}$ \\
\hline $\begin{array}{l}\text { No. of } \\
\text { Reported } \\
\text { Accidents }\end{array}$ & 234 & 97 & 46 & 56 & 89 \\
\hline $\begin{array}{l}\text { Percent } \\
\text { of Total }\end{array}$ & 45 & 18 & 9 & 11 & 17 \\
\hline
\end{tabular}

${ }^{1}$ Seven hundred thirty-eight accident reports have been compiled from OSHA investigations, company accident reports, workers' compensation reports, and published case histories; 216 did not include length of employment and are therefore not included in this table $[10,46-49]$.

from the highest to the lowest lost-time accident rates for the reporting company [67].

\section{H. Conclusion}

Although national injury statistics are not available for the oil and gas well drilling industry (SIC 1381), three techniques, using different data bases, were used to estimate the injury incidence rates for the drilling industry. The data bases and estimating techniques report different types 
of injuries (lost-time, compensable, SDS recordable) and, as such, are not entirely equatable. However, regardless of the type of injury or the estimating technique, the magnitude of the problem, occupational safety during oil and gas well drilling operations, is extensive. Workers were injured at the following average estimated incidence rates:

$$
\begin{aligned}
& \text { - Compensable injury incidence rate (TWC): } 38.1 \\
& \text { - Disabling lost-time injury incidence rate: } 11.8 \text {. } \\
& \text { o Estimated injury incidence rate for } 17 \text { SDS states: } 21.8
\end{aligned}
$$

The evidence further indicates that a substantial percentage of the well drilling industry's injuries occur while tasks associated with tripping, torquing, and joint spinning are being performed. Handling drill pipe and chains, operating tongs, and working from and climbing the derrick contribute substantially to drilling injuries. Materials handling, lifting, and falling (to a level below and to the working surface) contribute further to the industry's high injury incidence and severity rates.

Individual companies that submit their injury data to the IADC report varied lost-time injury frequency rates (per million person-hours)--ranging from 0 to more than $200[38-43]$. The diversity of reported injury rates could be indicative of a variable corporate approach to worker safety. The high injury incidence and severity rates found in the oil and gas well drilling industry and the uniqueness of the processes and technologies used in these drilling operations indicate the need for the development of comprehensive safety recommendations including the need for employee training and safety awareness. 


\title{
CHAPTER IV \\ COMPREHENSIVE SAFETY RECOMMENDATIONS \\ FOR OIL AND GAS WELL DRILLING
}

\begin{abstract}
According to an evaluation of existing State (Alaska, California, Michigan, Utah, and Wyoming), international (Canada), and the consensus of industry (API, ANSI, NFPA) safety standards, presented in Appendix B, most of the operations, tasks, and equipment utilized in well drilling operations are covered by at least one existing safety standard. For these instances, the applicable standard, or a consolidation of the existing standards, has been incorporated into safety recommendations. For operations not covered in any standards, such as guarding kelly bushings, elevator latching procedures, positioning of slips, techniques for transfer of drill pipe from pipe racks to vee-door, and water rescue equipment for reserve pits, recommendations are based on direct observation of industry in operation, information from industry experts, and good safety practices. No attempt has been made to present safety recommendations for tasks, tools, equipment, or operations common to other industries; e.g., handtools, general machine guarding, sanitary facilities, welding, or blasting. Safety standards and safe work practices for these areas are adequately addressed in OSHA General Industry Standards ( 29 CFR 1910) and should be applied to the drilling industry.
\end{abstract}

The safety recommendations for oil and gas drilling operations have been organized into three major areas:

A. General safety recommendations

B. Safety guidelines for well dri11 machinery and equipment

C. Safe work practices

A. General Safety Recommendations

1. Employee Instruction, Training, and Testing

When initially employed, a worker should receive instruction and training pertinent to the hazards, safety precautions, safe work practices, and use of personal protective equipment applicable to the type of work performed.

The instructions should adequately orient and alert the new employee to:

- The basic principles of a well drilling operation, including the safe work practices and hazards associated with rig equipment

- The purpose and operation of blowout prevention

- Hydrogen sulfide and respiratory protection

- Fire prevention and control

o Confined spaces and entry procedures

o Personal protective equipment. 
Each new employee should receive training in the safe use of all equipment or tools that are necessary for use and the safe performance of assigned tasks. The employer should require that the worker demonstrate his ability to safely operate the tool or equipment prior to using it in a drilling situation. If a new employee has been certified as qualified to operate the equipment or tool (by an approved training facility), then the training portion of this recommendation is not required. As an employee advances to new positions and tasks, he should demonstrate his knowledge and ability to safely operate the equipment and perform the tasks before he is required to perform them in a drilling situation. Retraining should be conducted as needed to ensure that employees are able to perform their tasks in a safe manner.

\section{First Aid and Emergency Communication}

Well sites may be located in remote and inaccessible areas. Anticipation of the emergencies likely to ocfur and appropriate contingency planning for them may save the lives of injured employees. Employers should develop and post a detailed emergency plan suitable for the current location of the well site, the surrounding population, formation pressures, and contaminants likely to be encountered.

\section{a. First Aid}

Drillers, tool pushers, supervisors, and persons in direct charge of crews in field operations should have a current certificate of first-aid training. There should be at least one employee with a current certificate of first-aid training at all well sites employing fewer than 15 persons. At well sites employing more than 15 persons, there should be at least two employees with current certificates of first-aid training.

First-aid equipment should be provided. This equipment s'ould be stored in sanitary places, protected from weather, available to all shifts, and conveniently located. The first-aid kit should be at least a 24-unit size and should be inspected and replenished weekly or whenever $25 \%$ of a unit has been used. Additional first-aid equipment should include one set of inflatable arm and leg splints; two all-wool blankets, or blankets equal in strength and fire resistance; and one stretcher.

The stretcher should be designed to adequately support an injured worker during handling and transportaton. In case the ordinary collapsible type is not adequate to support the worker during handing and transportation, a basket stretcher with adequate straps and harness should be provided.

Provisions should be made prior to commencement of the project for prompt transportation of an injured person to a physician or hospital. An effective communication system should be established 
to contact and direct the necessary medical/emergency teams to the proper location. Transport of seriously injured workers should not be undertaken by the employer unless personnel trained in moving injured persons are present and/or the injured would be further harmed by the delay. If the employer is going to transport an injured party, then the vehicles provided by the employer should:

- Be of sufficient size and suitability to accommodate a stretcher and accompanying first-aid attendant within the body of the vehicle

o Be designed and equipped so that there is a means of oral communication between the operator of the vehicle and the injured worker and accompanying first-aid attendant

o Protect the injured worker and the first-aid attendant from the elements

o Be clean.

Whenever possible, any seriously injured worker being transported should be accompanied by at least one person in addition to the driver. The driver or the accompanying person should have valid first-aid qualifications.

In areas where access by conventional transportation is not possible or the conditions of the road or terrain are detrimental to the welfare of the injured worker, an alternate means of transportation should be arranged for by the employer. A helicopter service would be one example of an acceptable alternate means of transportation.

\section{b. Emergency Communication}

More than one means of communication may be necessary to ensure prompt help in case of accidents or emergencies.

Telephone numbers of physicians, hospitals, and ambulances should be conspicuously posted. Explicit directions to the well site should be included on the posted notice (people tend to forget names and locations during medical emergencies). Ambulance and/or medical transport services should be kept informed of the rig's location and the best access routes.

In remote areas where telephones are not practical, radio equipment that is capable of communication with a station (manned company base station, police, or emergency base station) in one of the larger communities should be provided. Radio call signs and frequency settings should be posted. Radio schedules should be maintained and coordinated by personnel on drill sites with the nearby community stations. 


\section{Personal Protective Equipment}

Personal protective equipment should comply with current ANSI standards.

\section{a. Clothing}

Loose, ragged, or poorly fitted clothing should not be worn. Rotating parts (catheads, kelly bushings, spinning chains) may snag the clothing and cause injuries. Gloves are commonly worn by drilling employees and should be discarded when they become ragged or torn.

If the clothing worn by an employee becomes contaminated by a hazardous substance, the employee should remove the clothing without undue delay. The clothing should not be worn again until the hazardous substance has been removed. Additionally, If the clothing worn by an employee becomes wet with gasoline, naphtha, kerosene, light distillate, or light oils, the employee should not remain, or be required to remain, in a location where his clothing is in danger of igniting.

Employees should not be permitted to work with bare heads, bare arms, or other portions of their bodies uncovered in areas where they may be exposed to burns from corrosives or hot substances. Skin absorption of chemicals is not unusual and may result in skin rashes, chemical burns, and/or systemic poisoning.

Employees should not be permitted to wear jewelry or other adornments subject to snagging. Rings frequently snag on equipment or tools, which may result in the finger being pulled off.

Employees with long hair should keep it contained in a suitable manner while working. Hair and beard styles should not interfere with the wearing of head, eye, face, or respiratory protective equipment. As a condition of employment, employees working in medium or high hazard hydrogen sulfide environments should not be allowed to wear beards since the facial hair lying between the sealing surface of a respirator facepiece and the wearer's skin will prevent a good seal.

b. Foot Protection

Safety-toed boots should be worn in the working area.

\section{c. Head Protection}

Safety hats (hardhats) should be worn by each person in the work area. Hardhats should be secured by a chinstrap when worn in the derrick structure. When cold weather conditions dictate, 
industrial protective winter liners for the hardhats should be made available to workers.

\section{d. Eye Protection}

Properly fitted goggles, face shields, or other eye protection equipment, appropriate to the work being done, should be provided by the employer and worn by workers handling, or exposed to, material liable to injure or irritate the eyes, or when engaged in any work in which there is an eye hazard from flying objects, injurious light, heat rays, or other type of radiation.

- Goggles or face shields should be worn when mixing mud or chemicals.

o Goggles and/or face shields should be worn when using a grinder.

- Cutting goggles (of appropriate density) should be worn when using a cutting torch. Goggles protect the eyes from flash burns and slag.

o Welders should wear welding shields. Helpers and coworkers should be protected from "flashes" by dark flash glasses. If the welding is of some duration, then the use of flash screens is desirable. Welders or helpers performing chipping operations should be protected from slag "pop" by goggles and/or face shields.

Where harmful chemicals are being used, readily accessible facilities for rapid flushing of the eyes and/or skin should be available. Eyewash facilities should be provided on the drill floor as well as in the mud-mixing area. At a minimum, one quart of potable water, protected from freezing, should be imediately available in those areas. An additional four quarts of flushing liquid should be readily available to continue flushing the eye.

\section{e. Hearing Protection}

Whenever noise exposure on a time-weighted average (TWA) is more than $90 \mathrm{db}(A)$ [68], worker protection should be ensured either by using engineering controls which reduce noise levels, or by providing and requiring the use of appropriate protective equipment.

Areas and operations where appropriate engineering controls/ noise abatement techniques should be considered are:

- Engines - layout, sound barriers, employee isolation, or proximity to rig floor

- Electrical generators - layout, sound barriers, location

- Power transfer (belts, pulleys, compounds) - sound barrier. 
Hearing protection should be provided to all employees working at the drill site. Disposable earplugs should be readily available at the doghouse or drill floor. Alternatively, individual earplugs or ear muffs could be distributed at the time of employment. Ear muffs should be supplied to, and worn by, employees working on or near engines, transmissions, compounds, or generators that expose workers to excessive sound levels.

\section{Fal1 Protection}

Falls from elevated areas account for a relatively low percentage of the accidents that occur in drilling operations; however, those accidents that do occur usually are severe or fatal. Most of the falls occur while erecting the derrick, climbing the derrick ladders, or working from one of the platforms. Adequate worker protection can be provided during most, if not all, of these situations by the use of safety belts, lifelines and lanyards, safety nets, and climbing devices.

\section{a. Safety Belts}

When engaged in work 10 feet or more above the derrick floor, a worker should use a safety belt attached to a lanyard adequately secured to the structure, unless he is protected by another approved method. Workers engaged in racking pipe at the stabbing board, finger board, or other platform should be provided with, and wear, a safety belt. The use of a belly buster does not eliminate the need for a safety belt.

\section{b. Lifelines and Lanyards}

Lifelines and lanyards should be a minimum of 1/2-inch nylon, 3/4-inch manila, or equivalent, and should have nominal breaking strength of 5,400 pounds [68]. Safety belt lanyards should have a maximum length to provide for a fall of no more than 6 feet [68].

When an employee is at the stabbing board, the fall protection lanyard should be securely attached to:

- A manila or wire rope with a breaking strength not less than 9,000 pounds stretched across the derrick at a location approximately 7 feet above the stabbing board

- A solid support secured in the derrick at a location approximately 7 feet above the stabbing board

o A cross-member of the derrick structure at a point approximately 7 feet above the stabbing board [69]

o The derrick board handrail behind the worker.

\section{c. Safety Nets}

Safety nets should be provided as an alternative when work areas are more than 25 feet above the ground or water surface, or other 
surfaces where the use of ladders, scaffolds, catch platforms, temporary floors, safety lines, or safety belts is impractical. Operations should not be undertaken until the net is in place and has been tested [68]. To provide adequate worker protection:

- Nets should extend 8 feet beyond the edge of the work surface where employees are exposed and should not be more than 25 feet below such edge.

- The mesh size of nets should not exceed 6 inches by 6 inches. All new nets should meet accepted performance standards of 17,500 foot-pounds minimum impact resistance, as determined and certified by the manufacturers, and bear a label-of-proof test. Edge ropes should provide a minimum breaking strength of 5,000 pound 8 .

- Forged steel safety hooks or shackles should be used to fasten the net to its supports.

- Connection between net panels should develop the full strength of the net.

Nets can be augmented by the addition of debris and/or slag netting that protects employees from tools, bolts, and hot slag falling from above.

\section{d. Climbing Devices}

Ladder-climbing or fall-arresting devices should be used on the derrick ladder. Derrickmen should always climb the ladder rung by rung and not be permitted to "ride" the climbing device.

\section{Confined Workspaces}

The most important concept to follow when entering a confined space is to NEVER TRUST YOUR SENSES. What appears harmless may in fact be deadly. Employers and workers should consider each confined space to be life threatening. In general, confined spaces are enclosed areas, having limited access/egress, that may be subject to the formation of toxic atmospheres.

\section{a. Life-Threatening Hazards}

(1) Toxic gases and vapors

Tanks, cellars, and enclosures are all examples of areas that can be subject to the accumulation of toxic gases. Hydrogen sulfide may be a contaminant of petroleum formations and as such may be released in deadly concentrations during well drilling operations. Cellars, shale shakers, and deposition areas are subject to buildup of the hydrogen sulfide. Such areas, when confined or enclosed, should be treated as DEADLY. Carbon monoxide is produced by incomplete combustion 
of carbon products. It is a likely byproduct of compressors or other gasoline and diesel engines. Enclosed or confined areas adjacent to an engine exhaust should also be treated as contaminated.

\section{(2) Flammables and/or explosives}

Tanks, cellars, and enclosures are also subject to the accumulation of flammable vapors (hydrogen sulfide is also combustible and explosive at concentrations between $4.5 \%$ and $45 \%$ in air). The hydrocarbon gases being drilled for are also highly explosive when mixed with air. Tanks and cellars at well sites should be considered explosive until tests prove otherwise.

\section{(3) Lack of oxygen}

The OSHA acceptable minimum oxygen level is $19.5 \%$ of the atmosphere. [70]

\section{b. Entry into Confined Spaces}

Entry into a confined space should not be permitted until a formal written document is completed and signed by the tool pusher. This document should include what preparations have been made, the results of tests, the work to be done, tools to be used, and precautions to be taken. All personnel involved with the entry should be made familiar with these facts. A copy of this document should be maintained at the job site.

Prior to entry, the atmosphere of the confined space should be tested from the outside for flammability, toxicity, and oxygen content to ensure the absence of material harmful to personnel. Retesting should be done at intervals frequent enough to ensure that this condition is maintained while the space is occupied [71]. There should be provisions for immediately securing and posting a warning against unauthorized entry at the entrance to any confined space tested and found unsafe.

Where it is impossible or impractical to obtain safe conditions, approved personal protective equipment that protects against ali entry modes for materials in question should be used. Equipment that may be necessary for safe entry may include [71]:

- Self-contained breathing apparatus (NIOSH/MSHA approved)

- Safety harness and lifelines

- Communication system

- Lights

- Resuscitation equipment

- Protective clothing. 
Proper preparation should be the objective--protective equipment is the insurance.

The first person entering a confined space that contains, or is known to have contained, a harmful substance should wear a safety belt with a lifeline attached that is manned by an employee having the equipment and capability to effect a timely rescue. If it can be ascertained that conditions are as tested and can be maintained at that leve1, work can proceed without safety belts. In all cases, the rescue capability should be maintained at the appropriate entry area to assist in case of emergency.

While any employee is in a confined area, a standby person should remain at the entrance opening. The attendant should be provided with safety equipment similar to that required for employees inside the area. NOTE: If a worker is overcome by a toxic atmosphere, that same toxic atmosphere will affect unprotected persons entering the area to perform a rescue. Attendants and/or rescue personnel should be fully equipped (with a ready standby person) before effecting an emergency entry.

It may be necessary to remove materials such as sludge, polymers, or other materials from a confined space. This task may liberate vapors and/or gases that could change the test results obtained earlier. Monitoring, ventilation, and/or protective equipment should be provided and used to properly handle this task.

6. Signs and Labeling

Warning signs should be posted to denote any unusual or hazardous situation. Warning signs should be posted in areas where the use of personal protective equipment is necessary. Identification signs should be conspicuously posted to locate emergency equipment. Containers of poisonous, toxic, flammable, and/or explosive material should be properly labeled and appropriately stored according to content. Signing must conform to OSHA standards.

\section{Hydrogen Sulfide Environments}

Al1 well drilling sites should be classified into areas of potential and/or actual exposure to hydrogen sulfide by the definitions outlined below. The safety recommendations made are a minimum. The American Petroleum Institute (API) "RP 49: Recommended Practice for Safe Drilling of Wells Containing Hydrogen Sulfide" [72] details recommendations in more depth and should be followed in all medium and high exposure areas.

Definitions of hydrogen sulfide hazard areas and the precautions to be taken are as follows [73]:

a. No Hazard Area--any well that will not penetrate a known 
hydrogen sulfide formation. No special hydrogen sulfide equipment is needed.

b. Low Hazard Area--any well that will penetrate a formation containing hydrogen sulfide that could result in atmospheric concentration of $10 \mathrm{ppm}$ or less and/or in which the hydrogen sulfide zone has been effectively sealed off by casing/cementing and/or cementing method. The following are recommended for low hazard areas :

- Two 30-minute, self-contained breathing apparatus for emergency escape from the contaminated area only.

c. Medium Hazard Area--any well that will penetrate a formation containing hydrogen sulfide and is not defined as a low or no hazard area, including all exploratory (wildcat) well sites. The following are recommended for medium hazard areas:

o NIOSH/MSHA approved manifold air masks with emergency escape cylinders for each employee

o Two NIOSH/MSHA approved, 30-minute, self-contained breathing apparatus for emergency escape from the contaminated area only

o Two wind socks and streamers

o Oxygen resuscitator

o A properly calibrated, metered hydrogen sulfide detection instrument

o Audible and visual alarm system.

d. High Hazard Area--any operation expected to bring free hydrogen sulfide gas to the surface. The following are recommended for work in high hazard areas:

o Two NIOSH/MSHA approved, 30-minute, self-contained breathing apparatus for emergency escape from the contaminated area only

- Three wind socks and streamers

- Oxygen resuscitator

- Two hydrogen sulfide detectors. One should be a properly calibrated, metered detection instrument, and the other should be a pump type with detector tubes.

o A separate audible and visual warning system

- Employees should not be permitted on location without hydrogen sulfide safety training. Employees may be permitted on location for specific hydrogen sulfide training purposes not to include general rig training.

o Two means of egress at each location in a high hazard area should be provided.

- A means of communication or instruction for emergency procedures should be established and maintained on location along with the names and telephone numbers of the person or 
persons to be informed in case of emergencies.

- Signs should be posted 500 feet from the location on each road leading to the location warning of the hydrogen sulfide hazard.

- All hydrogen sulfide safety equipment should be checked to ensure readiness before each tour change.

e. Employee Instructions

Employees present at all medium and high hazard hydrogen sulfide
wells should be instructed in the use of the hydrogen sulfide
safety equipment provided onsite. Hydrogen sulfide safety
instruction should be given by a qualified person(s). The
instruction of personnel should include, as a minimum, the following elements:

- The characteristics of hydrogen sulfide and its hazards

o Proper first-aid procedures to be used in a hydrogen sulfide knockdown

o Use of personal protective equipment

o Use and operation of all hydrogen sulfide monitoring systems

o Corrective action and shutdown procedures.

\section{Illumination and lighting}

Lighting around a derrick should be sufficient to provide illumination at all times of at least:

- An average of 5 footcandle ( $f c$ ) power on the whole of the derrick floor, with no less than $3 \mathrm{fc}$ power at any point

- $5 \mathrm{fc}$ power at the finger board, mud pumps, and catwalk

- $3 \mathrm{fc}$ power at the shale shaker, stairways, and other working areas

- A minimum of $3 \mathrm{fc}$ power at all other walking and working surfaces $[69]$.

(NOTE: The above are minimum recommendations. Many circumstances, including weather, may warrant higher lighting values.)

Vehicle lights should not be used in lieu of rig lights for lighting of rig operations except in emergency. Lamps and reflectors should be cleaned frequently. Light beams should be directed toward the objects to be illuminated and away from the eyes of the workmen. All light cords and plug-ins should be kept in good condition.

\section{Fire and Explosion Prevention and Detection}

\section{a. General Requirements}

The employer should develop a fire protection program to be followed throughout all phases of the operation. Appropriate 
firefighting equipment should be provided. Access to the firefighting equipment should be maintained at all times. A minimum of four fire extinguishers having a minimum rating of 40 $B: C$ should be conveniently located at the rig. Additional extinguishers should be provided for the doghouse, the cellar, the generator area, and any flammable liquid storage areas.

Firefighting equipment should be periodically inspected and maintained in operating condition at all times [74]. A record should be kept showing the date when fire extinguishers were last inspected, tested, or refilled. After any use, fire protection and firefighting equipment should be made serviceable and returned to its proper location.

\section{b. Fire Prevention}

Smoking, open flames, or spark-producing equipment should be prohibited in areas subject to contamination or accumulation of flammable liquids or gases. Areas for the prohibition of smoking and open flame should include all areas within 75 feet [73] of the:

- Well head or shale shaker, whenever potentially hydrocarbonbearing formations are exposed in the well

o Degasser while it is operating

o Fuel storage areas.

The following procedures should be followed in areas where smoking and open flames are prohibited:

- Striking matches anywhere should be prohibited.

- Cigar/cigarette lighters and smoking materials should not be permitted.

o "No Smoking" or "No Open Flame" signs should be conspicuously posted.

Exhaust pipes from internal combustion engines, located within 75 feet of any well bore or in other nonsmoking areas, should be so constructed and used that any emission of flame or spark is suppressed.

Engine-driven light plants should be located at least 75 feet from the well bore unless properly protected to prevent them from becoming a source of ignition and should have an adequate overload safety device.

Welders' torch lighters of the spark type should be prohibited in areas where the atmosphere is contaminated by flamnable vapors or gases or where sources of ignition are forbidden, unless sheathed or otherwise protected against accidental operation.

Employee heating devices involving the use of an open flame or 
exposed electrical element should not be allowed in any crew doghouse located on the derrick, mast floor, or within 75 feet of the well bore. Heaters should be safely located more than 75 feet from the well bore or have an explosion-proof design.

\section{c. Flare Pits and Flare Lines}

Flammable waste vapors or gases should be burned or controlled to prevent hazardous concentrations from reaching sources of ignition or otherwise endangering employees. When a flare is used to burn flammable waste gases or vapors, the following precautions should be taken:

o Flare pits should be lit from the upwind side. When there is no wind or when the wind direction is undetermined, no attempt should be made to light the pit unless the operator can position himself in an explosive-free area. The use of hand-thrown rags or similar flaming objects should not be permitted [73].

- Reliable and safe means of remote ignition should be provided when hydrocarbon gases are released to the air through flares.

- Flares should be located in such a manner that unburned gases or vapors will be dispersed without creating a hazard to employees.

- Means should be provided to prevent the prolonged escape of hazardous quantities of unburned gases or vapors from flare installations. Automatic warning devices are acceptable, provided they are tested at such regular intervals that their operation will be assured.

o Where a flare has been extinguished, and the means of igniting the flare has failed, employees should not enter or be required to enter the involved area for the purpose of relighting, until tests have established that the area is free from flammable gases or vapors.

- All combustible material should be cleared for a safe distance from the flare pit or end of the flare [75].

\section{d. Lightning and Static Electricity}

Each stationary and portable steel derrick and mast in use where flammable vapors or gases are present (or may escape to the atmosphere in sufficient quantity that the ignition would endanger the safety of employees) should be effectively grounded to a ground pipeline, well casing, or other equivalent source of grounding. Where not effectively grounded or bonded by contact or connection, provisions should be made to prevent the accumulation of a static electrical charge, which could create a source of ignition in the presence of flammable vapors or gases. 
Conductors, used for bonding and grounding stationary equipment or conductors, should be of copper wire no smaller than No. 8 American Wire Gauge. Bonding and grounding clamps or clips should be attached with secure and positive metal-to-metal contact.

e. Flammable and Combustible Liquids

Only approved containers and portable tanks should be used for storage and handling of flammable and combustible liquids. Approved safety cans should be used for the handling and use of flammable liquids in quantities greater than 1 gallon [68].

No persons (except those having necessary duties or those authorized by the employer) should be permitted within the vicinity of $a$ job or operation where the atmosphere is known to be contaminated with hazardous concentrations of flammable vapors or gases.

Material used for cleaning should not have a flashpoint less than $100^{\circ} \mathrm{F}$; therefore, gasoline and naphtha should not be used [73]. Smoking or open flames should not be allowed within 75 feet of the handling of flammable liquids. Oxygen should not be stored or used in the vicinity of flammable liquids.

Any engine being refueled should be shut off during such refueling. An electrical bond should be maintained between containers when a flammable liquid is being transferred from one to the other. Dispensing nozzles and valves should be of the self-closing type [73].

Except for the fuel in the tanks of the operating equipment, no flammable fuel should be stored within 75 feet of a well bore. Drainage from any fuel storage should be in a direction away from the well and equipment. Spills should be immediately cleaned up [73]. The area around all storage facilities should be maintained reasonably free of oil, grease, and other combustible materials.

Fuel storage tanks should be protected by crash rails or guards to prevent physical damage unless by virtue of their location they have this protection. Adequate berms should be placed around storage tanks [70].

10. Electrical

\section{a. Electrical Hazard Zones}

Areas of the drilling rig are classified into "electrical hazard zones" based on the operative potential of release and accumulation of flammable gases [74]. Electrical equipment used in these zones must conform to OSHA regulations [70]. 


\section{b. Grounding and Bonding}

A11 temporary, 120-volt, single-phase, 15- to 20-ampere flexible electrical cords and receptacles must conform to OSHA grounding and bonding requirements by having a ground-fault circuit interrupter system or an assured equipment grounding program [70].

\section{Blowout Prevention}

Employees should be adequately trained to properly respond in the event of a "kick." Employees should recognize the importance of the circulating fluid in controlling formation pressure and the relationship of increasing mud return rates and subsequent pit gain in increasing formation pressure.

A blowout preventer operating test should be performed on each round trip but not more than once per day [76]. Blowout prevention equipment should be in accordance with the U.S. Geological Survey requirements. Blowout prevention equipment should be substantially constructed and securely fastened in place. Blowout prevention equipment should be maintained in a manner that will assure its proper functioning through the drilling operation. Unobstructed access to all blowout preventer controls should be maintained. Blowout preventer controls should be clearly identified as to their proper function.

Drilling operations should not proceed until blowout prevention equipment is found, upon test, to be serviceable. Additional recommendations for blowout prevention equipment systems, inspection, and testing are contained in API "RP 53: Recommended Practice for Blowout Prevention Equipment Systems" [76] and should be followed.

A kelly cock (upper safety valve) should be placed between the kelly and rotary swivel, and a lower kelly valve should be used below the kelly. Such stopcocks or controls should be of adequate strength to withstand the pressures and stresses imposed on them under normal use and predictable circumstances [76].

If the blind rams are closed for any purpose, the valves on the choke lines or relief lines below the blind rams should be opened prior to opening the rams to bleed off any pressure. Employees should not be permitted to stand near or over the opening in the rotary table when the blind rams or drill pipe rams are opened. Choke lines or relief lines should be secured or tied down to prevent whipping under pressure surges.

Additional controls may be installed wherever desired, provided, however, that such additional controls can in no way interfere with the proper closing function of the controls required by the section above. Such additional controls need not be shielded or sheltered. It is recommended that additional controls be located at a point conveniently near the driller's station so as to facilitate quick action in case of emergency. 
12. Inspection, Testing, and Maintenance of Rig Components

A record or $\log$ of all inspections, testing, maintenance, and adjustments and repairs should be kept at the well site.

a. Inspection

(1) Initial inspection

- Prior to initial use, all new and altered rigs should be inspected to ensure compliance with the recommendations made in section B., Safety Guidelines for Well Drilling Machinery and Equipment.

- The inspection procedure for rigs in regular service is divided into two classifications based on the intervals at which inspections should be performed. The intervals depend on the nature of the critical components of the drilling rig and the degree of their exposure to wear, deterioration, or malfunction. The classifications are: "frequent" inspections, which should be performed at daily to monthly intervals and after every rig-up, and "periodic" inspections, which should be performed at 1- to 12-month intervals.

(2) Frequent inspection

- The following items should be inspected for defects at daily to monthly intervals or as specifically indicated, including observation during operation for any defects that might appear between regular inspections:

- All functional operating mechanisms, for maladjustment interfering with proper operation (daily) and for excessive wear of components

- The weight indicator, for ascertaining whether the indicator is recording the estimated weight of the drill string (daily)

- Lines, tanks, valves, drain pumps, and other parts of air or hydraulic systems, for deterioration or leakage (daily)

- Hooks, for cracks, more than $15 \%$ in excess of normal throat opening, or more than a 10 degree twist from the plane of the unbent hook (daily); if any of these defects are observed the hooks should be discarded.

- Hoist or load attachment chains, including end connections, for excessive wear, twist, distorted links interfering with proper function, or stretch beyond manufacturer's recommendations (daily)

- Rope slings, including end connections, for excessive wear, broken wires, stretch, kinking, or 
twisting (daily)

- Rope reeving, for noncompliance with manufacturer's recommendations.

- All deficiencies should be examined carefully and a determination made as to whether they constitute a safety hazard.

(3) Periodic inspection

Bails, elevator links, upper side hook saddles, A-leg pins, and housing should be inspected for flaws at least once each year and each time the derrick or mast is rigged up. All derricks should be visually inspected each year of use. A written report of these inspections should be kept on file [77].

A complete inspection of the hoisting mechanism should be performed periodically at 1 - to 12-month intervals depending on activity, severity of service, and environment or as specifically indicated below. If any of the following deficiencies exist, the member should be either replaced or repaired:

- Deformed, cracked, or corroded members

- Loose bolts or rivets

- Cracked or worn sheaves and drums

o Worn, cracked, or distorted parts such as pins, bearings, shafts, gears, rollers, and locking or clamping devices

o Excessive wear on brake system parts, linings, pawls, and ratchets

- Load indicators over their full range, for any significant inaccuracies

- Gasoline, diesel, electric, or other powerplants for improper performance or noncompliance with applicable safety requirements

o Excessive wear of chain drive sprockets and excessive chain stretch

o Electrical apparatus, for signs of pitting or any deterioration of controller containers, limit switches, and pushbutton stations.

b. Testing

(1) Lcad test

Prior to initial use, all new, extensively repaired, and/or altered rigs should be tested under the direction of an authorized person. Before the drilling line is installed on the drum of the drawworks, the brake lining should be set or 
"burned in" by setting the brake and rotating the drawworks unless otherwise specified by the manufacturer of the brake lining. After pressure is applied on the brake, the engines should be loaded to almost stall. Next, the drilling line should be installed on the drum of the drawworks and the drilling line strung through the traveling block and the crown block. The derrick should then be raised a few inches of $f$ of the derrick stand, held in that position for several minutes, and checked for excess strain on the mast, substructure, and all hoisting 1 ines and component parts.

\section{(2) Operational tests}

Prior to initial use, all new and altered hoisting mechanisms should be tested to ensure the safe operation of:

- All hoisting and lowering equipment

o All limit switches and locking and safety devices.

\section{c. Maintenance}

A preventive maintenance program based on the drilling rig manufacturer's recommendations should be established. Adjustments and repairs should be made only by designated, qualified personnel.

When maintenance or servicing is to be accomplished on electrical lines, air lines, gas lines, or other lines containing hazardous materials, the line being worked on should be rendered safe by disconnecting, emptying, purging, or other means before work is begun.

Energized systems (electrical, mechanical, or thermal) should be locked out and tagged prior to initiating maintenance or repair work.

After adjustments and repairs have been made, the rig should not be operated until all guards have been reinstalled, safety devices reactivated, and maintenance equipment removed.

d. Ad justments and Repairs

Adjustments should be maintained to ensure correct functioning of components. The following are examples:

o All functional operating mechanisms

- Limit controls

o Control systems

o Brakes

o Powerplants. 
Repairs or replacements should be made promptly as needed for safe operation. The following are examples:

o Hooks showing defects should be discarded. Repairs by welding or reshaping are not acceptable.

- Load attachment chains and rope slings showing defects

o All critical parts that are cracked, broken, bent, or excessively worn.

\section{B. Safety Guidelines for Well Drilling Machinery and Equipment}

\section{General Recommendations}

Setting depths of all casing strings should be determined by taking into account formation fracture gradients and the maximum anticipated pressure to be maintained within the well bore $[73,78]$.

If and when it becomes necessary to run a production tubing, such casing should be cemented by the pump and plug method and should be properly tested by the pressure method before cement plugs are drilled [73, 78].

Drilling should not commence until:

o All guards, including those for the drawworks, are in place on all equipment to be operated

- All platforms, stairways, and handrails are secured in position

o The mast is secured; if pins are used, they should be secured by safety pins.

The escape line with buggy (geronimo) should be installed before the derrickman's first exposure in the derrick, usually at the time of the first trip. Machinery or equipment should be constructed, protected, placed, operated, and maintained to afford reasonable safety from accident to persons in and around drilling facilities.

Machinery and equipment should be operated only by persons authorized by the employer.

Cleaning and oiling machinery while it is in motion should be prohibited in all cases where exposure to harmful contact with moving parts is possible. Before any machinery or equipment is to be repaired, it should be shut down. The power should be disconnected, the control device tagged and locked out or otherwise made inoperative, and the key retained on the person making the repairs. Tags used for this purpose should warn against starting such machinery. Before any person starts any machinery or equipment, he should make certain that no person will be endangered by the equipment's being put into motion.

All belts, gears, shafts, pulleys, sprockets, spindles, drums, flywheels, or other reciprocating and rotating parts, with the exception of the rotary table, kelly, kelly-drive bushing, and cathead, should be guarded 
unless they are guarded by location; i.e., so positioned as to prevent any person from coming in contact with them. Specific safety recommendations for the design, guarding, and operation of the kelly bushings, catheads, and rotary tables are made in applicable categories.

On rotary drilling rigs, every counterweight above the derrick or mast floor and located inside the mast when not fully encased or running in permanent guides, should be attached to the frame of the derrick with a separate wire rope or chain safety line, adequate to prevent the counterweight from coming within 8 feet of the floor.

Tools, machine parts, or material of any kind should not be kept in a derrick or mast above the floor unless they are in use, in which case reasonable precautions should be taken to prevent their falling on persons below. Where pipe hooks are used above the derrick floor, every pipe hook should be secured to the derrick in a manner that will prevent the hook from falling.

Whenever it is reasonably practicable, the engine room, pump house, derrick floor, and racking platform should be adequately enclosed to a sufficient height to provide suitable protection for workers during seasons of inclement weather.

Machines designed for a fixed location should be securely anchored to prevent vibrational walking or moving.

An emergency stop device should be provided for each prime mover for drilling machinery. The device should be one that, once placed in the stop position, should be manually reset to the starting or running position before the prime mover can be started.

\section{Weight Indicators}

A weight indicator should be provided and used on every drilling rig and should be so constructed, installed, and maintained that it will register $\pm 5 \%$ of the load suspended from the hoisting lines. Calibration of the weight indicator should be performed by comparing the indicated drill string weight with the calculated weight. The calibration should be performed monthly, after each rig relocation, or more frequently as dictated by driller experience. The results should be recorded. Any weight indicator hung above the floor should be secured to the derrick by means of a wire rope, safety line, or chain, or equivalent means.

\section{Derricks and Masts}

\section{a. General}

Derricks and masts should have a permanent nameplate attached to the structure indicating the following:

- Name of manufacturer 
- Model number and serial number

- Rating including static hook load capacity with number of lines

o Whether guying is applicable and, if so, the recomended guying pattern $[74,79,80]$.

(NOTE: Derricks or masts constructed before this safety recommendation should have this same information recorded and available at the well site.)

Every derrick and its component parts should be constructed to conform to good engineering practices and should be maintained in safe condition. Bolts, nuts, and pins on elevators, wire lines, and catlines, as well as sheave and other anchor bolts in the derrick or mast, should be secured with cotter pins and lockwashers, or equivalent means.

b. Foundations

Every derrick in operation should be supported by a foundation. The derrick or mast and foundation should not be loaded beyond its design capacity. Where necessary to avoid exceeding the safe bearing capacity of soil on the location, supplemental footing should be provided to distribute concentrated loads from the derrick or mast and mast mount to the ground. The area and type of supplemental footing should be capable of distributing the gross weight of the derrick or mast under maximum anticipated hook load and loads imposed during raising and lowering of the structure [74]. Table IV-1 indicates the typical safe bearing capacity of several types of soils.

Foundation pads for drilling rigs should be graded and adequately drained. Location sites should be constructed and maintained so that oil, water, drilling fluid, and other fluids will drain away from the working area.

All auxiliary parts of derricks should be substantially constructed and maintained in a safe condition.

Reasonable provisions should be made to prevent derricks from collapsing as a result of wind velocity. This may be accomplished by using either one or both of the following methods:

- Using an adequate number of sufficiently strong guy lines arranged and anchored as specified by the rig manufacturer or in accordance with accepted engineering practices

o Constructing the derrick and foundations to resist overturning in accordance with accepted engineering practices. 
Soil ledge of hard rock, such as granite, trap, etc. Sound shale and other medium rock requiring blasting for removal

Hard pan, cemented sand, and gravel difficult to remove by picking

Soft rock, disintegrated; in natural ledge difficult to remove by picking

Compact sand and gravel requiring picking for removal Hard clay requiring picking for removal

Gravel, coarse sand in natural thick beds

Loose, medium, and coarse sand; fine, compact sand

Medium clay, stiff but capable of being spaded

Fine, loose sand

Soft clay
$50,000-200,000$

$20,000-30,000$

$16,000-20,000$

$10,000-20,000$

$8,000-12,000$

$8,000-10,000$

$8,000-10,000$

$3,000-8,000$

$4,000-8,000$

$2,000-4,000$

2,000

Source: Mark's Standard Handbook for Mechanical Engineers [81].

c. Anchors and Guying

Expanding anchors, pipe anchors, concrete anchors, or anchors otherwise engineered to prevent overturning should be used in accordance with the manufacturer's recommendations. Trees, rocks, driven stakes, or other temporary, movable objects should not be used for anchoring. Soil conditions, terrain, and use of surrounding 1 and will determine the most applicable. type of anchor. All anchors should satisfy the following conditions:

- All installed ground anchors, permanent or temporary, should meet the pullout recommendations for the conditions of service. The anticipated climatic conditions, including wind forces, for the geographic area should be a prime consideration in determining the anchor pullout recommendations and pattern spacing. Anchor breaking strength and pullout safety factors should be in accordance with the recommendations included in API "Spec 4E: Specification for Drilling and Well Servicing Structures" [82].

o Where soil is corrosive, metal components or permanent ground anchors should be galvanized or otherwise protected against corrosion [78]. 
Pull tests for all permanent-type ground anchors should be made for the geographical area and size and type of anchor involved. Representative pull tests should be conducted along the anchor working plane. Records of representative anchor pull tests for the area should be maintained.

Permanent anchors should be visually inspected by the user prior to each use. If significant damage or deterioration is apparent on inspection, anchors should be pull tested.

Temporary ground anchors should be of such type and so installed to provide pullout strengths that exceed the maximum anticipated guy line pull of the equipment to be used and conditions of service. Records of representative anchor pull tests for the area and size and type of anchor should be maintained by the installing company.

Portable masts, both structural and pole type, that require use of external guy lines to assure overturn stability should have the external guy lines in place immediately following raising of the mast.

Guy lines should be maintained in good condition sufficient for the loads to be incurred. Guy line strength, including auxiliary devices such as chains, boomers, and clamps, should be capable of withstanding loads for the anticipated service conditions.

Guy lines should be visually inspected prior to each rig-up. Guy lines should be removed from service and replaced if in any length of 10 diameters the total number of visible broken wires exceeds $10 \%$ of the total number of wires in the line, or if the guy line shows other signs of excessive wear, corrosion, or defect.

If a derrick or mast requires guying, neither should be rigged up on a worksite unless the anchors have been installed and tested in accordance with these recommended safe work practices.

Prior to imposing any load on a derrick or mast, all recommended load guys should be tensioned.

d. Gin Poles

A gin pole should consist of no less than two upright members supporting a horizontal header member, and the header should extend in a horizontal plane across the approximate center of the opening in the derrick top [75]. A gin pole should be installed on standard derricks when it is necessary to install, remove, or lift a crown block or to hoist or lower any material through the opening in the derrick top that is too heavy to be handled manually. 
The minimum clearance between the bottom of the horizontal header member of the gin pole and the tops of the beams on the derrick top that support the crown block should be no less than twice the overall height of the crown block or other material being handled.

A gin pole should be designed and constructed to sustain the maximum compression load imposed thereon.

When a standard derrick gin pole is used to install a crown block, access should be provided to the top of the derrick gin pole by means of a fixed ladder.

\section{Escape Equipment}

An auxiliary means of escape should be provided from the finger board of a standard-type derrick, from the pipe-racking platform on others, and from temporary stabbing boards. This auxiliary means of escape should be a specially rigged escape line by which an employee can reach the ground safely if a blowout, fire, or other emergency in or around the derrick should cut off his escape by way of the derrick or mast ladder.

- The escape line on masts and derricks that are 110 feet or more in height should be a $1 / 2$-inch minimum diameter wire line in good condition. A safety trolley or buggy equipped with a cam-type brake should be installed on the derrick exit line and kept at the level of the derrickman's working platform (monkey board). When the derrickman mounts the trolley, the cam brake holds the trolley in place until it is released by pushing the handle forward. With this type of trolley, he can easily control the speed of his descent.

- The escape buggy should be secured in a manner to ensure easy, but not premature, release.

- The derrick exit 1 ine and trolley should be in operational condition before drilling begins.

- Tension on the escape line should be periodically checked and adjusted to ensure safe landing of the user. Tension should be such that a person descending on the escape line can stop 20-25 feet from the anchor point. The ground anchor point of the escape line should be located a minimum lateral distance from derrick or mast equal to the height above ground to the point where the escape line is fastened to the derrick or mast. Tension lines should not be tied to power poles, pipelines, trees, rocks, vehicle bumpers, or other equipment [74].

The escape buggy should not be tested by "test runs." A daily visual inspection by the derrickman and testing for freedom of movement and braking are adequate. Other means of escape, such as an escape chute or slide, are acceptable if they provide the employee with an equal or better escape method. 


\section{Floors}

Every floor, platform, walk, or runway should be kept reasonably free of drilling fluids, mud, oil, grease, or other substances that create a slipping hazard or prevent or hamper the escape of workers in an emergency. The rig floor should be constructed of material designed and maintained to be slip resistant when wet or dry.

Every rig floor should completely cover the space within the perimeter of the derrick or the outer boundary of the floor when it extends beyond the perimeter of the derrick, except for openings necessary for the installation of equipment used in connection with the operations. When the openings are not occupied by the equipment or when it is not necessary to keep them open, they should be covered or otherwise guarded to prevent workers from accidentally stepping or falling in. Specifically, ratholes and mouseholes should be covered unless occupied by the kelly or drill pipe or constructed with a tube that extends 18 inches or more above the rig floor.

\section{Platforms}

With the exception of the stabbing board, every platform erected on the inside of a derrick should completely cover the space from the working edge of the platform back to the legs and girts of the derrick. All elevated platforms should be constructed to withstand four times the maximum intended load. All platform planks and other components should be secured adequately to prevent displacement.

\section{a. Crown Platforms}

On every jackknife derrick, a platform at least 2 feet wide should be provided on at least one side of the crown block. This platform should be equipped on its outer edges with a two-rail guard railing and a toeboard. Smaller platforms may be used if the employees are provided with, and required to use, safety belts and lanyards.

Every standard derrick used for drilling, except a jackknife derrick, should have a continuous outside derrick platform at least 2 feet wide completely around the derrick at an elevation no more than 2 feet above and no more than one girt (not to exceed 8 feet) below the monkey board. This platform should be equipped on its outer edges with a two-rail guard railing and toeboards [75].

Additional access platforms should be provided with openings that should be at least 30 inches by 30 inches to permit the passage of workers climbing derrick ladders. Standard railings around the outer edges of the platforms and toeboards should be 4 inches high around the inside and outside edges of the platform, except at access points.

Direct access should be provided to each outside derrick platform 
by the main derrick ladder, by an auxiliary derrick ladder from any lower outside derrick platform to which the main derrick ladder does not provide direct access, or by extending the outside derrick platform to the main derrick ladder.

\section{b. Racking Plat forms}

A monkey board should be provided in a standard derrick or mast at each elevation where an employee is normally required to handle pipe or other equipment racked in the derrick tower.

The working edge of monkey boards should be placed to permit sufficient clearance for safe passage of the traveling block and so that the elevator can be easily reached. A monkey board should not be positioned so that the hoisting line running to the hoist drum runs through, or is in contact with, the platform unless provisions are made to prevent the line from dangerously abrading the platform and to guard employees working on the platform from contact with the line.

Every monkey board on a standard derrick should completely cover the space from the working edge back to the legs and derrick girts. The monkey board or racking platform on a mast should be securely fastened to a structural member or mast legs and completely surround the working area. Every monkey board should be secured to the derrick with bolts or equivalent fastenings to resist being shifted or accidentally dislodged under normal operating conditions.

A vertical clearance of at least $6-1 / 2$ feet should be maintained above the decking of each monkey board [77]. Access to a monkey board on a standard derrick that is more than four feet above the outside derrick platform that serves it, and to which the main derrick ladder does not provide direct access, should be provided by means of an auxiliary derrick ladder. The ladder should run from the platform below to a point no less than $3-1 / 2$ feet above the monkey board.

A standard finger or finger brace should not be used as a racking platform except when it meets the recommendations for one and provides a safe working space between the traveling block or hoisting lines and the pipe racked in the derrick tower.

\section{c. Stabbing Boards}

A stabbing board should be provided for and used by employees when a platform is necessary for regular operating duties and the work cannot be safely performed from a fixed platform or monkey board.

A stabbing board should be at least 12 inches wide and should be strong enough to safely withstand the total weight of persons, 
equipment, or material that may be required or permitted to be placed thereon. When it is in position, the ends of a stabbing board should be fastened in a manner that will prevent the board from accidentally shifting of $\mathrm{fts}$ supports or falling on the floor. Placing the boards across a girt without firmly securing the ends is not adequate because they are easily displaced.

A safety line should be attached to each end of the stabbing board and secured to the derrick structure to prevent pieces from falling to the floor below in the event of accidental breakage or displacement.

After the stabbing board is used, it should be removed from the derrick.

\section{Guardrails}

The outer edges of all floors, platforms, walks, and runways that are four feet or more above the ground or another floor level, except entryand exitways and loading and unloading areas, should be guarded with standard guardrails [70]. The Vee-door or other material access ways to platforms or the rig floor should be guarded by a chain or cable capable of withstanding 200 pounds applied at the midpoint. The chain should be in place at all times except when material, such as drill pipe, is actually being moved through the platform access way.

A standard railing should not be used for other than personnel protection purposes.

A guardrail used and/or needed for the purpose of actual or potential containment of equipment or material should be of such construction and strength as to effectively contain the full load or stress expected to be applied. (For example, if 25 pieces of 6 -inch pipe are contained by a guardrail, or any attachment to the guardrail, such guardrail and attachment should be capable of safely holding that quantity of pipe, plus an additional allowance for at least two employees, assuming 200 pounds per employee) [78].

Toeboards should be provided to prevent material from falling off whenever the floor, platform, walkway, or runway is 10 feet or more above the next floor level or when persons are likely to be below. The hole opening resulting from the removal of the rotary table for installation of the blowout preventer is exempted.

Standard toeboards should be a minimum of 4 inches in vertical height from the top edge to the level of the floor, platform, walkway, or runway. Toeboards should be securely fastened in place and not have more than 1/4-inch vertical clearance above floor level. They may be constructed of any substantial material, either solid or with openings, not to exceed 1 inch in greatest dimension [70]. 
If material is stacked to such height that a standard toeboard does not provide protection, substantial paneling or screening from floor to intermediate rail or top rail height should be provided as required.

Rig floors, derrick walks, and engine room floors should not be used as storage platforms for idle equipment or material that is not for immediate use, unless it is properly racked or stored to avoid obstruction or congestion of the work area or access way.

\section{Exits and Stairs}

Where the difference in elevation is more than 18 . inches between the ground and other working levels, platforms, or floors, an exit should be provided by means of a stairway, ramp, walkway, or a combination of these. Typical areas that should be provided with safe exits are:

- A place along an edge of the drawworks enginehouse floor or platform that is as remote from the derrick floor as operating conditions will permit. This exit should be readily accessible from all areas of the enginehouse unless an alternate accessible exit remote from the derrick floor is provided.

o The end of the catwalk furthest from the derrick floor

o The junction of the derrick floor and Vee-door ramp

- The junction of the drilling fluid ditch walk and derrick floor.

Every runway should be at least 2 feet in width. When guardrails are provided on a runway, the clearance on the runway should still be at least 18 inches wide [68].

Derrick floors at wells having no connection walk, platform, or other floor should have at least one means of exit provided if the derrick floor is more than 18 inches but less than 4 feet above ground level. When the derrick floor is more than 4 feet above ground, two means of exit should be provided and located so that they offer alternative means of escape in case of emergency. One means of exit should be provided by a stairway, ramp, walkway, or a combination of these. A ladder may be used as the other means of exit. Where the derrick floor is 20 feet or more above ground, an additional, rapid means of descent, such as a slide, should be provided as a third exit for emergency use only and so posted [73].

Al1 "EXIT" doors of a drilling rig should open outwards and should not be held closed with a lock or an outside latch when workmen are working on the rig.

Standard railing should be provided on the open sides of all exposed stairways and stair platforms with four or more risers. Every stairway, ladder, ramp, runway, floor, and platform should be kept reasonably free of objects and substances that may create a slipping or tripping hazard, or prevent or hinder the escape of workers in an emergency. 


\section{Ladders}

Every derrick should be equipped with a fixed ladder or ladders arranged to provide access from the floor level, or from the vehicle bed on which it is mounted, to the crown safety platform and to any intervening fixed plat forms.

Fall protection should be provided and used by all persons climbing the derrick ladder(s). If the ladder is not constructed with approved cages and landing platforms, then a ladder climbing device or a fall arresting device should be provided. Platforms should be provided wherever fixed ladders are offset laterally, unless a ladder climbing safety assist device is utilized.

Where sections of ladders are spliced, they should be supported at the splice so the ladder will be aligned and the splice will not be stressed beyond its safe working limit.

Along the length and width of the back of the ladder, a space of at least 7 inches should be maintained clear of all obstructions that present a tripping hazard, prevent safe footing, or prevent a secure handhold to the ladder rungs or steps.

A ladder should not lean backwards from a vertical position. A ladder should not lean sideways more than $5-3 / 4$ degrees ( 1 foot horizontal in 10 feet vertical). Ladders from cantilever-type masts should not lean sideways more than 3 degrees or approximately 1 foot horizontal in 20 feet vertical [77].

Ladders should be constructed so that the rungs or steps are approximately horizontal at the normal operating position of the derrick. The distance between rungs should be uniform [77]. Every ladder should be substantially constructed and secured to the derrick with bolts, brackets, or equivalent safe fastenings.

The top end of each terminating ladder or ladder section providing access to any fixed platform in or on a derrick should extend at least 3-1/2 feet above the platform unless suitable handholds are provided [68]. An opening to permit the passage of employees climbing the ladder should be provided in every platform through which the ladder passes.

o The width of the opening should be at least 22 inches but no more than 30 inches.

o The ladder should be placed midway along the width of the opening.

- The openings should be clear and unobstructed for at least 30 inches outward on the climbing side.

10. Mud Pits, Tanks, and Reserve Pits

Portable tanks should be located where it is not possible for employees 
or equipment to come into contact with overhead powerlines.

All discharge lines should be properly secured. All fixed mud guns used for jetting should be pinned or whip checked when unattended. Hoses used for jetting operations should be manned when operational, and an employee should be stationed at the pump control to shut down the pressure in the event of an emergency [78].

When it is necessary for an employee to enter a mud tank that has contained toxic fluid, the safety recommendations presented in section 5.b., Entry into Confined Spaces, should be followed.

Standard railings should be provided on the inside of all mud tank walkways. Where such walkways are 4 feet or more above ground level, both sides should be provided with standard railings. Gusrdrails should be installed on both sides of walkways located over mud tanks.

Reserve pits should be:

- Equipped with a standard ring buoy and 90 feet of 1 ine

- Equipped with a readily accessible rescue hook similar to the type used at swimming pools

- Guarded if located in a high-traffic area

o Lighted well enough to ensure that employees will not inadvertently fall into them at night.

11. Pumps and Pressure-Relieving Safety Devices

All pressure vessels, safety pressure relief valves, pumps, fittings, piping, and hoses should be constructed, installed, operated, inspected, and repaired to conform to the ASME "Boiler and Pressure Vessel Code". [83]

Pumps should not be operated at unsafe speeds or in excess of their safe working pressure. Every power-driven piston or plunger-type pump should have the manufacturer's specification plate or markings showing the manufacturer's ratings of the pump. Where there is a likelihood of developing a pressure in the pump in excess of its safe working pressure, the pump should be equipped with an adequate pressure-relieving safety device such as a direct spring-loaded safety valve, a shear pin-set safety valve, a rupture disk, or other equivalent device.

Pressure-relieving devices should be installed and maintained as follows:

o There should be no intervening stop valves between the pump and its pressure-relieving device or between the pressure-relieving device and the point of discharge.

- The point of discharge from pressure-relieving devices should be at a place where the safety of employees is not endangered by the discharge fluids. 
- Pressure-relieving devices should be set to relieve at a pressure not in excess of the maximum allowable safe working pressure of the pump [77].

Every shear pin-set safety valve should have a metal plate affixed to it with holes drilled in it as a gauge for each size shear pin to be used with the valve and a table with stamped or raised letters and figures showing the pressure at which each size shear pin will shear.

Shear pins used in pressure-relief devices should be of a design and strength specified by the manufacturer. Allen wrenches or other hardened steel items should not be substituted. Every shear pin-set safety valve should have the valve stem and the shear pin enclosed in a manner that will prevent accidental contact with the valve stem and prevent the shear pin from flying when sheared.

Adequate drainage should be provided to prevent the accumulation of oils or drilling fluids around pump bases.

The piping on the discharge side of the pressure-relief device should be securely tied down.

The use of hydrallic, pneumatic, or gas pressure inside a pump to remove pump liners should not be permitted. This does not mean that the use of hydraulic or pneumatic tools made for this purpose is unsafe.

No pump should be set in motion when the fluid-end cylinder head is not secured in place unless precautions are taken to prevent injury to employees.

Every pump should be equipped with a bleeder pipe and valve through which the pressure in any part of the pump can be bled off to atmospheric or as near atmospheric pressure as is practicable, unless other piping and valves connected to the pump can be effectively used for this purpose.

Each disk used in a rupture disk-type, pressure-relieving device should have stamped on it the approximate pressure at which it will rupture, or be identified by an equivalent means.

Before beginning the removal of any cap, plug, plate, or cover from a pump or otherwise opening a pump, the pressure within the pump should be bled off to atmospheric or as near atmospheric pressure as is practicable.

Employees should be instructed in the dangers of high pressure systems and the sudden release of contained pressure.

12. Circulating Hose and Standpipe

The upper end of the standpipe should be securely fastened to the 
derrick or mast leg or to the derrick or mast girts, unless other adequate support is provided [75].

The standpipe end of the rotary hose should be secured to the standpipe or to the derrick or mast, and the other end to the swivel by a substantially constructed clamping device and safety chain or wire rope. The hose coupling is exposed to high pressure and vibration, a combination that can result in coupling disconnect [75].

The safety chain should be strong enough to safely support the rotary hose, contained circulating fluids, and dynamic circulating fluid pressures in the event of a coupling separation.

The ends of connecting hose sections should be secured together (whip checked) by means of clamps and a safety chain or wire rope. The clamps should be tightly fitted to and near the ends of the connecting hose sections, and the chain or wire rope securely fastened to each of the clamps.

When hose is used under pressure in a fluid circulating system of a well (in addition to that section between the swivel and standpipe), the ends of each section should be secured to the end of the adjoining hose or pipe in the manner described above [75].

\section{Ce11ars}

Stairways, runways, and ladders providing entry to a cellar should be substantially constructed to conform with good engineering practices and should be kept in safe condition. Well cellars, well floors, and ground areas adjacent to derricks should be kept free of oil accumulation that might create or aggravate fire hazards.

Cellars more than 6 feet deep and/or containing hazardous substances or water should be guarded with standard guardrails unless guarded by location [74].

When employees are required to be in a cellar, the cellar and the exits from it should be kept reasonably free of water, oil, drilling fluid, and other like substances that may endanger them. Loose equipment or material, except what is in use or about to be used, should not be kept in the cellar or in the shaft or exits.

\section{Pipe and Pipe Racks}

Every pipe and equipment storage rack and platform should be designed, constructed, and placed on substantial foundations and maintained to safely support the loads placed on it.

Each finger of a finger board should be bolted, welded, hinged and pinned, or attached by other equivalent means to its support beam and be capable of restraining the maximum intended load. 
Pipe racks should be set level laterally on a stable foundation. They may slope front to back to facilitate laying down or picking up pipe $[78]$.

Adequate provision should be made to prevent pipe, drill collars, drill stems, or similar round, rolling stock material from accidentally rolling off any storage rack. This may be achieved by nailing chock blocks to the decking of the rack and to the planks or spacers used between the layers of pipe or other material on the rack, or by other equally effective means.

When pipe is being transferred between pipe racks, catwalks, or trucks, the temporary supports or skids should be so constructed, placed, and anchored so that they will support their loads [78].

Pipe joints temporarily placed on the inclined ramp or Vee-door area should be:

- Chocked at the base to prevent kickback

o Positioned at the upper end in a manner to prevent them from falling sideways.

\section{Blocks}

All traveling blocks and their component parts should be substantially constructed to conform with good engineering practices and maintained in a safe condition. Traveling blocks, crown blocks, and related equipment should not be subjected to any load in excess of their design limitations .

\section{a. Crown Blocks}

Each sheave assembly of a crown block should be provided with a complete metal-bearing housing, a metal strap, or an equivalent housing, securely fastened to the crown block beams so that the sheaves, sheave bearings, or housings cannot accidentally be dislodged under normal operating conditions [84].

Each crown block should be securely fastened in place with bolts, metal clamps, or equivalent fastenings that will prevent it from being accidentally shifted or dislodged. Each crown block sheave should be securely fastened in place in a manner that will prevent it from jumping out of its bearings or becoming accidentally shifted or dislodged.

b. Traveling Blocks

The sheaves of a traveling block should be equipped with adequate guards that will prevent accidental contact by an employee with the sheaves or with the nip point where the hoisting lines run on and off the sheaves. 
Every traveling block sheave guard should be securely fastened to the traveling block to prevent it from becoming accidentally displaced under the most severe operating conditions, such as jarring on a stuck string of pipe, contact with the finger boards, or pipe standing in the derrick.

Every traveling block hook or other hook or line suspended from the traveling block, to which an elevator, elevator link, swivel bail, or other ecuipment is attached, should be equipped with a safety latch or device that will provide a completely and securely closed hook or link. The latch or device should be adequate enough to prevent material from becoming accidentally disengaged when used under the most severe operating conditions, such as jarring on a stuck string of pipe, or impact with the finger boards or pipe standing in the derrick [73].

Every traveling block, traveling block hook, elevator and elevator link, or similar traveling equipment should be free of projecting bolts, nuts, pins, or other parts on which the clothing of workmen might be caught or that may foul the derrick members or other equipment or material in the derrick.

The hoisting hook should be equipped with a safety latch or other equivalent device to prevent accidental release of the load being hoisted or lowered.

Traveling blocks should not be moved while the crown block is being lubricated.

16. Drawworks, Hoisting Lines, and Operations

The drawworks should not be operated without all guards in place. The front of the drawworks should be guarded by means adequate to prevent a worker from falling into the drum except during such operations as cutting or inspecting a drilling line.

a. Hoisting Ropes

API "RP 9B: Recommended Practice on Application, Care, and Use of Wire Rope for Oil Field Service" [85] should be followed.

Rope should be secured to the drum as follows:

- No less than five wraps of rope should remain on the drum when the hook is in its extreme low position.

- The rope end should be anchored securely to the drum.

Whenever rope is exposed to temperatures at which fiber cores would be damaged, rope with an independent wire rope or wire strand core or other temperature-resistant core should be used. Replacement rope should be the same size, grade, and construction as the 
original rope furnished by the drilling rig manufacturer, unless otherwise recommended by a wire rope manufacturer due to actual working condition requirements. A ton-mile program for wire rope use and replacement should be followed [84].

b. Rope Inspection

When any of the following conditions are present, a wire rope should be immediately removed from service:

- Reduction of rope diameter below nominal diameter due to loss of core support, internal or external corrosion, or wear or scraping of one-third the original diameter of outside individual wires

o Ten randomly distributed broken wires in one rope lay, or five broken wires in one strand in one rope lay

- Evidence of heat damage

- Corroded or broken wires at end connections

o Corroded, cracked, bent, worn, or improperly applied end connections

- Severe kinking, crushing, cutting, bird caging, or unstranding.

All rope that has been idle for a period of a month or more due to shutdown or storage of a rig on which it is installed should be given a thorough inspection before it is placed back in service. This inspection should be for all types of deterioration. The following limitations apply to the use of wire rope:

o Eye splices made in any wire rope should have not less than three full tucks. However, this recommendation should not operate to preclude the use of another form of splice or connection which $c$ an be shown to be as efficient and which is not otherwise prohibited [68].

- Eyes in wire rope bridles, slings, or running line should not be formed by wire rope clips or knots.

- The "Flemish eye," "farmer's eye," "contractor's standby", or any other knot should not be used in any wire rope.

- When U-bolt wire rope clips are used for form eyes, spacing and number of all types of clips should be in accordance with Table IV-2. Clip bolts should be retightened after the rope has been in use for 1 hour. clips should be applied so that the " $U$ " portion of the clip contacts the dead end of the rope $[68]$.

\section{c. Deadline Anchors}

Deadline anchors for hoisting lines should be so constructed, installed, and maintained that their strength equals or exceeds the working strength of the hoisting line. 
TABLE IV-2

NUMBER AND SPACING OF U-BOLT WIRE ROPE CLIPS

\begin{tabular}{cccc}
$\begin{array}{c}\text { Improved Plow Steel, } \\
\text { Rope Diameter } \\
\text { (inches) }\end{array}$ & $\begin{array}{l}\text { Number of C1ips } \\
\text { Frop Other }\end{array}$ & $\begin{array}{c}\text { Minimum } \\
\text { Spacing } \\
\text { (inches) }\end{array}$ \\
\hline $1 / 2$ & 3 & 4 & 3 \\
$3 / 8$ & 3 & 4 & $3-3 / 4$ \\
$3 / 4$ & 4 & 5 & $4-1 / 2$ \\
$7 / 8$ & 4 & 5 & $5-1 / 4$ \\
1 & 5 & 6 & 6 \\
$1-1 / 8$ & 6 & 6 & $6-3 / 4$ \\
$1-1 / 4$ & 6 & 7 & $7-1 / 2$ \\
$1-3 / 8$ & 7 & 7 & $8-1 / 4$ \\
$1-1 / 2$ & 7 & 8 & 9
\end{tabular}

Source: OSHA Construction Industry Standards, 29 CFR $1926 / 1910[68]$.

Provisions should be made to prevent the deadline from becoming accidentally disengaged from the tiedown.

\section{d. Line Spoolers or Winches}

Metal parts of line spoolers and line stabilizers should be guarded against contact with the hoisting line by rubber or other suitable nonmetallic material. Moving parts of power takeoff (cathead) line spoolers should be guarded.

Every overhead sheave or pulley on which a line spooler counterweight rope runs should be mounted in steel or iron brackets that are securely fastened to its support by bolts, wire cable, or adequate welding.

Control for line spoolers should be of the "deadman" type.

17. Catheads and Catlines

a. Manual Catheads

If a cathead is mounted on the end of a shaft that projects beyond the guard for other moving parts of machinery, the shaft end, key, or other device for securing the cathead to the shaft should be covered with a smooth thimble. The thimble cover should be of such design that a rope cannot wind around it.

There should be at least 20 inches of working area between the 
outer flanges of a cathead and a substructure guardrail or prefab wall [75].

Every cathead on which a rope is manually operated should have a reasonably smooth surface and should be free of projections on which employees' clothing may be caught. Cracked or broken catheads should not be used.

The horizontal friction surface of every cathead on which a rope is manually operated should be of uniform diameter between the inner and outer flanges, within a 1/4-inch tolerance. A cathead on which a rope is manually operated should be replaced or rebuilt when wear has created grooves or deformations in excess of three-sixteenths of an inch below the true surface line.

Every cathead on which a rope is manually operated should be equipped with an antirope-fouling device that will separate the beginning of the second wrap of rope from the first wrap at the point where the first wrap begins contact with the cathead. The device should be so designed and fitted in place that its inner edge is not more than three-eighths of an inch at any point from the friction surface of the cathead. Antirope-fouling devices and rope guides should be maintained free of sharp edges that could cut or abrade the ropes in use on the cathead.

Every cathead on which a rope is manually operated should have a suitable rope guide that will hold the on-running break rope, spinning rope, snapping-up rope, and kelly pull-back rope in alignment with their normal running position against the inner flange of the cathead.

\section{b. Automatic Catheads}

Rotating and reciprocating parts of every automatic cathead not protected by guards used for other moving parts of the machinery should be protected by shield guards. Openings of such sizes as are necessary for the run of the rope to the cathead are permitted.

Every cathead that uses chain should be equipped with a manually operated cathead clutch or with another device that is adequate enough to keep the rotation of the cathead under control when it is in use. The clutch or device should be of the "nongrab" type and should release automatically when not manually held in the engaged position.

Wire rope lines used on automatic catheads should be designed to withstand the stresses imposed on them. End fastenings for a wire rope used on an automatic cathead should be made in accordance with the manufaccurer's recommendations. A "contractor's standby" (half hitch and clips) should not be used as an end fastening on the rope. 


\section{c. Catlines}

Catlines and high lines should be designed to safely 1 ift or otherwise handle the loads. The maximum allowable working loads should be based on manufacturers' tables.

A post or guard should be provided to deflect cathead lines away from the driller's position. Where posts are of the rotating type, the top and bottom ends should be guarded to contain the post in case the shaft fractures.

A catline grip should be provided and used to keep the catline tight when the line is not in use.

\section{Chains and Spinning Chains}

All chains should be discarded or repaired if:

o They have been stretched to the point where links bind, kink, or lock

- There is a link showing more than $10 \%$ distortion or when a link has been broken [75]

- There is a link with metal reduced by wear, at any point, to less than $90 \%$ of its original cross-sectional area [75].

Chains that have been connected together for use as a spinning line should be connected and used as follows:

- A section of unbroken chain fastened to the cathead may be connected to a section of unbroken chain of smaller size.

- The connector link should be located where it will not come in contact with pipe being rotated.

- If there is a broken link in a spinning chain and the other links of the chain are not deformed or weakened, it is permissible to repair the chain with a tempered connecting link of the proper size for that chain.

- A cold-shut connecting link that is not tempered should never be used to repair a chain of any kind.

In the event of rupture of a link in the section of larger chain, both sections of chain should be discarded at once from further use as a spinning line. No part of any chain that has been broken should be used in a spinning line. To eliminate any necessity for use of broken chain, every rig where chain is used in a spinning line should be provided with spare chain in good condition. Every chain used in a spinning line should have a fiber tailrope between 8 and 12 inches in length fastened to the pipe end of the chain.

Connections between lengths of cathead chain, tong chains, and spinning chain should be of the connecting link or swivel type and of strength equal to the lighter chain. Connecting links and swivels should be of a 
size and type suitable for the chain in use.

If chains of different sizes are connected together for use in a spinning line, a spare chain of like size should be provided for each chain so connected.

\section{Elevators}

Elevators should be equipped with a positive locking/latching device designed to prevent drill pipe or casing from prematurely disengaging. Every drill pipe casing and tubing should be provided with a complementary (to the elevator latch) collar or protrusion designed to prevent elevator links/latches from becoming accidentally disengaged.

Elevators should be free of projections that could catch on derrick structure or rigging items.

20. Slips

The handles of drill pipe slips should be long enough to extend at least 2 inches beyond the greatest radial dimension of the drill pipe elevator box (except in those instances where the handles would be so long they would project beyond the inner edge of the circular guard covering the top outer surface of the rotary table). In such cases they should be as long as possible without projecting beyond the inner edge of the guard [77]. Any slip hook used for lifting should be equipped with a safety latch.

21. Tongs, Tong Backup Posts, Kelly Pull-Back Posts, and Safety Lines

Each pipe tong should be attached to the derrick or a back-up post by means of a wire rope known as a safety line. This safety line should have a breaking strength above the capacity of the pull that is exerted on the tongs by means of the automatic cathead. Both ends of the safety line should be secured by the required number of clamps (Table IV-2) properly installed, with the U-bolt of the clamp on the dead end of the cable.

The wire rope and connections should be frequently inspected and replaced according to the manufacturer's specifications. Special attention during inspection should be paid to wire rope rot from weathering and to cable clamp tightness.

Each tong to which a breaking or making-up 1 ine is attached and being used on a cathead should have a safety line attached to prevent the tongs being pulled to the cathead and also to prevent the tongs from traveling with the rotating pipe in case the breaking line should fail.

Tong backup posts, kelly pull-back posts, and tong safety lines should not be secured to derrick or mast girts or to derrick or mast legs unless the legs are so constructed and the 1 ines so attached that the 
stresses imposed will not result in structural damage to the legs [77].

A kelly pul1-back post with device attached, onto or through which to run the pull-back rope, should be provided for pulling the kelly back to the rathole. The pull-back post should be secured either to the derrick foundation, side sills, or floor sills and should not be attached to or come in contact with the derrick legs, girts, or braces.

Tong dies should be inspected regularly and replaced as a set as they become worn. The tongs should be inspected and greased before each tripping operation.

\section{Power Tongs}

The control device on power tongs should be designed or guarded to prevent accidental activation [77]. The power input pressure line used on power tongs should be disconnected before any repair, replacement, or other work of a similar nature is done on tongs, chains, dies, or their component parts $[73,74]$.

High pressure lines (hydraulic or air) should have a safety pressure relief valve that should never be set higher than the manufacturer's specifications for the working pressure of the lines or valve [74].

Hydraulic tongs should be backed up with a safety device able to withstand the full torque of the power tool.

\section{Kelly Bushings, Rotary Tables, and Machine/Equipment Guarding}

All belts, gears, shafts, pulleys, sprockets, spindles, drums, flywheels, or other reciprocating or rotating parts, with the exception of the kelly and the cathead, should be guarded by a guard of sufficient strength to prevent any person from coming in contact with them, unless they are guarded by location [73]. The kelly bushing should be guarded when the outer and/or upper exposed surface(s) have corners, bolts, grabs, handles, "J" hooks, or other projections that are likely to catch or snag employees or their clothing or ropes, lines, hoses, chains, and similar equipment.

Rotary tables should have a substantially constructed metal guard adequately covering the outer edge of the table and extending downward to completely cover all the exposed rotating side of the table including the pinion gear [73]. All rotary table gears in motion should be enclosed with a substantially constructed metal guard.

- All sprockets and power-driven chains (except spinning chains) should be enclosed to prevent accidental contact of employees with the moving parts.

o Guards should be constructed of heavy metal, strong enough to withstand the impact of a broken flying chain, and should be adequately secured in place. 
o Lag screws, spikes, or nails should not be used as the primary means of securing guards in place.

Rig machinery should not be operated without all guards properly maintained and in position, except during maintenance, repair, or rig-up work or when limited testing is being performed by a qualified person.

No employee should clean or lubricate any machinery where there is danger of contact with a moving part until such machinery has been stopped, deenergized, tagged, and a safety lock installed.

Any counterweight above the derrick floor when not fully enclosed should be directed away from the working surfaces or be guarded.

\section{Safe Work Practices}

\section{General}

Alcohol, drugs, or other intoxicants should not be permitted on the well site, and employees should not be allowed to work while intoxicated or under the influence of drugs.

The offgoing driller should inform the oncoming driller of any special hazards or ongoing work that may affect the safety of the crew. Oncoming tour employees should be alerted by the driller to ongoing work that could affect their safety.

Firefighting equipment should not be tampered with and should not be removed for other than the intended firefighting purpose or for servicing.

If lubrication fittings are not accessible with guards in place, machinery should be stopped for oiling and greasing.

Rigging equipment for material handling should be checked prior to use on each shift and as necessary during its use to ensure that it is safe. Defective rigging equipment should be removed from service.

Combustible materials, such as oily rags and waste, should be stored in covered metal containers. The contents should be disposed of daily.

\section{Housekeeping}

Good housekeeping is the first prerequisite of accident prevention and should be a primary concern of all supervisors and workmen. An excessively littered or dirty work area should not be tolerated as it constitutes an unsafe, hazardous condition of employment.

- The area around the base of the derrick ladder should be kept clear to provide unimpeded access to the ladder.

o Work areas and walkways should not be obstructed. 
o The rotary table of the rig floor should be kept picked up and free of undue accumulation of oil, water, ice, or circulating fluids.

Bagged materials should be stacked by stepping back the layers and cross-keying the bags at least every 10 bags high. Noncompatible materials should be segregated in storage.

\section{Hoisting and Rotary Operations}

Drillers should never engage the rotary clutch without watching the rotary table. The rotary clutch should not be engaged until the rotary table is clear of personnel and material.

Unless the drawworks is equipped with an automatic feed control, the brake should not be left unattended without first being tied down. Except during drilling, drawworks controls should not be left unattended while the hoisting drum is in motion.

Drill pipe or casing should not be picked up suddenly--a sudden jerk may cause the bottom end to whip about, endangering employees working on the floor.

The driller should never begin hoisting drill pipe until he has ascertained that the pipe is latched in the elevator or the derrickman has signaled that he may safely hoist the drill pipe.

When visibility on the rig floor is obscured, no worker should be required or permitted to work on the rig floor while the rotary table is in motion.

During instances of unusual loading of the derrick or mast, such as when making any unusually hard pull, only the driller or other essential supervisory personnel should be on the rig floor and no one should be in the derrick or mast.

The brakes on the drawworks of every drilling rig should be tested by each driller when he comes on shift to determine whether they are in good order, and brakes should also be examined at weekly intervals by the tool pusher or other person authorized by him.

A hoisting line with a load imposed should not be permitted to be in direct contact with any derrick member, stationary equipment, or material in the derrick unless specifically designed/intended for line contact.

Workers should never stand near the well bore whenever any wire line device is being run.

Hoisting control stations should be kept clean and controls labeled as to their function. 


\section{Riding Hoisting Equipment}

Employees should not be permitted to ride the traveling block or elevators except in an emergency and then they should:

o Wear an approved safety belt with appropriate lanyard and safety attachment anchored and adjusted to prevent a fall of more than 5 feet.

o Have the full and undivided attention of the employee operating the hoisting equipment. The operator should be a trained and competent person.

The catline should not be used as a personnel carrier except under emergency conditions; the person operating the cathead should be fully trained and competent.

In an emergency, workers should not slide down any pipe, kelly hose, cable, or rope line other than the escape line and buggy.

In an emergency, an injured worker may be lowered from the derrick by means of the traveling blocks or catlines, in which case the rotary table should be stopped. An experienced employee should operate the controls. Approved fall protection should be provided and used.

\section{Catline Operations}

An experienced worker should attend the controls while a manually operated cathead is in use and should stop the rotation of the cathead promptly in case of an emergency. The cathead operator should check the kill switch at the cathead position before using the catline. The kill switch should be clearly labeled.

Operators of manually operated catheads should keep their operating area clear at all times and should keep that portion of the catline not being used coiled or spooled. They should never be permitted to stand within the catline coil. The operator should not use more wraps than necessary to pick the load--the heavier the load, the more wraps needed. No more than a single layer of wrap should be permitted on the cathead.

Precautions should be taken to prevent entanglement of other lines with a line in use on a cathead. Personnel should not stand near, step over, or go under a caule or catline while it is under tension.

A line should not be left wrapped on or in contact with an unattended, manually operated cathead. Catlines should not be wrapped around the cathead until the load has been secured at the rigging end.

A splice should not be allowed to come in contact with the friction surface of a cathead. It can easily grab the rotating head. Wire line should not be used on a mechanical cathead. 
No part of a rope being used on a cathead should be touched except the free end. Catlines should not be wrapped around any portion of an employee's body. The tight line should not be touched for the purpose of guiding or removing fouled loops. The engine clutch should be disengaged before removing fouled rope.

Employees rigging loads on catlines should:

o Keep out from under the load

- Keep fingers and feet where they will not be crushed

- Be sure to signal clearly when the load is to be picked

- Use standard visual signals only and not depend on shouting to coworkers

o Make sure the load is properly rigged, since a sudden jerk in the catline will shift or drop the load.

\section{Pipe Handling}

Pipe should be loaded and unloaded, layer by layer, with the bottom layer pinned or blocked securely on all four corners. Each successive layer should be effectively chocked or blocked.

During loading, unloading, and transferring of pipe or other similar tubular material (rolling stock), workers should not be permitted on top of the load. Employees should not be permitted to go between pipe racks and a load of pipe during loading, unloading, and transferring operations. Boomers should not be released from trucks loaded with pipe until the trucks are in position and all employees have been informed that the offloading is to begin. Pipes should be loaded on or unloaded from trucks one layer at a time.

Pipe or casing should be rolled from the ends or from behind in order to get out of the way if the joint gets out of control. Employees should never attempt to stop rolling pipe or casing--they should be instructed to stand clear and get out of the way. To prevent incidents of finger wounds from sharp pipe threads or wickers, pipe threads should be cleaned with a brush.

Slips are heavy; slip handles should be used to lift and move slips. Employees should not be permitted to kick slips into position. Rat-and mouseholes should be kept covered when not occupied by the kelly or pipe joint.

When pipe is hoisted, especially during tripping operations, floorhands should not stand where the bottom end of the pipe can whip and strike them. Employees should be instructed to never turn their backs on pipe being tailed to the rotary table.

Pipe stored on racks or catwalks should be chocked to prevent rolling. 
Subs should be screwed completely into and made up tightly to the drill collars before the collars are lifted.

Employees should not be permitted to work immediately below pipe stored on the inclined ramp. All rigging and pipe handling should be performed from above where the employee is not exposed to falling or tipping pipe. Pipe hoisting lines should be properly attached to the joint of pipe to be lifted.

\section{Derrick Operations}

The derrick climber should be used when climbing the derrick. Derrickmen should be tied off or otherwise protected from falling whenever working from an unguarded platform.

The pipe elevators or traveling blocks are not to be used as a means of access to the derrick platforms.

The safety buggy and escape line should be checked by the derrickman prior to each tripping operation.

A means, such as a pipe hook or tag line, should be available for use by the derrickman to assist in maneuvering, stacking, and securing pipe in the derrick. If pipe hooks are used above the derrick floor, then the pipe hook should be secured to the derrick in a manner that will prevent the hook from falling.

All stands of pipe and drill collars racked in a derrick should be secured with rope or otherwise adequately secured.

An adequate horizontal supporting member should be provided in the derrick with each end secured to and on the outside of adjacent derrick legs. The stands of pipe and drill collars should be tied to the horizontal member unless the derrick girts are of adequate strength to be used for that purpose without being broken, permanently bent, or otherwise damaged, or unless other adequate provisions are made for securing the pipe and drill collars.

Drill pipe, collars, or tubing should be racked to safely distribute the load in the finger boards.

Whenever drill pipe, drill collars, or tubing are racked in the derrick, provision should be made for drainage of any fluids from the pipe stands. A drain pan should be installed on the derrick floor pipe rack into which the drill pipe and drill collars can drain.

Tools, derrick parts, or materials of any kind should not be thrown from any point above the first girt of a derrick. A handline should be used to lower the item to the level below. A canvas bucket should be used as a hoisting container for bolts or other small items. Tools, equipment, or materials of any kind should not be left unsecured in or on a derrick 
where they may become accidentally dislodged. Tools or other materials should not be carried up or down a ladder unless properly secured to the body, leaving both hands free for climbing.

The derrickman should ensure that the elevators are properly clamped onto all pipe joints prior to signaling the driller to engage the load.

8. Making and Breaking Joints

Tongs should be used for the initial making up and breaking of the joint. The rotary table should not be used for the initial breaking of a joint.

Employees engaged in making or breaking joints should not be permitted to stand within the arc of the tong handles when the tong pull 1 ine is tensioned. Employees should handle the tongs only by the appropriate hand les.

Employees should be trained in the safe use of spinning chains. Spinning chains should not be handled near the rotary table while it is in motion. Workers should not place the chain on the joint of pipe in the mousehole while the rotary table is in motion. Spinning chain should not be permitted to lodge in the threaded area of the pipe joint. Damaged, torn, or loose clothing should not be worn during spinning chain operations. 


\section{REFERENCES}

1. Baker, R. Primer of Oil Well Drilling. Austin, TX: Petroleum Extension Service, University of Texas at Austin. 1979. 94 pp.

2. Criteria for a Recommended Standard-Occupational Exposure to Hydrogen Sulfide. DHHS (NIOSH) Publication No. 77-158. US Department of Health and Human Services, Public Health Service, Centers for Disease Control, National Institute for Occupational Safety and Health. 1977. 149 pp.

3. Pettigrew G.L. Preliminary Report on Hydrogen Sulfide Exposure in the Oil and Gas Industry. Dallas, TX: US Department of Health, Education, and Welfare, Public Health Service, Dallas Regional office, 1976, 4 pp.

4. Adams N.; Ingram, L.; Carter, D. $\mathrm{H}_{2} \mathrm{~S}$ Detection and Protection. Pet Eng 51(11):26, 28 . 1979 .

5. The Killer $\mathrm{H}_{2} \mathrm{~S}$. Alberta, Canada, Workers Health, Safety and Compensation, Occupational Health and Safety Division. 1974. 14 pp.

6. Carter, D.R.; Adams, N.J. Hydrogen Sulfide in the Drilling Industry, in Proceeding of the 4th Deep Drilling and Production Symposium; Amarillo, TX; April 1-3, 1979. Dallas, TX: Soc of Pet Eng of AIME. 1979. pp 123-35.

7. $\mathrm{H}_{2} \mathrm{~S}$ Detection and Production--Part 7. Metallic Corrosion From $\mathrm{H}_{2} \mathrm{~S}$. Pet Eng 52(7):64, 66, 70, 73. 1980 .

8. US Land Drilling Contractors, in 1980 Land Drilling and Oilwell Servicing Contractors Directory, 7 ed. Tulsa, OK: Penn Well Publishing Co. 1980. pp 15-92.

9. Industrial Facilities Listing, $0 i 1$ and Gas Well Drilling, SIC 1381. Compiled by NIOSH, from Dun and Bradstreet Industrial Profile. Cincinnati, OH: US Department of Health and Human Services, Centers for Disease Control, National Institute for Occupational Safety and Health. January 1981. (unpublished).

10. Pearson G.W. Safety Information Profile 0 il and Gas Field Operations, DHHS (NIOSH) Contract 210-80-0042. Morgantown, WV: US Department of Health and Human Services, Public Health Service, Centers for Disease Control, National Institute for Occupational Safety and Health. 1981 . 84 pp. (unpublished).

11. Rotary-rig Activity by States. Oil Gas J 79(4):140. 1981. 
12. Wiley C.L. 29th Annual Reed Rock Bit Rotary Rig Census. Drilling 42(13): 51-78. 1981 .

13. No Letup in Sight for Big Surge of Drilling in U.S. Oil Gas J 78(42): 93-97. 1980 .

14. Statistics--Hughes Rig Count. Oil Gas J 79(27):208. 1981.

15. McCaslin J.C. 1980--Biggest Drilling Year Since 1957. 0il Gas J $78(4)$ : $125-30.1980$.

16. Well Forecast for 1975. Oil Gas J 73(4):110. 1975.

17. We11 Forecast for 1976. Oil Gas J 74(4):114. 1976.

18. Well Forecast for 1978. Oil Gas J 76(5):137. 1978.

19. Well Forecast for 1979. 0il Gas J 77(5):125. 1979.

20. U.S. Department of Labor, Bureau of Labor Statistics. Occupational Injuries and Illnesses in the United States by Industry, 1972. Washington, DC: 1972. p 16.

21. U.S. Department of Labor, Bureau of Labor Statistics. Occupational Injuries and Illnesses in the United States by Industry, 1973. Wa shington, DC: 1973. P 13.

22. U.S. Department of Labor, Bureau of Labor Statistics. Occupational Injuries and Illnesses in the United States by Industry, 1974. Washington, DC: 1974. p 19.

23. U.S. Department of Labor, Bureau of Labor Statistics. Chartbook on Occupational Injuries and Illnesses in 1975. Washington, DC: $1975 . p$ 16.

24. U.S. Department of Labor, Bureau of Labor Statistics. Chartbook on Occupational Injuries and Illnesses in 1976. Washington, DC: 1976. p 19.

25. U.S. Department of Labor, Bureau of Labor Statistics. Occupational Injuries and Illnesses in the United States by Industry, 1976. Washington, DC: 1976. p 25.

26. U.S. Department of Labor, Bureau of Labor Statistics. Occupational Injuries and Illnesses in the United States by Industry, 1977. Washington, DC: 1977. p 24.

27. U.S. Department of Labor, Bureau of Labor Statistics. Occupational Injuries and Illnesses in the United States by Industry, 1978. Washington, DC: 1978. p 23. 
28. U.S. Department of Labor, Bureau of Labor Statistics. Occupational Injuries and Illnesses in the United States by Industry, 1979 and 1980. Washington, DC: 1980. p 17.

29. American Petroleum Institute. Total Wells Drilling in the United States 1973. Quarterly Review of Drilling Statistics for the United States $\operatorname{VII}(4): 15.1974$.

30. American Petroleum Institute. Total Wells Drilling in the United States 1974. Quarterly Review of Drilling Statistics for the United States VIII(4):15. 1975.

31. American Petroleum Institute. Total Wells Drilling in the United States 1975. Quarterly Review of Drilling Statistics for the United States IX(4):15. 1976.

32. American Petroleum Institute. Total Wells Drilling in the United States 1976. Quarterly Review of Drilling Statistics for the United States X(4):15. 1977 .

33. American Petroleum Institute. Total Wells Drilling in the United States 1977. Quarterly Review of Drilling Statistics for the United States XI(4):15. 1978 .

34. American Petroleum Institute. Total Wells Drilling in the United States 1978. Quarterly Review of Drilling Statistics for the United States XII(4):15. 1979 .

35. Texas Workers' Compensation State Board of Insurance Raw Data Cards--Classification Code 6202. Austin, TX: 1971-1979.

36. McGee, E. International Association of Drilling Contractors. Unpublished Report. Houston, TX: February 1982. 1 p.

37. American National Standard: Method of Recording and Measuring Work Injury Experience, ANSI 216.1-1967. New York, N.Y. American National Standards Institute Inc. 1967.

38. International Association of Drilling Contractors. Injury Statistics Report for 1975. Houston, TX: 1976. 12 pp. (unpublished).

39. International Association of Drilling Contractors. Injury Statistics Report for 1976. Houston, TX: 1976. 14 pp. (unpublished).

40. International Association of Drilling Contractors. Charlie Report for 1977: Drilling Industry Injury Statistics. Houston, TX: 1977. 14 pp. (unpublished).

41. International Association of Drilling Contractors. Charlie Report for 1978: Drilling Industry Injury Statistics. Houston, TX: 1978. 16 Pp. (unpublished). 
42. International Association of Drilling Contractors. Charlie Report for 1979: Drilling Industry Injury Statistics. Houston, TX: 1980. $13 \mathrm{pp}$. (unpublished).

43. International Association of Drilling Contractors. Charlie Report for 1980: Drilling Industry Injury Statistics. Houston, TX: 1981. 23 PP. (unpublished).

44. U.S. Department of Labor, Bureau of Labor Statistics. Occupational Safety and Health Statistics--Concepts and Methods, Report No. PL 518. Washington, DC: 1978. pp i-5.

45. U.S. Department of Labor, Bureau of Labor Statistics, Supplementary Data System (SDS). Unpublished Accident and Injury Data for 1976-1979.

46. Occupational Safety and Health Administration. OSHA Accident Investigation Reports of $0 i 1$ and Gas Drilling Accidents Compiled from Seven Reporting Regions. 1976-81.

47. Cloe, W.W. Selected Occupational Fatalities to 0il/Gas Well Drilling Rigs as Found in Reports of OSHA Fatality/Catastrophe Investigations, NTIS 80-226939. Springfield, VA: US Department of Commerce, National Technical Information Services. 1980. 74 pp.

48. Class 4-03 1979 Fatals Investigated (January 1 to December 31). Alberta, Canada, Workers Health, Safety and Compensation, Occupational Health and Safety Division, Research and Education Branch. 1979. 3 pp.

49. Class 4-03 1980 Fatals Investigated (January 1 to December 31). Alberta, Canada, Workers Health, Safety and Compensation, Occupational Health and Safety Division, Research and Education Branch. 1980. 2 pp.

50. Panov, G.E.; Artamonov, V.S. [Investigation of the Causes of Traumatism in Drilling Deep Wells, Using the Filming Method.] Izv Vyssh Uchebn Zaved Neft i Gas (5):21-24. 1979. (Rus).

51. Panov, G.E.; Polosenova, N.S. [Nature of Errors and Mistakes Committed by Workers Engaged in Drilling Boreholes.] Izv Vyssh Uchebn Zaved Neft i Gas (6):19-22. 1977. (Rus).

52. Safety and offshore 0il. Washington, DC: National Academy Press. 1981. $331 \mathrm{pp}$.

53. Whitney S.H. Analysis of Drilling Rig Accidents, in Safety and offshore Oil--Background Papers of the Committee on Assessment of Safety of OCS Activities. Washington, DC: National Academy of Sciences. 1981. pp 155-67.

54. Webster's Third New International Dictionary. Springfield, MA: G.C. Merriam Co. 1976. 
55. McIntosh, T.S. How Dangerous is offshore Drilling? Ocean Ind $16(8): 17,20,22,24,138,141-44,146.1981$.

56. National Council of Compensation Insurance. Workers' Compensation Experience--Code 6235. New York, NY: 1972-1978. unpaginated.

57. National Safety Council. Accident Facts, 1980 ed. Chicago, IL: 1981. $96 \mathrm{pp}$.

58. McNair, W.L.; Fusco, T.A. Training Rig Electricians. Drilling 42(10):7-81. 1981.

59. Pickard, W.; Williams, B.; Dunn, R.; Littlefield, B.; O'Brien, T.B. Manpower Needs. Drilling-DCW 41(5):46. 1980.

60. Gassett, P.L. Drilling Today--A Candid Look at Costs, Training, Tech nolngy. World 0i1 191(5):69-73. 1980.

61. Safety in the oil Fields, Report of a study for The Government of Alberta, Division of Occupational Health and Safety (Sep 14-Dec 15, 1979). Alberta, Canada, Workers Health, Safety and Compensation, Occupational Health and Safety. 1979. 52 pp.

62. Chase, W.; Brand, J.; Gibeau, C.; Gaudette, L. Lost Time Accidents in Drilling and Related Industries Alberta 1977. Alberta, Canada, Workers Health, Safety and Compensation, Occupational Health and Safety Division, 1979. 60 pp.

63. Hinze, J. Turnover, New Workers, and Safety. J Const Div (ASCE) 104(CO4):409-17. 1978.

64. Whitman, J.E. Survey of Lost Time Occupational Injuries Occurring on Conoco Operated Properties in ocs Waters, in Safety and offshore oil--Background Papers of the Committee on Assessment of Safety of OCS Activities. Washington, DC: National Academy of Sciences. 1981. PP 169-79.

65. Grisham, J. Floorhand School Reaps Benefits. Drill Contract (Aug): 66-67. 1980 .

66. Cromwe11, V.P. Lafayette Floorhand School Opens. Drill Contract (Dec):68, 70-71. 1980.

67. Parker Drilling Goes Mobile with Training Center on Wheels. Drilling 42(10):USA14-15. 1981.

68. U.S. Department of Labor. Construction Industry Standards-29 CFR 1926/ 1910. Occupational Safety and Health Administration. 1979. 618 pp. 
69. The Petroleum and Natural Gas Safety Regulations, Alberta Regulation 270/76 Effective December 1, 1976, in The Occupational Health and Safety Act. Alberta, Canada, Workers Compensation Board, Occupational Health and Safety, 1976, pp 141-80

70. U.S. Department of Labor. General Industry Standards - 29 CFR 1910. Occupational Safety and Health Administration. 1978. 820 pp.

71. Working in Confined Spaces, Criteria for a Recommended Standard. DHEW (NIOSH) Publication No. 80-106. U.S. Department of Health, Education and Welfare, Public Health Service, Centers for Disease Control, National Institute for Occupational Safety and Health. 1979. 68 pp.

72. American Petroleum Institute. API Recommended Practice for Safe Drilling of Wells Containing Hydrogen Sulfide, API RP 49. Dallas, TX: 1978. $11 \mathrm{pp}$.

73. State of Utah Occupational Health and Safety Rules and Regulations Oil, Gas Geothermal and Related Service Standards. Utah State Industrial Commission, Occupational Safety and Health Administration. 1980. 62 pp.

74. American Petroleum Institute. API Recommended Practice for Occupational Safety and Health for Oil and Gas Well Drilling and Servicing Operations, API RP 54. Dallas, TX: 1981. 55 pP.

75. Petroleum Safety Orders-Drilling and Production, Subchapter 14 of Industrial Regulations, Chapter 4 of California Administrative Code, Title 8. North Highlands, CA: California Division of Industry Safety, Department of General Services, Office of Administrative Hearings. 1952.

76. American Petroleum Institute. API Recommended Practice for Blowout Prevention Equipment Systems, API RP 53. Dallas, TX: 1978, 58 pP

77. State of Alaska Petroleum Occupational Safety and Health Standards--Subchapter 8. Juneau, AK: Department of Labor, Division of Occupational Safety and Health. 1978. $110 \mathrm{pp}$.

78. State of Wyoming Occupational Health and Safety Rules and Regulations for $0 i 1$ and Gas Well Drilling, Effective February 8, 1980. Cheyenne, WY: The State of Wyoming Health and Safety Administration. 1980. 54 pp.

79. American Petroleum Institute. API Specification for Steel Derricks (Including Standard Rigs), API Std. 4A. Dallas, TX: 1967.

80. American Petroleum Institute. API Specification for Portable Masts, API Std 4D. Dallas, TX: 1967.

81. Baumeister, T.; Avallone, E.A.; Baumeister, I., III, (eds). Mark's Standard Handbook for Mechanical Engineers, ed 8. New York, NY: McGraw-Hi 11 Book Co. 1978. pp 12-20. 
82. American Petroleum Institute. API Specification for Drilling and Well Servicing Structures, API Spec. 4E. Dallas, TX: 1974.

83. The American Society of Mechanical Engineers. ASME Boiler and Pressure Vessel Code. New York, NY: 1977.

84. Petroleum Extension Service, The University of Texas at Austin. Unit I: The Rig and Its Maintenance. Rotary Drilling Series. Austin, TX: 1980. 12 Lessons.

85. American Petroleum Institute. API Recommended Practice on Application, Care, and Use of Wire Rope for Oil Field Service, API RP 9B. Dallas, TX: 1980 .

86. State of Michigan Safety Standards Part 57. Oil and Gas Drilling and Servicing Operations, Lansing, MI: Department of Labor, General Industry Safety Standards Commission. 1979. 15 pp.

87. Outer Continental Shelf Standard: Safety Requirements for Drilling Operations in a Hydrogen Sulfide Environment. Reston, VA: Geological Survey. 1976. $20 \mathrm{pp}$.

88. American Petroleum Institute. API Specification for Rotary Drilling Equipment, API Spec 7. Dallas, TX: 1979.

89. American National Standard: Safety Standard for Mechanical Power Transmission Apparatus, ANSI B15.1-1972. New York, NY: American National Standards Institute Inc. 1972. 12 pp.

90. National Fire Protection Association. National Electrical Code, NFPA70-1981. Quincy, MA: 1981.

91. American Petroleum Institute. Glossary of Drilling--Fluid and Associated Terms, API Bulletin No. D-11. Dallas, TX: 1979. 
APPENDIX A

REVIEW OF ACCIDENT CASE HISTORIES 
APPENDIX A

REVIEW OF ACCIDENT CASE HISTORIES

Accident statistics from national and state surveys that demonstrate the high injury incidence and severity rates of the oil and gas well drilling industry (SIC 1381) were presented in Chapter III. A tabulation of 738 accident reports compiled from Federal and state osHA investigations, workers' compensation reports, published accident case bistories [10, 46-49], and company records of incidents that occurred during drilling operations is divided according to whether the employees were injured performing tasks that are unique to drilling operations or are typical of accidents associated with numerous other occupations; e.g., construction, manufacturing, or mining.

\section{A. Accidents Unique to Drilling Operations}

Injuries that result from hazards unique to oil and gas well drilling operations can be broadly classified into two major categories: those injuries incurred from task-specific accidents and those injuries incurred during more catastrophic events. Of the 33 accident case histories that follow, 27 are representative of injuries sustained by workers performing tasks unique to well drilling operations and 6 are representative of accidents common to many industries.

\section{Task-Specific Accidents}

The first category of accident case histories is representative of incidents that occurred during task-specific operations. This major category has been further subdivided into accidents that occurred during drilling operations, derrick tasks, and materials handing activities.

In many instances, the cited case histories depict accidents classifiable into more than one subcategory.

\section{a. Drilling Operations}

Drilling operations have been further categorized by the tools or equipment used in performing the task such as:

(1) Slips

Case No. 0355, 1979

Accident

\begin{tabular}{l} 
Type \\
\hline Caught \\
between
\end{tabular}

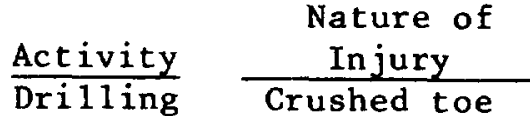

$$
\text { Injury }
$$

Crushed toe

\section{Equipment} or Too 1

slips and rotary table
Length of

Employment 
The rig crew was in the process of adding a length of drill pipe to the string. An employee was setting the slips into the master bushing-rotary table to suspend the drill string. As the slips were inserted, the employee's foot slipped into the opening and was caught between the slip and the rotary table; one of his toes was crushed.

\section{Comments:}

Surfaces wet with water and/or circulating fluids can be expected to be slippery. Handling heavy items on slippery surfaces can result in slips and falls. Where this hazard is compounded by the presence of moving equipment (rotary tables, kelly bushings), the potential for injury is increased.

Case No. 0654, 1977

\begin{tabular}{|c|c|c|c|c|}
\hline $\begin{array}{l}\text { Accident } \\
\text { Type }\end{array}$ & Activity & $\begin{array}{l}\text { Nature of } \\
\text { Injury }\end{array}$ & $\begin{array}{l}\text { Equipment } \\
\text { or Tool }\end{array}$ & $\begin{array}{l}\text { Length of } \\
\text { Employment }\end{array}$ \\
\hline $\begin{array}{l}\text { Caught in } \\
\text { or between }\end{array}$ & Drilling & $\begin{array}{l}\text { Amputation } \\
\text { of leg }\end{array}$ & $\begin{array}{l}\text { Slips, drill } \\
\text { pipe, and } \\
\text { tongs }\end{array}$ & N/A 1 \\
\hline
\end{tabular}

The rig crew was "breaking out" the drill pipe. The initial step involves using the pipe tongs to "break out" the torqued drill pipe coupling. The tongs were positioned as close to the rotary table as possible to avoid bending the drill pipe. Mechanical forces were applied to the tongs by the cathead-chain system typical of drilling rigs. Once the coupling was "broken," the joint had to be raised a few feet prior to "spinning out" the threaded portion. The tongs were left in place with the jaws unclamped.

An employee placed a foot on the slips to hold them in place while a driller hoisted the drill string. The pipe joint was apparently spun out before the slips were set, and the employee's foot became caught by a slip handle. His leg was severed below the knee when it was squeezed between the drill pipe and a breakout tong line.

\section{Comment s:}

This accident was directly attributable to the premature spinning of the pipe by the driller. The accident potential was further increased by the presence of machinery and equipment (tongs) not required for the task being performed (spinning). The pressure on the crew to perform all tasks as rapidly as possible further compounds accident probabilities. The time pressure to "make hole" could be responsible for the lack of sufficient communication between crew members rushing to complete individual tasks.

\footnotetext{
Not available.
} 
(2) Tongs

Case No. 0552,1975

$\frac{\begin{array}{c}\text { Accident } \\ \text { Type }\end{array}}{\text { Struck by }} \frac{\text { Activity }}{\text { Drilling }} \frac{\begin{array}{c}\text { Nature of } \\ \text { Injury }\end{array}}{\text { Fatal }} \frac{\begin{array}{c}\text { Equipment } \\ \text { or Tool }\end{array}}{\text { Tongs }} \frac{\begin{array}{c}\text { Length of } \\ \text { Employment }\end{array}}{\text { N/A }}$

The rig crew was "breaking out" a connection in the drill string. A pipe tong was attached to the drill pipe and connected to a backup post with 5/8-inch wire rope. The rotary table was engaged in reverse to supply the torque necessary to "break" the connection. The employee was holding the jaws of the tongs when the safety line snapped, causing the backup tong handle to strike him. The employee's chest was crushed by the impact from the tong handle.

Comments :

Two factors contributed to this fatal accident. Tongs are routinely powered by the catheads on the drawworks. A safety line's breaking strength is selected to be compatible with the maximum forces that can be generated by the cathead. Rotary tables deliver the force necessary to turn the drill string. When the rotary table is used to torque the coupling, there is no method used to determine if the safety factor and/or breaking strength of the snub line is being exceeded. NOTE: The breaking strength of new 5/8-inch wire rope is approximately 30,000 pounds.

The second contributing factor of this accident was the position of the deceased when the force was applied to the tongs. If the employee had not been in the path of travel of the pipe tong, he would not have been killed; the accident would have been a "near miss."

Case No. 0633, 1976

Accident

$\frac{\text { Type }}{\text { Struck by }} \frac{\text { Activity }}{\text { Drilling }}$ and caught

between

$\begin{array}{ccc}\begin{array}{c}\text { Nature of } \\ \text { Injury }\end{array} & \begin{array}{c}\text { Equipment } \\ \text { or Tool }\end{array} & \begin{array}{c}\text { Length of } \\ \text { Employment }\end{array} \\ \text { Tongs } & \text { 2 days }\end{array}$

The rig crew was "breaking out" a connection in the drill string. The worker had clamped the break out tong to the drill pipe. The driller engaged the rotary table in reverse to supply the force necessary to disengage the coupling. The $5 / 8$-inch wire rope safety line for the tong was connected to the derrick structure with one cable clamp. This connection failed, allowing the tong handle to first strike the employee (with great force) and then pin him against the brake handle. 
Comments:

This fatal accident could have been prevented if the proper number of cable clamps had been used. Additionally, tongs are normally powered by the catheads on the drawworks. Rotary tables deliver an undetermined amount of force to the tong system. This situation lends itself to equipment failure.

of equal importance in the prevention of accidents involving safety line failure is allowing the positioning of employees in the tong handle's direction of travel. This positional hazard could be improved by employee training.

Case No. 0045,1979

$\begin{array}{lllll}\begin{array}{c}\text { Accident } \\ \text { Type }\end{array} & \text { Activity } & \begin{array}{c}\text { Nature of } \\ \text { Injury }\end{array} & \begin{array}{c}\text { Equipment } \\ \text { or Tool }\end{array} & \begin{array}{c}\text { Length of } \\ \text { Employment }\end{array} \\ \begin{array}{l}\text { Caught } \\ \text { between }\end{array} & \text { Drilling } & \begin{array}{c}\text { Fractured } \\ \text { finger }\end{array} & \begin{array}{c}\text { Tongs and } \\ \text { drill pipe }\end{array} & 1 \text { week }\end{array}$

The rig crew was pulling the drill pipe out of the hole. A worker placed his hand in the wrong position on the tongs and caught his finger between the drill pipe and the tong head as he positioned the tongs on the pipe. The employee sustained a fractured finger as well as multiple lacerations to other fingers.

Comments:

Tongs are equipped with handles and hand guides. Proper training and guidance in their operation could effectively lower the frequency of incidents involving tong latchings.

(3) Elevators

Case No. 0488,1978

$\frac{\begin{array}{c}\text { Accident } \\ \text { Type }\end{array}}{\text { Struck by }} \frac{\text { Activity }}{\text { Drilling }} \frac{\begin{array}{c}\text { Nature of } \\ \text { Injury }\end{array}}{\text { Fatal }} \frac{\begin{array}{c}\text { Equipment } \\ \text { or Tool }\end{array}}{\begin{array}{c}\text { Elevator } \\ \text { and casing }\end{array}} \frac{\begin{array}{c}\text { Length of } \\ \text { Employment }\end{array}}{\text { N/A }}$

Two workers were in the process of wrapping rope around a steel casing that was in the well bore. Another casing was being hoisted to make a connection. One of the two workers had just walked under the elevated load when the elevator latch came open, dropping the 30-foot section of steel casing on his head and fatally injuring him.

Comments :

Examination of the elevator, which dropped the drill pipe, revealed that a safety chain had never been installed. The elevator did not 
have the double safety latch system or a safety chain and pin. Redundant safety mechanisms should be used to prevent accidents of this type.

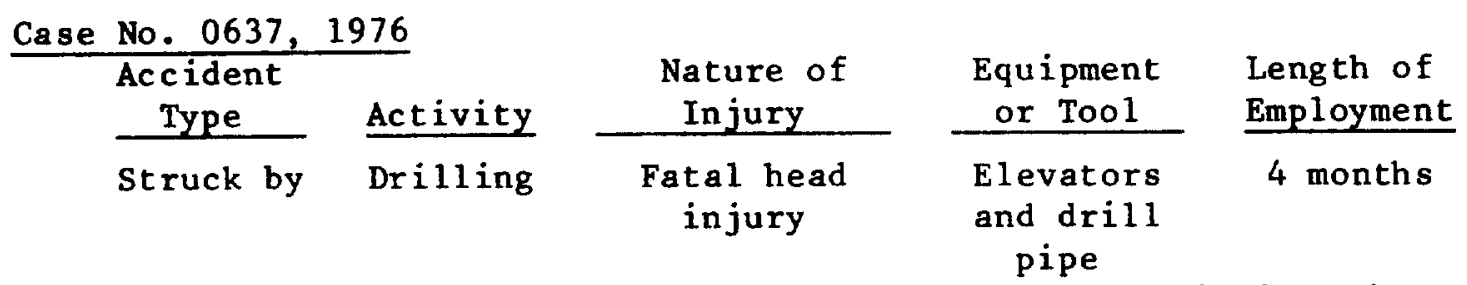

Drilling of the well had been completed and the drilling pipe was being removed. The procedure for withdrawing the drilling pipe was being followed. The elevators were attached to the belled portion of the drill pipe to bring each section of pipe ( 500 pounds) about 4 feet above the top of the drilling floor. The section was then clamped to hold the drill string in the well while the elevated connection was broken loose and the pipe spun-out from the pipe remaining in the well hole. To facilitate movement, the bottom of the pipe was placed on a hook suspended from a pulley that rides on a cable stretched from the mast to a point beyond the pipe rack. As the pipe was lowered, the small end of the pipe moved out toward the pipe rack along the cable.

When the accident occurred, a section of pipe had been broken loose and was being rigged for lowering to the pipe racks. The cables above the hoisting block became twisted, turning the elevators 180 degrees, as well as reversing their position, so that they were upside down when the top of the pipe reached the drilling floor. The floorhands unlatched the elevators but were unable to remove the elevators. When they attempted to relatch the elevators, the driller, believing the elevators had been latched, rehoisted the pipe, which was raised about 20 feet above the drilling floor. At this point the elevators opened and the section of drill pipe fell to the rig floor, striking an employee on the head.

\section{Comments :}

The driller was unable to see the operation (1atching the elevator) from his control station. He hoisted the drill pipe without receiving a signal other than a noise he interpreted as the latching of the elevators. Clear hoisting signal methods, similar to those used in crane operations, could have prevented this accident--crane operators do not raise or move a load until signaled by a person designated as a signalman.

Case No. 0365, 1979

Accident

Type
$\begin{aligned} & \text { Caught } \\ & \text { between }\end{aligned}$ Drilivity $\quad \frac{\begin{array}{c}\text { Nature of } \\ \text { Injury }\end{array}}{\text { Crushed hand }}$

\begin{tabular}{|c|c|}
\hline $\begin{array}{c}\text { Equipment } \\
\text { or Too } 1\end{array}$ & $\begin{array}{l}\text { Length of } \\
\text { Employment }\end{array}$ \\
\hline $\begin{array}{l}\text { levator or } \\
\text { lril1 pipe }\end{array}$ & 5 weeks \\
\hline
\end{tabular}

dril1 pipe 
The crew was removing the drill pipe from the well bore and laying it down in the Vee-door. The pipe was suspended by the elevators. The bottom of the drill pipe was pushed/pulled by floorhands until it was suspended over the Vee-door. The driller then lowered the hoist along with the drill pipe and elevators. An employee unlatched the elevators (suspended out of plumb by the hoist), which then swung back and crushed his hand against the stand of pipe in the rotary.

Case No. 0048, 1979

\begin{tabular}{|c|c|c|c|c|}
\hline $\begin{array}{l}\text { Accident } \\
\text { Type }\end{array}$ & Activity & $\begin{array}{c}\text { Nature of } \\
\text { Injury }\end{array}$ & $\begin{array}{l}\text { Equi pment } \\
\text { or Tool }\end{array}$ & $\begin{array}{l}\text { Length of } \\
\text { Employment }\end{array}$ \\
\hline & Drilling & Mashed fingers & Elevator & 4 months \\
\hline
\end{tabular}

and caught

between

A derrickman was unlatching the elevators from the drill pipe when the elevator swung out, mashing his hand between the pipe and the elevator.

Comments:

Better supervision was needed in coordinating the drilling activity; i.e., employees on the derrick cannot be allowed to rush through tasks to keep up with floorhand operations.

(4) Catlines

Case No. 0658,1979

\begin{tabular}{|c|c|c|c|c|}
\hline $\begin{array}{l}\text { Accident } \\
\text { Type } \\
\end{array}$ & Activity & $\begin{array}{l}\text { Nature of } \\
\text { In jury }\end{array}$ & $\begin{array}{c}\text { Equi ipment } \\
\text { or Too } 1\end{array}$ & $\begin{array}{l}\text { Length of } \\
\text { Employment }\end{array}$ \\
\hline $\begin{array}{l}\text { Fal1 to } \\
\text { below }\end{array}$ & $\begin{array}{l}\text { Position- } \\
\text { ing stab- } \\
\text { bing board }\end{array}$ & Fractured leg & Catline & $\mathbf{N} / \mathbf{A}$ \\
\hline
\end{tabular}

A catline was being used to position a stabbing board on the derrick. The injured employee was guiding (hands on) the stabbing board into position. He was not wearing a safety belt or lanyard. The stabbing board jammed on the derrick, the catline broke, and the stabbing board and the employee fell.

The injured employee was saved from probable death by the driller who broke his fall by catching him. The driller sustained multiple fractured ribs from this accident.

Comment s:

This injury could have been prevented had the injured employee been wearing a safety belt. 
Case No. 0662, 1981

Accident

Type

Caught

between

and $\mathrm{fall}$

to below

\section{Activity \\ Dri11ing}

Nature of

In jury

Amputated hand; ruptured spleen
Equipment or Tool

Cathead or wire line
Length of

Employment

N/A

An employee was to run a $1 / 8$-inch wire rope through a pulley sheave located at the derrick runaround platform. The wire was to attach a geolograph, used to record drilling rates. The employee wrapped the wire rope around his hand and proceeded to climb the derrick.

The wire line became snagged in a space between the bottom plate and the clutch mechanism of the cathead. The line wound around the cathead and yanked the employee off the derrick; as he fell he struck a beam and ruptured his spleen. The wire line continued to wrap around the cathead until it became taut enough to amputate the employee's hand.

\section{Comments:}

The employee committed an unsafe act when he wrapped the wire around his hand to carry it up the derrick. Failure to instruct the employee in the safe procedures necessary to complete a task is the responsibility of management. (This was the first time the injured employee had performed this task. Furthermore, no one was stationed at the rig controls to stop the catheads in the event of an emergency.)

(5) Working surfaces

Case No. 0575, 1975

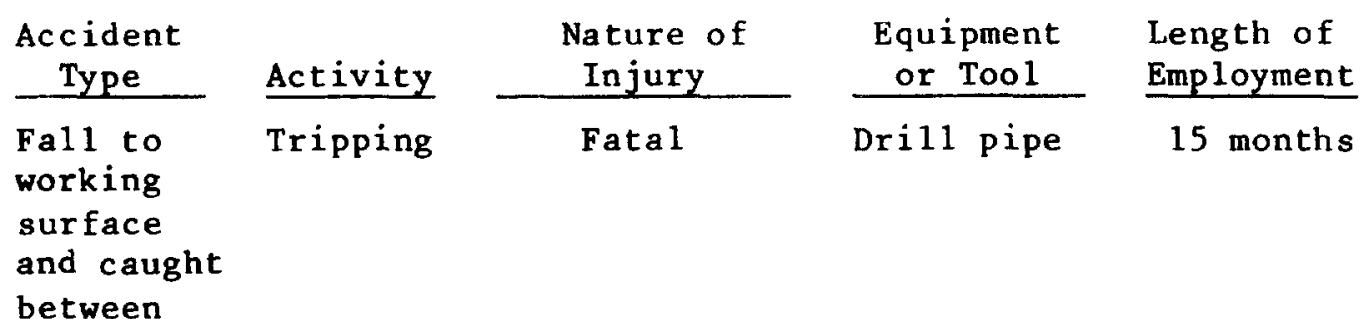

This crew had removed approximately 6,300 feet of drill pipe from the hole during the tripping operation. There were approximately 6,000 feet of "thribble" stands of drill pipe in the derrick pipe rack. Each "thribble" stand of pipe was approximately 94 feet in length. The crew had placed one stand of pipe from the offside rack in the hole. The derrickman was on the monkey board about 90 feet above the floor, the driller was at his control panel, and one floorhand had his back to the rotary table pulling the spinning chain from the cathead. The second floorhand was positioned near the rotary table, waiting to stab the next stand of pipe, while the motorman (the employee to be fatally 
injured) was in back of the offside pipe rack ready to tail the pipe in the hole. The driller raised the elevators to the monkey board level and stopped their travel while the derrickman loaded one of the two remaining stands of pipe from the offside rack. The driller then raised the stand of pipe approximately 18 inches above the floor. As the motorman attempted to tail the pipe, he slipped and wrapped both arms around the pipe. The pipe swung back in the direction of the stand of pipe, still in the offside rack, crushing his head between the two stands of pipe and fatally injuring him.

Case No. 0388,1979

\begin{tabular}{|c|c|c|c|c|}
\hline $\begin{array}{c}\text { Accident } \\
\text { Type }\end{array}$ & Activity & $\begin{array}{l}\text { Nature of } \\
\text { Injury }\end{array}$ & $\begin{array}{l}\text { Equipment } \\
\text { or Tool }\end{array}$ & $\begin{array}{l}\text { Length of } \\
\text { Employment }\end{array}$ \\
\hline $\begin{array}{c}\text { Fall to } \\
\text { below }\end{array}$ & Drilling & $\begin{array}{l}\text { Bruised chest } \\
\text { and rib cage }\end{array}$ & Cellar & 19 days \\
\hline
\end{tabular}

An employee had been working as a floorman for 19 days. He fell into an unguarded cellar under the rig substructure and bruised his chest and rib cage.

\section{Comments:}

Since the cellar was full of water and contained blowout prevention equipment, the potential existed for the employee to strike his head and drown while unconscious.

"Near-miss" accidents should serve as a warning. Open cellars should be guarded as a matter of standard operating procedure.

Case No. 0371,1979

\begin{tabular}{|c|c|c|c|c|}
\hline $\begin{array}{c}\text { Accident } \\
\text { Type }\end{array}$ & Activity & $\begin{array}{l}\text { Nature of } \\
\text { Injury }\end{array}$ & $\begin{array}{l}\text { Equipment } \\
\text { or Tool }\end{array}$ & $\begin{array}{l}\text { Length of } \\
\text { Employment }\end{array}$ \\
\hline $\begin{array}{c}\text { Fall to } \\
\text { below }\end{array}$ & N/A & Fractured rib & $\begin{array}{l}\text { Cellar } \\
\text { ladder }\end{array}$ & 1 month \\
\hline
\end{tabular}

A floorhand attempted to climb down a ladder into the cellar. His hand slipped and he fell into the cellar. He bruised his back and fractured a rib.

\section{Comments:}

Ladders entering cellar openings from above should be designed with adequate handrails above the openings. 
Case No. 0195,1979

$\begin{gathered}\text { Accident } \\ \text { Type }\end{gathered}$
Fall to $\frac{\text { Activity }}{\text { Drilling }} \frac{\begin{array}{c}\text { Nature of } \\ \text { Injury }\end{array}}{\text { Fractured foot }} \frac{\begin{array}{c}\text { Equipment } \\ \text { or Too1 }\end{array}}{\text { Mousehole }} \frac{\begin{array}{c}\text { Length of } \\ \text { Employment }\end{array}}{14 \text { years }}$

working

surface

The driller had pulled a joint of drill pipe out of the mousehole to add to the string when he stepped back into the mousehole. He fractured his foot.

Comments:

All holes in the floor of a drilling rig are potential hazards. They should be covered when not in use to prevent employees from stepping into them.

Case No. 0342, 1979

Accident

Type

Fall to

working

surface

$\frac{\text { Activity }}{\text { Driling }}$

\begin{tabular}{l}
$\begin{array}{l}\text { Nature of } \\
\text { Injury }\end{array}$ \\
\hline $\begin{array}{l}\text { Bruised hip } \\
\text { and strained } \\
\text { back }\end{array}$
\end{tabular}

\section{Equipment} or Too 1

Mousehole
Length of

Employment

1 month

A floorhand was helping another employee move a well head from the rig floor. He inadvertently stepped into the unguarded mousehole and fell. He sustained a bruised hip and pulled muscles in the lower back.

\section{Corments :}

When unoccupied, mouseholes and ratholes should be covered to prevent employees from accidentally stepping into them.

Case No. 0661,1979

\begin{tabular}{|c|c|c|c|c|}
\hline $\begin{array}{l}\text { Accident } \\
- \text { Type } \\
\end{array}$ & Activity & $\begin{array}{l}\text { Nature of } \\
\text { Injury }\end{array}$ & $\begin{array}{l}\text { Equipment } \\
\text { or Too } 1 \\
\end{array}$ & $\begin{array}{l}\text { Length of } \\
\text { Employment }\end{array}$ \\
\hline $\begin{array}{l}\text { Fall to } \\
\text { below } \\
\text { fluid }\end{array}$ & $\begin{array}{l}\text { Circulat- } \\
\text { ing in- } \\
\text { spection }\end{array}$ & Fatal drowning & Reserve pits & N/A \\
\hline
\end{tabular}

A fatal drowning occurred at a well drilling site when an employee slipped from a reserve pit embankment into the slurry. This incident occurred at night in an unlighted area. Employees were operationally required to be in the reserve pit area three or more times each shift. 


\section{Comments :}

Guardrails around the dike embankment were not in evidence, personal flotation lifejackets were not provided, and no water rescue devices were onsite.

\section{b. Derrick Tasks}

The derrickman on a well drilling operation performs his tasks from various elevated work platforms in the mast. He is exposed to falls while climbing the derrick ladder, working with the pipe stands, and moving from the ladder to his platform station. The derrickman is also exposed to crushing injuries from shifting stands of pipe and elevator latching tasks.

Adequate and continuous fall protection is a prerequisite for the safety of employees working on a derrick. Conditions beyond the control of the derrickman (wind, vibration, pipe movement) make even momentary unprotected exposures hazardous.

Case No. 0656,1977

\begin{tabular}{|c|c|c|c|c|}
\hline $\begin{array}{l}\text { Accident } \\
\text { Type }\end{array}$ & Activity & $\begin{array}{l}\text { Nature of } \\
\text { Injury }\end{array}$ & $\begin{array}{c}\text { Equipment } \\
\text { or Too } 1\end{array}$ & $\begin{array}{l}\text { Length of } \\
\text { Employment }\end{array}$ \\
\hline $\begin{array}{l}\text { Fall to } \\
\text { below }\end{array}$ & Tripping & Fatal & $\begin{array}{l}\text { Derrick } \\
\text { platform }\end{array}$ & 8 months \\
\hline
\end{tabular}

The drilling crew was completing the final phase of a tripping operation. Forty-seven hundred feet of drill pipe, in 60-foot increments, had been returned to the hole. The final stand of pipe would not go into the hole, so the driller replaced it in the derrick rack. When the kelly was reattached to the hoist, the driller raised the block. For unknown reasons, the block struck the derrick structure, causing the derrickman to fall 50 feet from the derrick platform to his death.

Further investigation revealed that the derrickman was observed earlier in the tripping operation wearing a safety belt. It was determined that the derrickman had removed his safety belt to leave the derrick platform. He either did not put it back on to assemble the single pipe stand or he had again removed it prior to descending the derrick ladder.

\section{Comments:}

In either instance, the wearing of a safety belt could have prevented this fatal accident. The transfer point from climbing the ladder (with a fall arresting device) to the donning of the safety belt and lanyard worn during the tripping operation leaves the employee at risk during this transfer period. The use of retractable lifelines would provide fall protection during tripping operations, as well as provide 
protected freedom of movement during transfer from the derrick ladder to the work station.

Case No. 0641,1972

$\begin{array}{ccccc}\begin{array}{c}\text { Accident } \\ \text { Type }\end{array} & \text { Activity } & \begin{array}{c}\text { Nature of } \\ \text { Injury }\end{array} & \begin{array}{c}\text { Equipment } \\ \text { or Tool }\end{array} & \begin{array}{c}\text { Length of } \\ \text { Employment }\end{array} \\ \begin{array}{c}\text { Fall to } \\ \text { below }\end{array} & \text { Tripping } & \begin{array}{l}\text { Multiple frac- } \\ \text { tures of legs } \\ \text { and arms; head } \\ \text { and interna } \\ \text { injuries }\end{array} & \begin{array}{l}\text { Derrick } \\ \text { ladder }\end{array} & \text { N/A } \\ & & & \end{array}$

The drilling crew was preparing to begin a tripping operation. The derrickman was climbing the derrick ladder when he lost his grip and fell about 70 feet to the derrick floor. He suffered multiple injuries.

\section{Comments :}

This accident could have been prevented by the wearing of a derrick climber or other fall arresting climbing device.

c. Materials Handling Activities

The most common type of accident that occurs in materials handling operations is the "caught between" situation; e.g., when a load is being handled and a finger or toe gets caught between two objects. Rolling stock (drill pipe and collars) can shift and/or fall from a pipe rack or truckbed. Employees must be alert to the hazards attendant to pipe handling and racking.

Vertical storage of drill pipe on the inclined ramp requires adequate slippage protection and employee procedural training in order to handle them safely.

Improper rigging of loads can easily result in load shifts and objects falling on those below. Materials handling procedures are frequently not given the necessary emphasis in safety training; i.e., materials handing is a support activity to the task of "making hole" and as such may be slighted.

Case No. 0508, 1973

\begin{tabular}{|c|c|c|c|c|}
\hline $\begin{array}{l}\text { Accident } \\
\text { Type }\end{array}$ & Activity & $\begin{array}{l}\text { Nature of } \\
\text { Injury }\end{array}$ & $\begin{array}{c}\text { Equipment } \\
\text { or Tool }\end{array}$ & $\begin{array}{l}\text { Length of } \\
\text { Employment }\end{array}$ \\
\hline $\begin{array}{l}\text { Struck by } \\
\text { pipes }\end{array}$ & $\begin{array}{c}\text { Pipe } \\
\text { handling }\end{array}$ & Fatal & Drill pipe & N/A \\
\hline
\end{tabular}

The rig was actively drilling. Two crew members were hoisting (by catline) 30 -foot drill pipe sections from the pipe rack/catwalk to the 
derrick incline. One man was working the catline, and one man was rigging the pipe at ground level. The incline, located below the Vee-door, was serving as a temporary storage point for the drill pipe; i.e., drill pipe that was expected to be added to the drill string during the shift was stored in a location conducive to its rapid addition to the drill string. The drill pipe was blocked at the bottom, but no precautions were taken at the top to prevent the pipe from slipping; e.g., 30-foot-long pipe joints stored almost vertically may tend to topple sideways. The five pipes stored in the incline toppled and fatally crushed the man working below.

A retaining safety device at the top of the incline could prevent similar accidents of this type.

Case No. 0576, 1979

$\begin{gathered}\text { Accident } \\ \text { Type }\end{gathered}$
Struck by $\frac{\text { Activity }}{\text { Drilling }} \frac{\begin{array}{c}\text { Nature of } \\ \text { Injury }\end{array}}{\begin{array}{c}\text { Fractured foot; } \\ \text { contusions }\end{array}} \quad \frac{\begin{array}{c}\text { Equipment } \\ \text { or Tool }\end{array}}{\text { Drill pipe }} \frac{\begin{array}{c}\text { Length of } \\ \text { Employment }\end{array}}{\text { N/A }}$

Two men were handling drill pipe on the inclined pipe ramp below the Vee-door of a drilling rig. Two joints of drill pipe got away and slid down the ramp, striking and injuring both employees. A pipe joint weighs about 500 pounds and is about 30 feet long.

This accident happened after the two men had pulled five joints of drill pipe onto the pipe ramp with an air tugger. Two joints ended up crossed over three joints already on the ramp. All joints were positioned against a pipe stop near the bottom of the ramp. When one joint was moved from the bottom end of the ramp, it went over the pipe stop. The other crossed joint followed. One joint slid on top of the pipe racks, and the other joint slid to the ground under the pipe racks, striking both employees and causing a fractured foot in one and contusions in both.

\section{Comment s :}

This accident reflects a lack of procedural instruction to employees. A pipe should never be handled from below. Retainers 10cated at the upper level of the pipe ramp may have prevented the pipe from slipping.

Case No. 0513, 1975

\begin{tabular}{|c|c|c|c|c|}
\hline $\begin{array}{l}\text { Accident } \\
\text { Type } \\
\end{array}$ & Activity & $\begin{array}{l}\text { Nature of } \\
\text { Injury }\end{array}$ & $\begin{array}{l}\text { Equipment } \\
\text { or Tool } \\
\end{array}$ & $\begin{array}{l}\text { Length of } \\
\text { Employment }\end{array}$ \\
\hline $\begin{array}{l}\text { Struck by } \\
\text { kelly } \\
\text { bushing }\end{array}$ & Drilling & Fatal & $\begin{array}{l}\text { Kelly bushing } \\
\text { assembly }\end{array}$ & N/A \\
\hline
\end{tabular}


The employees were in the process of making up joints of pipe, a normal task in a drilling operation. The kelly bushing separated, falling approximately 30 feet to the rig floor and fatally striking one of the employees.

Investigation revealed that there was no positive locking device used to secure the kelly bushing assembly to the hoist. It was also found that the bolt holding the split ring on the kelly bushing, to prevent disengagement of the assembly, had worked loose and had not been tightened.

Case No. 0130,1975

\begin{tabular}{|c|c|c|c|c|}
\hline $\begin{array}{l}\text { Accident } \\
\text { Type }\end{array}$ & Activity & $\begin{array}{c}\text { Nature of } \\
\text { Injury }\end{array}$ & $\begin{array}{l}\text { Equipment } \\
\text { or Tool }\end{array}$ & $\begin{array}{l}\text { Length of } \\
\text { Employment }\end{array}$ \\
\hline $\begin{array}{l}\text { Struck by } \\
\text { kelly } \\
\text { bushing }\end{array}$ & Dril1 ing & $\begin{array}{c}\text { Broken collar } \\
\text { bone }\end{array}$ & $\begin{array}{c}\text { Kelly bushing } \\
\text { assembly }\end{array}$ & N/A \\
\hline
\end{tabular}

The employee was setting the slips into the rotary table on the rig floor. The kelly bushing fell approximately 10 feet from the hoisted kelly, striking the employee on the neck. His collar bone was broken by the impact.

\section{Comments :}

Employees should be protected from falling objects by proper rigging techniques and equipment inspections. Safety chains or other redundant safety equipment could have prevented this accident.

Case No. 0655

Accident

\begin{tabular}{|c|c|c|c|c|}
\hline $\begin{array}{c}\text { Accident } \\
\text { Type }\end{array}$ & Activity & $\begin{array}{l}\text { Nature of } \\
\text { Injury }\end{array}$ & $\begin{array}{c}\text { Equipment } \\
\text { or Too1 }\end{array}$ & $\begin{array}{l}\text { Length of } \\
\text { Employment }\end{array}$ \\
\hline Struck by & Drilling & Fatal & Rotary hose & $\mathrm{N} / \mathrm{A}$ \\
\hline
\end{tabular}

The night crew had just commenced drilling activities. They had made a connection to the drill stem. The slips, which hold the drill stem while connections are being made, were pulled up. The mud pump had just been activated by the driller, when the rotary hose, which was attached to the swivel, came loose at the point of the connection and fell approximately 45 feet to the derrick floor. The mud hose struck the employee on the side of the head and shoulder, fatally injuring him.

Investigation disclosed a new mud hose had recently been installed. The safety chain, provided for the purpose of restraining the end of the hose in the event of an accidental separation of the hose from its point of connection at the swivel, had not been reconnected. 
Case No. 0497, 1981

$\begin{array}{ccccc}\begin{array}{c}\text { Accident } \\ \text { Type }\end{array} & \text { Activity } & \begin{array}{c}\text { Nature of } \\ \text { Injury }\end{array} & \begin{array}{c}\text { Equipment } \\ \text { or Tool }\end{array} & \begin{array}{c}\text { Length of } \\ \text { Employment }\end{array} \\ \begin{array}{c}\text { Caught } \\ \text { between }\end{array} & \begin{array}{c}\text { Instal1- } \\ \text { ing } \\ \text { Hydril }\end{array} & \text { Fatal } & \begin{array}{l}\text { Hoist and } \\ \text { blowout } \\ \text { preventer }\end{array} & \text { N/A }\end{array}$

The well drilling operation had progressed through the installation and cementing of the surface casing. The drilling crew was installing the upper portion of a blowout preventer. They were using the main hoist to "pick" the equipment from the ground to its position below the drill floor (in the substructure area). The rig was equipped with only two slings long enough to perform the task. Tag lines were not used to position and stabilize the load. During the positioning operation, the equipment tipped and fatally crushed one of the employees.

A number of events contributed to this incident. The drilling crew is frequently assigned tasks that are not part of the everyday drilling routine. In this instance, the rigging, picking, and placement of a heavy load ( 12,000 pounds) in a constricted space was beyond the expertise of the crew. A four-point pick made from two points should never be performed. Hands-on positioning of heavy loads, instead of using tag lines, is not an acceptable practice.

\section{Comments:}

Proper training, appropriate equipment, and operational supervision could have prevented this death.

\section{Catastrophic Events}

Catastrophic accidents involve the destruction of the drilling rig and/or injuries to multiple employees. Blowouts, derrick collapse, and hydrogen sulfide accidents are included in this category. These accidents may frequently involve loss of 1 ife as well as the major destruction of equipment. Insurance companies and corporate decisionmakers become involved in accident investigations and prevention policies. Although these incidents frequently make for media headline material, the actual loss of employee life and $1 \mathrm{imb}$ represents a small percentage of the total well drilling occupational worker incidence and severity rates [2].

\section{a. Derrick or Mast Collapse}

Derrick or mast collapse is most common during rigging-up and rigging-down procedures. The greatest strains are exerted on the mast components during these operations. Inspection of the derrick structure is important for the detection of sulfide embrittlement, weld weakness, oxidation, and bent members [6,7]. Weight indicators and recorders allow the driller to stay with mast load tolerances; 
consequently, they must be maintained and inspected. Manufacturer rig capacities and guying requirements should always be followed.

Case No. 0567, 1976

Accident

$\frac{\text { Type }}{\begin{array}{c}\text { Fall to } \\ \text { below }\end{array}} \quad \frac{\text { Activity }}{\text { Drilling }}$

$\begin{gathered}\text { Nature of } \\ \text { Injury }\end{gathered}$
$\begin{gathered}\text { Fractured } \\ \text { pelvis }\end{gathered}$

Length of

Employment

$\frac{\text { or Tool }}{\text { Kig mast }} \frac{\text { Employm }}{\text { N/A }}$

This accident happened just after the crew had pulled the last drill collar out of the well. After removing the bit, a gust of wind turned the drill rig over into an adjacent canyon. The derrickman on the finger board rode it down and sustained a fractured pelvis.

Water from breaking drill pipe at the rotary table drains under the rig floor to the ground near the mast footings. This condition may have softened the ground and contributed to the turnover.

Although the manufacturer of the derrick recommended that the mast be guyed, it was not. Outriggers improve stability but are not designed to substitute for a guying system. Additionally, the outriggers on the driller's side were not installed because the mud box and stairs precluded the placement of an outrigger.

Case No. 0493

$\frac{\begin{array}{c}\text { Accident } \\ \text { Type }\end{array}}{\text { Fall }} \frac{\text { Activity }}{\text { Rigging }} \frac{\begin{array}{c}\text { Nature of } \\ \text { Injury }\end{array}}{\text { Fatal }} \frac{\begin{array}{c}\text { Equipment } \\ \text { or Tool }\end{array}}{\text { Rig mast }} \frac{\begin{array}{c}\text { Length of } \\ \text { Employment }\end{array}}{10 \text { days }}$

The sequence of events leading to the collapse of the rig was as follows: The crew had just completed a drilling job on an approximately 12,000-foot hole and the mast was being prepared for letdown. Two members on each side of the rig climbed up to unlock the mast leg locking lugs. Before the lugs could be pulled, the driller had to take tension on the bridle hookup to loosen the lugs. The two men on each side pulled the lugs while the driller took tension on the bridle. Three men then got down while the derrickman climbed the approximately 143-foot mast to hook the "angel flight" line at a higher elevation to permit the counterweight to go down to near ground level where it could be disconnected for the mast letdown. The derrickman was above the mast pipe racking platform, near the 120-foot level. The driller at his stand on the floor reported that he took a tension of 60,000 to 70,000 pounds, so he picked it back up to 60,000 ; it then bled down to about 40,000. The third time he picked it up to 60,000 pound, the left rear leg of the mast collapsed and the mast fell to the front left quarter. The derrickman fell with the mast. 
Although this accident occurred when the crew was preparing to lay the mast down, the events leading up to this accident could occur during any phase of a drilling operation. The driller, who supervises activities during the drilling operation, is responsible for checking the weight indicator for load forces on the mast throughout the drilling operation.

In this incident, the driller had taken a weight reading of the mast load. He was trying to maintain a weight of 60,000 pounds as indicated on the meter when in actuality he had exceeded the safe load of the mast. When the meter bled down, rather than stopping to determine where the fault was, the driller continued with the operation.

\section{B. Accidents Not Unique to Drilling Operations}

Employees of drilling contractors may be injured in accidents due to:

o Working with saws, hammers, grinders, drills, chain hoists, or pipes

- Working with electricity, pressurized air, or other energized systems

- Falling from or slipping on ladders, floors, scaffolds, or walkways.

The six accident case histories that follow are representative of injuries sustained by workers performing tasks not unique to well drilling operations.

Case No. 0671,1977

Accident Type

Electrocution

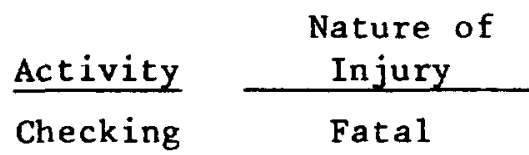
oil level
Equipment or Tool

Jumper cables
Length of Employment

N/A

The deceased, who had been checking oil levels for a start-of-shift operation, was found on the rig floor between the motor for the drawworks and the diesel tank (which supplies fuel for the rig motor and the powerplant). The night shift had "jumped" the powerplant battery with the motor battery. The jumper cables were removed from the motor battery but not from the powerplant battery, and were left lying across a large diesel storage tank located between the powerplant and the motor floor.

The deceased was found lying on his back, his head resting on a mud pipe with the grounded side of a jumper cable clip across his chest. The cable was clasped in his right hand; his chest appeared burned. Another employee grabbed the cable clamp and could feel a "pulsation" through the clamp. When he could not remove the cable from the hand of the deceased, another employee jerked the cable off the ground side of the powerplant battery. The autopsy stated that the shock caused ventricular fibrillation, which made him fall to the floor and strike 
his head on a pipe. The ground cable was conducting current from an undetermined source.

Case No. 0659,1979

$\frac{\begin{array}{c}\text { Accident } \\ \text { Type }\end{array}}{\text { Struck by }} \frac{\text { Activity }}{\text { Unloading }} \frac{\begin{array}{c}\text { Nature of } \\ \text { Injury }\end{array}}{\text { Fatal }} \frac{\begin{array}{c}\text { Equipment } \\ \text { or Tool }\end{array}}{\text { Drill pipe }} \frac{\begin{array}{c}\text { Length of } \\ \text { Employment }\end{array}}{\text { N/A }}$
drill pipe

A load of drill pipe was positioned to be unloaded from a highway tractor-trailer. The boomer load binder chain, which held the drill pipe in place enroute, had been released.

An employee was fatally injured when a drill pipe rolled off the bed of the truck and struck him. The employee was standing in the path the rolling stock would travel in when offloaded.

Case No. 0148, 1979

\begin{tabular}{|c|c|c|c|c|}
\hline $\begin{array}{l}\text { Accident } \\
\text { Type }\end{array}$ & Activity & $\begin{array}{l}\text { Nature of } \\
\text { Injury }\end{array}$ & $\begin{array}{c}\text { Equipment } \\
\text { or Tool }\end{array}$ & $\begin{array}{l}\text { Length of } \\
\text { Employment }\end{array}$ \\
\hline & Hammering & No lost time & Hammer & 3 months \\
\hline
\end{tabular}

An employee was hammering a drilling head when he pulled the hammer back too far, hitting himself in the mouth.

Case No. 0001,1979

\begin{tabular}{|c|c|c|c|c|}
\hline $\begin{array}{l}\text { Accident } \\
\text { Type }\end{array}$ & Activity & $\begin{array}{l}\text { Nature of } \\
\text { Injury }\end{array}$ & $\begin{array}{l}\text { Equipment } \\
\text { or Too1 }\end{array}$ & $\begin{array}{l}\text { Length of } \\
\text { Employment }\end{array}$ \\
\hline $\begin{array}{l}\text { Foreign } \\
\text { body in } \\
\text { eye }\end{array}$ & $\begin{array}{l}\text { Clearing } \\
\text { pump }\end{array}$ & No lost time & Mud pump & 4.5 months \\
\hline
\end{tabular}

A derrickman was cleaning the mud pump when a piece of dirt got into his eye. He did not report the incident right away. Two days later he needed to go to the doctor and have his eye cleaned.

Case No. 0144,1979

\begin{tabular}{|c|c|c|c|c|}
\hline $\begin{array}{l}\text { Accident } \\
\text { Type } \\
\end{array}$ & Activity & $\begin{array}{l}\text { Nature of } \\
\text { Injury }\end{array}$ & $\begin{array}{l}\text { Equipment } \\
\text { or Tool }\end{array}$ & $\begin{array}{l}\text { Length of } \\
\text { Employment }\end{array}$ \\
\hline & Hoisting & No lost time & Jack handle & 3 days \\
\hline
\end{tabular}

An employee was jacking up a catwalk with a jack, when the jack handle slipped and hit him in the jaw. 
Case No. 0272,1979

\begin{tabular}{|c|c|c|c|c|}
\hline $\begin{array}{l}\text { Accident } \\
\text { Type }\end{array}$ & Activity & $\begin{array}{l}\text { Nature of } \\
\text { Injury }\end{array}$ & $\begin{array}{c}\text { Equipment } \\
\text { or Tool }\end{array}$ & $\begin{array}{l}\text { Length of } \\
\text { Employment }\end{array}$ \\
\hline Fire & $\begin{array}{c}\text { Lighting } \\
\text { heater }\end{array}$ & $\begin{array}{l}\text { Burns to face } \\
\text { and hands }\end{array}$ & Heater & 1 year \\
\hline
\end{tabular}

A floorhand was relighting a gas heater in the "doghouse." He neglected to turn the butane off prior to striking a match. The gas flashed and burned his hands and face. 
APPENDIX B

REVIEW OF STATE, FEDERAL, INTERNATIONAL, AND CONSENSUS SAFETY STANDARDS 


\section{APPENDIX B}

REVIEW OF STATE, FEDERAL, INTERNATIONAL, AND CONSENSUS SAFETY STANDARDS

The purpose of this appendix is to compare existing state, Federal, international, and consensus standards related to, and impacting on, oil and gas we11 drilling. Included are the OSHA General Industry Standards (29 CFR 1910) [70]; state standards with oil and gas well drilling regulations; international standards from Canada (Alberta) [69]; and consensus standards developed by API [74].

The first section of this appendix tabulates existing national standards that relate to oil and gas well drilling. The second section reviews state, international, and consensus standards that specifically address activities, operations, tasks, tools, and conditions typical of well drilling operations.

\section{A. Existing National Standards}

National standards do not specifically regulate oil and gas well drilling, but OSHA General Industry Standards (29 CFR 1910) apply to many of the operations, tasks, and conditions typically present at a well site. Table B-1 presents existing national standards which may be applicable to the activities or conditions at a well site.

\section{B. Existing State, International, and Consensus Standards}

An examination of standards from all 50 states, plus Puerto Rico and the Virgin Islands, determined that only Alaska [77], California [75], Michigan [86], Utah [73], and Wyoming [78] have standards that specifically address oil and gas well drilling. The remaining states reprint the national standards. The California Petroleum Safety Orders are in the process of revision; the revised standard, not yet enacted into law, is used in this appendix to represent drilling regulations in California.

Occupational safety and health standards for oil and gas well drilling operations were requested from Germany, the United Kingdom, France, the Netherlands, Sweden, Australia, Canada, and Mexico. The Canadian (Alberta) standards that regulate oil and gas well drilling operations are included for review [67]. The United Kingdom has standards for the petroleum industry, but does not regulate drilling operations. The remaining countries do not have safety standards that specifically address well drilling operations.

The industry consensus standards developed by API have been reviewed and compared with existing state standards. In many instances, state standards have adopted portions of the API standards. 
TABLE B-1

GENERAL INDUSTRY STANDARDS WHICH MAY BE APPLICABLE

TO THE OIL AND GAS WELL DRILLING INDUSTRY

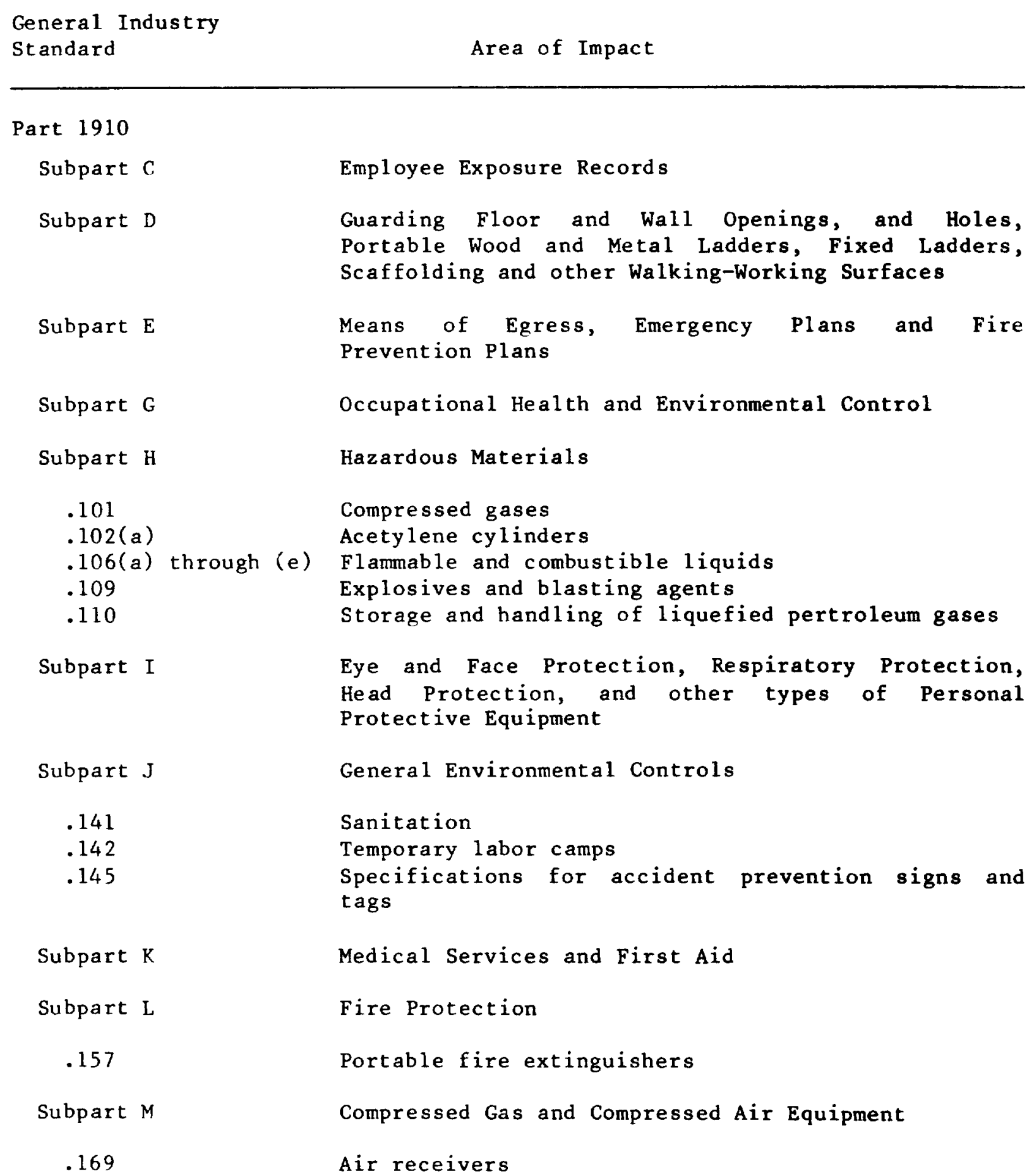


TABLE B-1

GENERAL INDUSTRY STANDARDS WHICH MAY BE APPLICABLE TO

THE OIL AND GAS WELL DRILLING INDUSTRY (Concluded)

General Industry

St andard

Area of Impact

Part 1910

Subpart N

Materials Handling and Storage

.176

.179

Handling materials

.180

Overhead and gantry cranes

.184

Crawler locomotive and truck cranes

Slings

Subpart 0

Machinery and Machine Guarding

.212

.215

.219

General requirements for all machines

Abrasive wheel machinery

Mechanical power-transmission apparatus

Subpart $P$

Hand and Portable Power Tools and other Hand-Held Equipment and Guarding Requirements

Subpart Q

Welding, Cutting, and Brazing

Subpart S

Electrical Systems and Equipment

Subpart $\mathrm{Z}$

Toxic and Hazardous Substances

A topical comparison and evaluation of existing state, international, and API standards referenced in this document are presented in this section; however, the subject matter discussed is either not addressed or only partly addressed by the national standards (Table $B-1$ ).

1. First Aid and Communications

a. First Aid

Alaska requires all supervisors and foremen to be trained and certified in first aid and at least one trained person to be onsite at all times when work is in progress. The presence of certified first-aid personnel is similarly required by California, Michigan, Wisconsin, and Utah. Canada requires the tool pusher and one additional worker per crew to be certified in first aid. The API 
consensus standard requires the presence of a person certified in first aid when medical services are not reasonably available.

All States and Canada require the presence of unit-type, first-aid kits (usually 24-unit size), stretchers, and blankets. In addition, Wyoming requires arm and leg splints. Provisions for eyewash facilities are made by Wyoming, Utah, Michigan, and API. The availability of a transportation vehicle of sufficient size to accommodate a stretcher is required by Canada, while the listed States require only that transport be available. Canada also mandates that alternative means of transportation be supplied if the condition of the road is detrimental to the injured person.

\section{b. Communication}

All pertinent State standards and Canada provide for the presence of adequate communication to emergency facilities and the posting of phone numbers. Wyoming requires that radio numbers be posted and specifies that radio communication be provided when phones are not available.

\section{Personal Protective Equipment}

\section{a. Genera1}

All standards prohibit the wearing of loose clothing, jewelry, and long hair in the work area.

b. Foot Safety

Safety-toed footwear is required in work areas by API, Utah, Wyoming, and Canada. Wyoming also requires metatarsal protection when necessary.

\section{c. Fall Protection}

The API requires that safety belts and attached lanyards be worn when the fall potential is greater than 10 feet, except when freedom of movement is required and during rigging-up and rigging-down operations. California, Michigan, Utah, and Wyoming require that safety belts be worn in accordance with the OSHA construction or general industry standards. Canada requires safety belts or alternative means of fall protection when working above 10 feet 6 inches. Alaska requires safety nets when workplaces are more than 25 feet above ground and when safety belts are impractical.

Ladder cages with platforms or ladder climbing devices are required by all the examined standards. 


\section{d. Respiratory Protection, Hydrogen Sulfide}

Wyoming and Utah require increasingly stringent hydrogen sulfide detection and warning systems as well as respiratory protection programs to be coordinated with increasing levels of hydrogen sulfide. The API consensus standards (which references their safe work practices guide for hydrogen sulfide environments [72]) and the "Outer Continental Shelf Standard: Safety Requirements for Drilling in Hydrogen Sulfide Environments" [87] offer adequate worker protection.

\section{Fire Protection and Prevention}

\section{a. Fire Prevention}

California and Alaska prohibit smoking and the carrying of unprotected matches or lighters in the well area. The well area is variously defined as 50-100 feet from the well bore. Open flames, spark sources, and exhaust heat from internal combustion engines are prohibited in the well area by Alaska, California, Wyoming, and Utah. The API qualifies its fire protection requirements by "designated areas" and "safety heater" provisions.

Adequate standards for the lighting of flare pits and lines are in effect in Utah, Alaska, California, Wyoming, and Canada. The API does not address this problem.

Grounding and bonding of the derrick to ensure protection against static electricity is adequately regulated in Alaska, California, and Canada. The API does not address static discharge.

\section{b. Fire Protection}

Provisions are made in all the well drilling standards for the presence and inspection of portable fire extinguishers. The API, Michigan, Utah, and Wyoming require that four 20-pound, B:C-rated fire extinguishers be readily available on drilling rigs. California requires a 10-pound extinguisher, whereas Canada mandates that four 30-pound extinguishers be available on the drill rig. Wyoming also requires that a 150-pound, B:C-rated fire extinguisher be located at each well drilling site.

\section{Derricks}

All of the standards address the problems of derrick integrity. Identification, rating capacity, guying patterns, anchoring, and inspection are mandated in Alaska, Michigan, Utah, California, and Wyoming. The API has similar requirements for worker protection. Procedural guying diagrams and wind effects are included in the Wyoming standards. A yearly magnaflux inspection of A-legs, elevator links, block hooks, 
and pins is required by Alaska. The API tabulates soil stabilities relative to derrick support.

\section{a. Derrick Ladders}

The examined standards regulate the construction of derrick ladders.

\section{b. Derrick Floor}

All existing standards attend to housekeeping and maintaining the derrick surface free from oil and grease. Utah specifies cleats, mats, and grates if the surface condition necessitates it.

c. Mousehole, Rathole

Only the California standard specifies that if a rathole is unoccupied and does not have at least a 12-inch protruding pipe guide, then it must be covered or guarded. Utah requires that all floor holes be guarded when not in use.

\section{d. Vee-doors}

A chain or wire rope cable is required by all standards to protect the worker from falls through the Vee-door.

\section{e. Derrick Exits}

The API requires a minimum of two access/egress stairs (one of which may be a ladder) for derricks with floors over 6 feet in height. Canada, Alaska, Michigan, and Wyoming have similar requirements for providing alternative exits from the derrick floor, and they also provide for exit locations relevant to prevailing winds and potential gas accumulations. Utah requires three exits from the derrick floor. No mention is made in any standard of emergency escape facilities such as slides from elevated derrick floors.

\section{Hoisting Lines and Operation}

\section{a. Hoisting Lines}

The API standard for wire rope specification, slipping, and cutoff procedures [85] referenced by all states, requires a safety factor of " 3 " for normal operations and " 2 " when "setting casing, pulling on stuck pipe, or similar infrequent operations."

b. Deadline Anchors

Deadline anchors are required by API to be constructed so that their strength equals or exceeds the working strength of the 
hoisting line. Similar regulations exist in the State standards.

c. Weight Indicators

The API standards and all referenced States similarly require the presence of an accurate (5\%) weight indicator. Monthly calibration to calculated drill string weight is required by API and Michigan.

d. Crown and Traveling Blocks

Alaska and California regulations address the engineering design and use of crown and traveling blocks. The API has similar requirements in its standard and their recommended "Specification for Rotary Drilling Equipment" [88] details proper guarding techniques.

e. Drawworks

Drawworks guards are required by Alaska, Utah, California, and Canada. Visual inspection of the drawworks is required by all standards. Brake testing by the driller (each shift) is mandated by Alaska.

\section{f. Hoist Operations}

Drillers are required by all standards to be at their stations during load movements. Alaska and California also require clearly labeled controls. All standards require that brake handles be tied down when the driller is not at his station (autofeed drawworks are exempt). All standards allow an employee to ride an unloaded traveling block if he is tied off with approved safety belt and lanyard.

\section{Rotary Equipment and Guarding}

The examined states all require guarding of the rotary table by substantially constructed material extending downward and covering all gears, pins, and sprockets. Wyoming, Alaska, and California specifically exclude the kelly bushing and the kelly from guarding requirements as does $A P I$. Utah and Michigan require that all gears, pulleys, and rotating parts be guarded but do not specifically address the kelly.

Standards exist in all states, Canada, and API requiring that the driller shall not operate the rotary table while personnel and/or equipment are in contact with the rotating parts. The driller is also required to watch the rotary area when it is in motion.

All standards require exposed moving gears, chains, sprockets, belts, and other similar parts to be guarded. The ANSI B15.1-1972 "Safety 
Standard for Mechanical Power Transmission Apparatus" [89] is referenced in the API standard. California, Wyoming, and Alaska provide the specific guarding requirements in the text of their regulations.

7. Catheads and Catlines

All States, Canada, and API provide adequate standards for operator controls, friction surface wear, rope splices, unattended catheads, headache posts, and automatic cathead mechanisms. Alaska, California, and Wyoming also provide for rope antifouling devices. Cathead protection, rope coiling, and employee hand position have been addressed in the California standard.

Riding on the catline is prohibited except in emergency situations by all standards.

8. Tongs, Backup Posts, Safety Lines, and Breaking/Making Connections

All standards provide for the tongs to be attached to a backup system. Provisions are made in all standards for proper attachment of lines to girders or posts. Canada specifies that a derrick girder not be used as a backup post unless it is designed as such. Inspection and maintenance procedures are similar in all standards.

Rotary tables are specifically excluded by all standards as a power source for the initial "breaking" of a connection. The rotary table is allowed to spin the joint once it has been broken. Safety lines to prevent backspin of tong handles are required in California, Alaska, and Canada. There are no regulations that address the employee's position during pipe joint breaking and making procedures.

9. Elevators and Latching

Specific regulations for elevator latching procedures and safety latch requirements are not addressed by any of the standards.

10. Slips and Slip Handles

The handling and positioning of slips are not addressed by any of the standards. The California standards regulate $s$ ip handle length.

11. Chains

All standards address the hazards of moving chain.

12. Pipe Racks and Pipe Handling

Wyoming, Utah, Michigan, Canada, and API similarly address the problems of drill pipe racking and transfer of pipes from trucks. Alaska and California regulate in greater detail pipe chocking, binding, and employee positions during pipe transfer from trucks to racks. 
Techniques for transfer of drill pipe from pipe racks to catwalk to inclined ramp to Vee-door are not addressed by any of the standards. Employee positions under pipe loads stored or being rigged in the Vee-door area do not exist. Pipe handling, rigging, and tag lines are only partly addressed by the existing standards.

Racking and securing of pipe stands during tripping is covered by all the standards.

13. Circulating Fluid, Tanks, Reserve Pits

\section{a. Circulating Fluid}

Chemical exposure to harmful additives in circulating fluids is regulated by Federal OSHA standards (29 CFR 1910.1001-.1046). Personal protective equipment is also regulated by Federal OSHA Standards (29 CFR 1926.100 and .102).

b. Tanks

Guarding of both sides of walkways over mud tanks is mandated in Canada. Wyoming specifies that the inside section of walkways on mud tanks be provided with standard guardrails and the outside be guarded if more than 4 feet above ground level. Wyoming also requires hazardous substance testing prior to employee entry of tanks that have contained toxic material. These provisions are not required by $A P I$.

\section{c. Reserve Pits}

California requires open pits constituting a hazard to employees to be guarded or fenced. Water rescue equipment specific to reserve pits is not addressed by any standard.

\section{Electrical--Hazard Zones}

Wyoming, Utah, Michigan, and API diagrammatically depict hazard zones (e.g., shale shakers, mud pits, and various enclosed areas on rig substructures) that are classified into different explosive hazard areas. Electrical equipment specified by the national electrical code, NFPA 701980 [90], is mandated by national, State, and API standards for these zones.

15. Cellars

Access/egress to cellars is regulated by all standards. Guarding of the cellar perimeter should be attended to, thus preventing employees from falling into it. Atmospheric testing for flammable gas and hydrogen sulfide prior to cellar entry is not specified in existing regulations. 


\section{Blowout Prevention}

Employee training in blowout prevention equipment, blowout drills, and practices referenced by the API standard "Recommended Practice for Blowout Prevention Equipment Systems" [76] provide necessary worker protection.

17. Employee Training

All standards require that employees be trained in hazard recognition specific to their tasks. Specific guidelines are not given for operational training areas, duration of training, and certification. 
GLOSSARY OF TERMS USED IN THE OIL AND GAS WELL DRILLING INDUSTRY

acid fracture

acidize

air drilling

annular blowout

annular space

artificial lift

automatic slips
A combination of oil and acid or water and acid under high pressure used to separate or fracture hard limestone formations.

To treat oil-bearing limestone or other formations, using a chemical reaction with acid, to increase production. Hydrochloric acid or other acid is injected into the formation under pressure. The acid etches the rock, enlarging the pore spaces and passages through which the reservoir fluids flow. The acid is then pumped out and the well swabbed and put back into production.

A method of rotary drilling that uses compressed air as its circulation medium. This method of removing cuttings from the well bore is as efficient or more efficient than the traditional methods using water or drilling mud; in addition, the rate of penetration is increased considerably when air drilling is used. However, a principal problem in air drilling is the penetration of formations containing water, since the entry of water into the system reduces its efficiency.

A large valve, usually installed above the ram preventers, that forms a seal in the annular space between the pipe and well bore or, if no pipe is present, on the well bore itself.

The space around a pipe in a well bore, the outer wall of which may be the wall of either the bore hole or the casing; sometimes termed the annulus.

Any method used to raise oil to the surface through a well after reservoir pressure has declined to the point at which the well no longer produces by means of natural energy. The most common methods of artificial lift are sucker rod pumps, hydraulic pumps, submersible pumps, and gas 1 ifts.

An air or hydraulic fluid operated device that fits into the opening in the rotary table when the drill stem must be suspended in the well bore (as when a connection, or trip, is being made). Automatic slips, also called power 
backoff joint

backup post

bail

bailer

bailing

barite or baryte

belly buster

be $1 t$

bentonite

bit

bit breaker slips, eliminate the need for roughnecks to set and take out slips manually.

A section of pipe with left-hand threads on one end and conventional right-hand threads on the other.

A post, column or stanchion secured to the derrick, derrick floor, or derrick foundation, the purpose of which is to make secure the dead end of the safety line.

A cylindrical steel bar (similar to the handle or bail of a bucket, only much larger) that supports the swivel and connects it to the hook. The two cylindrical bars that support the elevators and attach them to the hook are sometimes called bails.

A long cylindrical container, fitted with a valve at its lower end, used to remove water, sand, mud, or oil from a well.

To recover bottomhole fluids, samples, or drill cuttings by lowering a cylindrical vessel called a bailer to the bottom of a well, filling it, and retrieving it.

Barium sulfate, $\mathrm{BaSO}_{4} ;$ a mineral used to increase the weight of drilling mud.

A rope/belt retaining device used on stabbing boards. It allows the derrickman to lean past his overbalance point to handle pipe. Not to be confused with fall protection equipment.

A flexible band or cord connecting and passing about each of two or more pulleys to transmit power or impart motion.

A colloidal clay, composed of montmorillonite, which swells when wet. Because of its gel-forming properties, bentonite is a major component of drilling muds.

The cutting or boring element used in drilling oil and gas wells. Most bits used in rotary drilling are roller-cone bits. The bit consists of the cutting elements and the circulating element. The circulating element permits the passage of drilling fluid and utilizes the hydraulic force of the fluid stream to improve drilling rates.

A heavy plate that fits in the rotary table and holds the drill bit while it is being made up in or broken out of the drill stem. 
blind ram

block

blooey line

blowout

blowout preventer (BOP)

bore hole

break out

breakout cathead

breakout tongs

bullet perforator
An integral part of a blowout preventer, serving as the closing element. Its ends do not fit around the drill pipe but seal against each other and shut off the space below completely.

Any assembly of pulleys on a common framework; in mechanics, one or more pulleys, or sheaves, mounted to rotate on a common axis. The crown block is an assembly of sheaves mounted on beams at the top of the derrick. The drilling line is reeved over the sheaves of the crown block alternately with the sheaves of the traveling block, which is hoisted and lowered in the derrick by the drilling line. When elevators are attached to a hook on the traveling block and when drill pipe is latched in the elevators, the pipe can be raised or lowered in the derrick or mast.

The discharge pipe from a well being drilled by air drilling, which conducts the air or gas used for circulation away from the rig to reduce the danger of fire and to transport the cuttings a suitable distance from the well.

An uncontrolled flow of gas, oil, or other well fluids occurring when formation pressure exceeds the pressure applied to it by the column of drilling fluid.

One of several values installed at the wellhead to prevent the escape of pressure either ir the annular space between the casing and drill pipe or in open hole (i.e., hole with no drill pipe) during drilling or completion operations.

The well bore; the hole made by drilling or boring.

To unscrew one section of pipe from another section, especially drill pipe while it is being withdrawn from the well bore. During this operation, the breakout tongs are used to start the unscrewing operation.

A device attached to the shaft of the drawworks that is used as a power source for unscrewing drill pipe; usually located opposite the driller's side of the drawworks.

Tongs that are used to start unscrewing one section of pipe from another section, especially drill pipe coming out of the hole; also called lead tongs.

A tubular device that, when lowered to a selected depth within a well, fires bullets through the casing to provide holes through which the well fluids may enter. 
cable-tool
drilling

casing

casing string

cathead

catline

cellar

cement casing

cementing

cementing materials

chain drive

chain tongs
A drilling method in which the hole is drilled by dropping a sharply pointed bit on the bottom of the hole. The bit is attached to a cable, and the cable is repeatedly picked up and dropped as the hole is drilled.

Steel pipe placed in an oil or gas well as drilling progresses to prevent the wall of the hole from caving in during drilling and to provide a means of extracting petroleum if the well is productive.

The entire length of all the joints of casing run in a we11. Casing is manufactured in lengths of about 30 feet, each length or joint being joined to another as casing is run in a well.

A spool-shaped attachment on a winch around which rope for hoisting and pulling is wound.

A hoisting or pulling line powered by the cathead and used to lift heavy equipment on the rig.

A pit in the ground to provide additional height between the rig floor and the well head to accommodate the installation of blowout preventers, ratholes, mouseholes, and so forth. It also collects drainage water and other fluids for subsequent disposal.

To fill the annulus between the casing and hole with cement to support the casing and prevent fluid migration between permeable zones.

The application of a liquid slurry of cement and water to various points inside or outside the casing.

A slurry of portland cement and water and sometimes one or more additives. They affect either the density of the mixture or its setting time. Additives include accelerators (such as calcium chloride), retarders (such as gypsum), weighting materials (such as barium sulfate), lightweight additives (such as bentonite), and a variety of lost circulation materials (such as mica flakes).

A drive system using a chain and chain gears to transmit power. Power transmissions use a roller chain, in which each link is made of side bars, transverse pins, and rollers on the pins. A double roller chain is made of two connected rows of links, a triple roller chain of three, and so forth.

A tool consisting of a handle and a releasable chain that is used for turning pipe or fittings that are too large 
choke

choke 1 ine

choke manifold

Christmas tree

combination string

coming out the hole

complete a we11 completion rig in diameter to use a pipe wrench. The chain is tightened around the pipe or fitting.

An orifice installed in a line to restrict the flow and control the rate of production. Surface chokes are part of the Christmas tree and contain a choke nipple, or bean, with a small-diameter bore that serves to restrict the flow. Chokes are also used to control the rate of flow of the drilling mud out of the hole when the well is closed in with the blowout preventer and when a kick is being circulated out of the hole.

An extension of pipe from the blowout preventer assembly used to direct well fluids from the annulus to the choke manifold.

The arrangement of piping and special valves, called chokes, through which drilling mud is circulated when the blowout preventers are closed to control the pressures encountered during a kick.

The control valves, pressure gauges, and chokes assembled at the top of a well to control the flow of oil and gas after the well has been drilled and completed.

A casing that has joints of various collapse resistance, internal yield strength, and tensile strength designed for various depths in a specific well to best withstand the conditions of that well. In deep wells, high tensile strength is required in the top casing joints to carry the load, whereas high collapse resistance and internal yield strength are needed for the bottom joints. In the middle of the casing, average qualities are usually sufficient. The most suitable combination of types and weights of pipe helps to ensure efficient production at a minimum cost.

To pull the drill stem out of the well bore. This withdrawal is necessary to change the bit, change from a core barrel to the bit, run electric logs, prepare for a drill-stem test, run casing, and so on.

To finish work on a well and bring it to productive status.

A portable servicing or workover rig that is selfpropelled, using the hoisting engines for motive power. Because the driver's cab is mounted on the end opposite the mast support, the unit must be backed up to the well head. Also known as a backover rig. 
compound

crown block

cuttings

deadline

deadline

tiedown anchor

degasser

derrick

derrick climber

derrickman

desander
The mechanism used to transmit power from the engines to the pump, drawworks, and other machinery on a drilling rig. It is composed of clutches, chains and sprockets, belts and pulleys, and a number of shafts, both driven and driving. Also used to connect two or more power-producing devices such as engines to run one piece of driven equipment such as the drawworks.

An assembly of sheaves or pulleys mounted on beams at the top of the derrick over which the drilling line is reeved.

The fragments of rock dislodged by the bit and brought to the surface in the drilling mud. Washed and dried samples of the cuttings are analyzed by geologists to obtain information about the formations drilled.

The driling line from the crown block sheave to the anchor, so called because it does not move.

A device to which the deadline is attached to the mast or derrick substructure. Also called a deadline anchor.

The equipment used to remove unwanted gas from a liquid, especially from drilling fluid.

A large load-bearing structure, usually of bolted cunstruction. In drilling, the standard derrick has four legs standing at the corners of the substructure and reaching to the crown block. The substructure is an assembly of heavy beams used to elevate the derrick and provide space to install blowout preventers, casing heads, and so forth. Because the standard derrick must be assembled piece by piece, it has largely been replaced by the mast, which can be lowered and raised without disas sembly.

A counterweighted device to assist the derrickman in climbing on derricks. Attached to a safety harness running on a wire rope cable, the device has adjustable counterweights and physically assists workers climbing and descending the derrick.

The crew member who handles the upper end of the drill stem as it is being hoisted out of or lowered into the hole. He is also responsible for the conditioning of the drilling fluid and the circulation machinery.

A centrifugal device for removing sand from drilling fluid to prevent abrasion of the pumps. It may be operated mechanically or by a fast-moving stream of fluid 
desilter

diesel-e lectric power

diesel engine

directional

drilling

doghouse

drawworks

drill collar

drill pipe

drill stem

drill string inside a special cone-shaped vessel, in which case it is sometimes called a hydrocyclone.

A centrifugal device, similar to a desander, used to remove very fine particles, or silt, from drilling fluid to keep the amount of solids in the fluid to the lowest possible level.

The power supplied to a drilling rig by diesel engines driving electric generators, used widely offshore and gaining popularity onshore.

A high-compression, internal-combustion engine used extensively for powering drilling rigs. In a diesel engine, air is drawn into the cylinders and compressed to very high pressures; ignition occurs as fuel is injected into the compressed and heated air. Combustion takes place within the cylinder above the piston, and expansion of the combustion products imparts power to the piston.

Intentional deviation of a well bore from the vertical. Controlled directional drilling makes it possible to reach subsubsurface areas laterally remote from the point where the bit enters the earth, and involves the use of turbo-drills, Dyna-Drills, whipstocks, or other deflecting tools.

A small enclosure on the rig floor used as an office for the driller or as a storehouse for small objects. Also, any small building used as an office or for storage.

The hoisting mechanism on a drilling rig. It is essentially a large winch that spools off or takes in the drilling line and thus raises or lowers the drill stem and bit.

A heavy, thick-walled tube, usually steel, used between the drill pipe and the bit in the drill stem, used to put weight on the bit so that the bit can drill.

The heavy seamless tubing used to rotate the bit and circulate the drilling fluid. Joints of pipe 30 feet long are coupled together by means of tool joints.

All members in the assembly used for drilling by the rotary method from the swivel to the bit, including the kelly, drill pipe and tool joints, drill collars, stabilizers, and various subsequent items.

The column, or string, of drill pipe, not including the drill collars or kelly. Often, however, the term is 
driller

drilling fluid

drilling line

drum

elevators

fast 1 ine

finger

finger board

finger brace

f i sh loosely applied to include both the drill pipe and drill collars.

The employee directly in charge of a drilling rig and crew. His main duty is operation of the drilling rig and hoisting equipment, but he is also responsible for the downhole condition of the well, operation of downhole tools, and pipe measurements.

Circulating fluid, one function of which is to force cuttings out of the wellbore and to the surface. While a mixture of clay, water, and other chemical additives is the most common drilling fluid, wells can also be drilled using air, gas, or water as the drilling fluid. Also called circulating fluid.

A wire rope hoisting 1 ine, reeved on sheaves of the crown block and traveling block (in effect a block and tackle), the primary purpose of which is to hoist or lower drill pipe or casing from or into a well. Also, a wire rope used to support the drilling tools.

A cylinder around which wire rope is wound in the drawworks. The drawworks drum is that part of the hoist upon which the drilling 1 ine is wound.

A set of clamps that grip a stand, or column, of casing, tubing, drill pipe, or sucker rods, so that the stand can be raised or lowered into the hole.

The end of the drilling line that is affixed to the drum or reel of the drawworks, so called because it travels with greater velocity than any other portion of the 1 ine.

Steel, fingerlike projection that forms a slot in the finger board.

A rack that supports the tops of the stands of pipe being stacked in the derrick or mast. It has several steel fingerlike projections that form a series of slots into which the derrickman can set a stand of drill pipe as it is pulled out of the hole.

Any structural member either in direct or indirect contact with the finger to resist either horizontal, vertical, or diagonal movement of the finger.

An object left in the well bore during drilling operations that must be recovered or drilled around before work can proceed. It can be anything from a piece of scrap metal to a part of the drill stem. To recover 
fishing

foaming agent

formation

fracturing

formation

pressure

formation testing from a well any equipment left there during drilling operations, such as a lost bit or drill collar or a part of the drill string. To remove from an older well certain pieces of equipment, such as packers, liners, or screen pipe, to allow reconditioning of the well.

To recover from a well any equipment left there during drilling operations, such as a lost bit or drill collar or part of the drill string; to remove from an older well certain pieces of equipment, such as packers, liners, or screen pipe, to allow reconditioning of the well.

A chemical used to lighten the water column in gas wells, in oil wells producing gas, and in drilling wells in which air or gas is used as the drilling fluid so that the water can be forced out with the air or gas to prevent its impeding the production or drilling rate.

A method of stimulating production by increasing the permeability of the producing formation. Under extremely high hydraulic pressure, a fluid (such as water, oil, alcohol, dilute hydrochloric acid, liquefied petroleum gas, or foam) is pumped downward through tubing or drill pipe and forced into the perforations in the casing. The fluid enters the formation and parts or fractures it. Sand grains, aluminum pellets, glass beads, or similar materials are carried in suspension by the fluid into the fractures. These are called propping agents or proppants. When the pressure is released at the surface, the fracturing fluid returns to the well and the fractures partially close on the proppants, leaving channels for oil to flow through them to the well. This process is often called a frac job.

The force exerted by fluids in a formation, recorded in the hole at the level of the formation with the well shut in. It is also called reservoir pressure or shut-in bottomhole pressure.

The gathering of data on a formation to determine its potential productivity before installing casing in a wel1. The conventional method is the drill-stem test. Incorporated in the drill-stem testing tool are a packer, valves or ports that may be opened and closed from the surface, and a pressure recording device. The tool is lowered to bottom on a string of drill pipe and the packer set, isolating the formation to be tested from the formations above and supporting the fluid column above the packer. A port on the tool is opened to allow the trapped pressure below the packer to bleed off into the drill pipe, gradually exposing the formation to 
gas 1 ift

geronimo

gin pole

gun perforate

guy 1 ine

hoist

hoisting drum

hook

hydraulic fracturing

hydrogen sulfide atmospheric pressure and allowing the well to produce to the surface, where the well fluids may be sampled and inspected.

The process of raising or lifting fluid from a well by injecting gas down the well through tubing or through the tubing-casing annulus. Injected gas aerates the fluid to make it exert less pressure than the formation does; consequently, the higher formation pressure forces the fluid out of the well bore.

An emergency escape 1 ine affixed to the monkey board section of a derrick. In the event of an impending blowout or structural collapse, an employee may grab a slide attached to the wire rope cable and escape to the ground.

A structural framework erected on top of the derrick for lifting material to the top of the derrick.

To create holes in casing and cement set through a productive formation. A perforation gun is lowered into the hole and fired to detonate high-powered jets or shoot steel projectiles (bullets) through the casing and cement and into the productive formation. This process allows the flow of formation fluids from the reservoir into the we 11 bore.

A wire line attached to a mast or derrick to stabilize it. Load guys provide the main support for the structure; wind guys attached to ground anchors provide lateral support.

An arrangement of pulleys and wire rope or chain used for lifting heavy objects; a winch or similar device; the drawworks.

The large, flanged spool in the drawworks on which the hoisting cable is wound.

A large, hook-shaped device from which the elevator bails or the swivel is suspended. It is designed to carry maximum loads ranging from 100 to 650 tons and turns on bearings in its supporting housing.

The forcing into a formation of liquids under high pressure to open passages for oil and gas to flow through and into the wel1 bore.

A gaseous compound, $\mathrm{H}_{2} \mathrm{~S}$, of sulfur and hydrogen commonly found in petroleum, which causes the foul smell of sour petroleum fractions. 
intermediate casing string

jackknife mast

jet

jet perforate

joint

ke11y

kelly bushing

kelly cock

kelly spinner

kick
The string of casing set in a well after the surface casing to keep the hole from caving in and to seal off troublesome formations. Sometimes called protection casing.

A structural steel, open-sided tower raised vertically by special lifting tackle attached to the traveling block.

A hydraulic device operated by pump pressure to clean mud pits and tanks in rotary drilling and to mix mud components. Also, in a perforation gun using shaped charges, a highly penetrating stream of exploded particles that cuts a hole in the casing, cement, and formation.

To create a hole through the casing with a shaped charge of high explosives instead of a gun that fires projectiles. Once detonated, the charges emit short, penetrating jets of high-velocity gases that cut holes in the casing and cement and some distance into the formation. Formation fluids then flow into the well bore through these perforations.

A single length (about 30 feet) of drill pipe or drill collar, casing, or tubing that has threaded connections at both ends.

The heavy square or hexagonal steel member suspended from the swivel through the rotary table and connected to the topmost joint of drill pipe to turn the drill stem as the rotary table turns.

A device fitted to the rotary table through which the kelly passes and the means by which the torque of the rntary table is transmitted to the kelly and to the drill stem. Also called the drive bushing.

A valve installed between the swivel and the kelly. When a high-pressure backflow begins inside the drill stem, the valve is closed to keep pressure off the swivel and rotary hose.

A pneumatically operated device mounted on top of the kelly that, when actuated, causes the kelly to turn or spin. It is useful when the kelly or a joint of pipe attached to it must be spun up; that is, rotated rapidly in order to make it up.

An entry of water, gas, oil, or other formation fluid into the well bore. It occurs because the pressure exerted by the column of drilling fluid is not great enough to overcome the pressure exerted by the fluids in 
lead tongs

$\log$

logging

make a

connection

make a trip

make up

makeup cathead

making hole

Marsh funne1

mast

master bushing

monkey board

motorman the formation drilled. If prompt action is not taken to control the kick or kill the well, a blowout will occur.

The pipe tongs suspended in the derrick and operated by a wire 1 ine connected to the breakout cathead. Also called breakout tongs.

A systematic recording of data, as from the driller's $\log$, mud $\mathrm{log}$, electrical well $\mathrm{log}$, or radioactivity $\mathrm{log}$ run in wells being produced or drilled to obtain various characteristics of downhole formations.

The recording of information about subsurface geologic formations.

To attach a joint of drill pipe onto the drill stem suspended in the well bore to permit deepening of the well bore.

To hoist the drill stem out of the well bore to perform one of a number of operations such as changing bits, taking a core, and so forth, and then to return the drill stem to the well bore.

To assemble and join parts to form a complete unit (as to make up a string of casing) or to screw together two threaded pieces.

The cathead used as a power source for screwing together joints of pipe.

To deepen the hole made by the bit; to drill ahead.

A calibrated funnel used in field tests to determine the viscosity of drilling mud.

A portable derrick capable of being erected as a unit, as distinguished from a standard derrick, which cannot be raised to a working position as a unit.

A device that fits into the rotary table. It accommodates the slips and drives the kelly bushing so that the rotating motion of the rotary table can be transmitted to the kelly. Also called rotary bushing.

The derrickman's working platform. Double board, tribble board, fourble board; a monkey board located at a height in the derrick or mast equal to two, three, or four lengths of pipe, respectively.

The crew member on a rotary drilling rig responsible for 
mousehole

mousehole connection

mud

mud logging

mud pit

mud pump

mud return 1 ine

perforate

perforating gun

pipe rack the care and operation of drilling engines.

Shallow bores under the derrick, usually lined with pipe, in which joints of drill pipe are temporarily suspended for later connection to the drill string.

The addition of a length of drill pipe or tubing to the active string.

The liquid circulated through the well bore during rotary drilling and workover operations. It functions to bring cuttings to the surface, to cool and lubricate the bit and drill stem, to protect against blowouts by holding back subsurface pressures, and to deposit a mud cake on the wall of the bore hole to prevent loss of fluids to the formation. The mud used in modern drilling operations is a complex, three-phase mixture of liquids, reactive solids, and inert solids. The liquid phase may be freshwater, diesel oil, or crude oil and may contain one or more conditioners.

The recording of information derived from examination and analysis of formation cuttings made by the bit and mud circulated out of the hole.

A series of open tanks, usually made of steel plates, through which the drilling mud is cycled to allow sand and sediments to settle out. Additives are mixed with the mud in the pit, and the fluid is temporarily stored there before being pumped back into the well. Mud pits are also called shaker pits, settling pits, and suction pits, depending on their main purpose.

A large, reciprocating pump used to circulate the mud on a drilling rig.

A trough or pipe, placed between the surface connections at the well bore and the shale shaker, through which drilling mud flows upon its return to the surface from the hole.

To pierce the casing wall and cement, with the use of a perforating gun, to provide holes through which formation fluids may enter.

A device, fitted with shaped charges or bullets, that is lowered to the desired depth in a well and fired to create penetrating holes in casing, cement, and formation.

A horizontal support for tubular goods. 
pipe rams

racking pipe

ram

ram blowout preventer

rathole

rathole connection

reeve

reeve the line

remote blowout preventer panel

remote choke pane 1

reserve pit
A sealing component for a blowout preventer that closes the annular space between the pipe and the blowout preventer or well head.

The act of placing stands of pipe in orderly arrangement in the derrick while hoisting pipe from the well bore.

The closing and sealing component on a blowout preventer. One of three types--blind, pipe, or shear-may be installed in several preventers mounted in a stack on top of the well bore. Blind rams, when closed, form a seal on a hole that has no drill pipe in it; pipe rams, when closed, seal around the pipe; shear rams cut through drill pipe and then form a seal.

A blowout preventer that uses rams to seal off pressure on a hole that is with or without pipe. It is also called a ram preventer.

A hole in the rig floor 30-35 feet deep, lined with casing that projects above the floor, into which the kelly and swivel are placed when hoisting operations are in progress.

The addition of a length of drill pipe or tubing to the active string. The length to be added is placed in the rathole, made up to the kelly, pulled out of the rathole, and made up into the string.

To pass (as the end of a rope) through a hole or opening in a block or similar device.

To string a wire-rope drilling line through the sheaves of the traveling and crown blocks to the hoisting drum.

A set of controls used to open and close the blowout preventers; the panel is placed some distance away from the rig so that the controls can be operated without personnel present on the rig floor.

A set of controls, usually placed on the rig floor, that is manipulated to control the amount of driling fluid being circulated out through the choke manifold. This procedure is necessary when a kick is being circulated out of a well.

A mud pit in which a supply of drilling fluid has been stored. Also, a waste pit, usually an excavated, earthen-walled pit. It may be lined with plastic to prevent contamination of the soil. 


\begin{abstract}
rig
rig-down

rig-up

rotary

rotary bushing

The derrick or mast, drawworks, and attendant surface equipment of a drilling unit.

To dismantle the drilling rig and auxiliary equipment following the completion of drilling operations; also called teardown.

To prepare the drilling rig for making hole; to install tools and machinery before drilling is started.

The machine used to impart rotational power to the drill stem while permitting vertical movement of the pipe for rotary drilling.

A metal lining that fits into the opening of the rotary table to reduce its size for special purposes, such as fitting the slips or the kelly bushing. It is also called the master bushing.
\end{abstract}

rotary drilling

rotary helper

rotary hose

rotary swivel

rotary table

safety 1 ine

shale shaker

A drilling method in which a hole is drilled by a rotating bit to which a downward force is applied. The bit is fastened to and rotated by the drill stem, which also provides a passageway through which the drilling fluid is circulated. Additional joints of drill pipe are added as drilling progresses.

A worker on a drilling rig, subordinate to the driller; sometimes called a roughneck, floorman, or rig crewman.

The hose on a rotary drilling rig that conducts the drilling fluid from the mud pump and standpipe to the swivel and kelly; also called the mud hose or the kelly hose.

The swivel attached to the top of the kelly that permits the kelly to be rotated when suspended from the traveling block hook during drilling operations.

The principal component of a rotary, or rotary machine, used to turn the drill stem and support the drilling assembly. It has a beveled gear arrangement to create the rotational motion and an opening into which bushings are fitted to drive and support the drilling assembly.

A wire rope, one end of which is fastened to the end of a pipe tong handle and the other end secured to hold the tongs while such tongs are in use.

A series of trays with sieves that vibrate to remove cuttings from the circulating fluid in rotary drilling operations. The size of the openings in the sieve is 
shear ram

sheave

slips

slurry

sour gas

spinning cathead

spinning chain

spud-in

stab

stabbing board selected to match the size of the solids in the drilling fluid and the anticipated size of cuttings. Also called a shaker.

The components in a blowout preventer that cut, or shear, through drill pipe and form a seal against well pressure. Shear rams are used in mobile offshore drilling operations to provide a quick method of moving the rig away from the hole when there is no time to trip the drill stem out of the hole.

A grooved pulley.

Wedge-shaped pieces of metal with teeth or other gripping elements that are used to prevent pipe from slipping down into the hole or to hold pipe in place. Rotary slips fit around the drill pipe and wedge against the master bushing to support the pipe. Power slips are pneumatically or hydraulically actuated devices that ailow the crew to dispense with the manual handling of slips when making a connection. Packers and other downhole equipment are secured in position by slips that engage the pipe by action directed at the surface.

A plastic mixture of cement and water that is pumped into a well to harden; there it supports the casing and provides a seal in the well bore to prevent migration of underground fluids.

Natural gas containing hydrogen sulfide.

A spooling attachment on the makeup cathead to permit use of a spinning chain to spin up or make up drill pipe.

A Y-shaped chain used to spin up (tighten) one joint of drill pipe into another. In use, one end of the chain is attached to the tongs, another end is attached to the spinning cathead, and the third end is free. The free end is wrapped around the tool joint and the cathead pulls the chain off the joint, causing the joint to spin (turn) rapidly and tighten up. After the chain is pulled off the joint, the tongs are secured in the same spot, and continuous pull on the chain (and thus on the tongs) by the cathead makes the joint up to final tightness.

To begin drilling; to start the hole.

To guide the end of a pipe into a coupling or tool joint when making up a connection.

A temporary platform erected in the derrick or mast $20-40$ 
stand of pipe

st andpipe

stimulation

sub

substructure

swab

swabbing

swive 1 feet above the derrick floor. The derrickman or another crew member works on the board while casing is being run in a well. The board may be wooden or fabricated of steel girders floored with antiskid material and powered electrically to raise or lower it to the desired level. A stabbing board serves the same purpose as a monkey board or safety platform but is temporary instead of permanent.

A length of drill pipe, tubing or other pipe consisting of one or more joints in a continuous section that is stood, racked, or hung in a derrick.

A vertical pipe rising along the side of the derrick or mast, which joins the discharge line leading from the mud pump to the rotary hose and through which mud is pumped going into the hole.

Any process undertaken to enlarge old channels or create new ones in the producing formation of a well.

A short, threaded piece of pipe used to adapt parts of the drilling string that cannot otherwise be screwed together because of differences in thread size or design. A sub may also perform a special function. Lifting subs are used with drill collars to provide a shoulder to fit the drill pipe elevators. A kelly saver sub is placed between the drill pipe and kelly to prevent excessive thread wear of the kelly and drill pipe threads. A bent sub is used when drilling a directional hole. Sub is a short expression for substitute.

The foundation on which the derrick or mast and usually the drawworks sit; contains space for storage and well control equipment.

A hollow, rubber-faced cylinder mounted on a hollow mandrel with a pin joint on the upper end to connect to the swab line. A check valve that opens upward on the lower end provides a way to remove the fluid from the well when pressure is insufficient to support flow.

Operation of a swab to bring well fluids to the surface when the well does not flow or require artificial lift or stimulation to bring oil to the surface.

A rotary tool that is hung from the rotary hook and traveling block to suspend and permit free rotation of the drill stem. It also provides a connection for the rotary hose and a passageway for the flow of drilling fluid into the drill stem. 
tag line

thribble

throw the chain

tongs

tool joint

tool pusher

torque

transmission

trave 1 ing block
A utility rope or cable that is attached to unwieldy loads being hoisted by a crane to allow a load handler better control of the movement of the load.

Three sections of drill pipe removed from the hole (while joined) during a trip.

To flip the spinning chain up from a tool joint box so that the chain wraps around the tool joint pin after it is stabbed into the box. The stand or joint of drill pipe is turned or spun by a pull on the spinning chain from the cathead on the drawworks.

The large wrenches used for turning when making up or breaking out drill pipe, casing, tubing, or other pipe; variously called casing tongs, rotary tongs, and so forth according to the specific use. Power tongs are pneumatically or hydraulically operated tools that serve to spin the pipe up and, in some instances, to apply the final makeup torque.

A heavy coupling element for drill pipe made of special alloy steel. Tool joints have coarse, tapered threads and seating shoulders designed to sustain the weight of the drill stem, withstand the strain of frequent coupling and uncoupling, and provide a leakproof seal. The male section of the joint, or the pin, is attached to one end of a length of drill pipe, and the female section, or box, is attached to the other end. The tool joint may be welded to the end of the pipe or screwed on, or both. A hard metal facing is often applied in a band around the outside of the tool joint to enable it to resist abrasion from the walls of the bore hole.

A employee of a drilling contractor who is in charge of the entire drilling crew and the drilling rig. Also called a drilling crew foreman, manager, supervisor, or rig superintendent.

The turning force that is applied to a shaft or other rotary mechanism to cause it to rotate or tend to do 80 . Torque is measured in foot-pounds, joules, meter-kilograms, and so forth.

The gear or chain arrangement by which power is transmitted from the prime mover to the drawworks, mud pump, or rotary table of a drilling rig.

An arrangement of pulleys, or sheaves, through which drilling cable is reeved, which moves up and down in the derrick or mast. 
Vee-door

we 11 bore

well completion

we 11 head

whipstock

wildcat

wire rope

workover
An opening in a side of a derrick at the floor level having the form of an inverted "V." This opening is opposite the drawworks. It is used as an entry to bring in drill pipe and casing from the pipe rack.

A bore hole; the hole drilled by the bit. A well bore may have casing in it or may be open (i.e., uncased), or a portion of it may be cased and a portion of it may be open. Also called bore hole or hole.

The activities and methods necessary to prepare a well for the production of oil and gas; the method by which a flow line for hydrocarbons is established between the reservoir and the surface. The method of well completion used by the operator depends on the individual characteristics of the producing formation or formations. These techniques include the following types of completions: open-hole, sand exclusion, tubingless, multiple, and miniaturized.

The equipment installed at the surface of the well bore. $A$ well head includes such equipment as the casing head and tubing head.

A long, steel casing that uses an inclined plane to cause the bit to deflect from the original borehole at a slight angle.

A well drilled in an area where no oil or gas production exists. With present-day exploration methods and equipment, about one wildcat out of every nine proves to be productive although not necessarily profitable. Also, to drill wildcat wells.

A cable composed of steel wires twisted around a central core of hemp or other fiber to create a rope of great strength and considerable flexibility. Wire rope is used as drilling line (in rotary and cable-tool rigs), coring line, servicing line, winch line, and so on.

To perform one or more of a variety of remedial operations on a producing oil well with hope of restoring or increasing production. Examples of workover operations are deepening, plugging back, pulling and resetting the liner, squeeze cementing, shooting, and acidizing.

From: $\quad$ References $[1,73,91]$. 
DEPARTMENT OF HEALTH AND HUMAN SERVICES

PUBLIC HEALTH SERVICE

CENTERS FOR DISEASE CONTROL

NATIONAL INSTITUTE FOR OCCUPATIONAL SAFETY AND HEALTH ROBEAT A. TAFT LABORATORIES

4676 COLUMBIA PARKWAY, CINCINNATI, OHIO 45226

OFFICIAL BUSINESS

PENALTY FOA PRIVATE USE. $\$ 00$
Special Fourth Class-Book

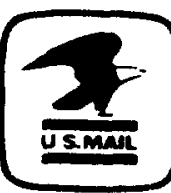

POSTAGE AND FEES PAID U.S. DEPARTMENT OF HHS HHS 396

Redistribution using indicia is illegal. 